\title{
GRAFITOS CERÁMICOS DE SEGOBRIGA (1997-2006)
}

\author{
GRAFFITI ON POTTERY FROM SEGOBRIGA
}

\author{
JUAN MANUEL ABASCAL PALAZÓN \\ Universidad de Alicante \\ ROSARIO CEBRIÁN FERNÁNDEZ \\ Parque Arqueológico de Segobriga
}

\begin{abstract}
Resumen: Este trabajo incluye 243 fragmentos cerámicos con grafitos latinos, griegos e ibéricos, descubiertos en Segobriga en las excavaciones oficiales de la ciudad romana y sus alrededores. Muchos de ellos son incompletos, pero algunos presentan el nombre del recipiente (panna) y cuentas de control de alfar. Casi todos están grabados en terra sigillata.

Palabras clave: Grafitos, terra sigillata, panna, Segobriga, Hispania citerior.
\end{abstract}

Abstract:This work includes 243 ceramic fragments with Latin, Greek and Iberian graphites, discovered in Segobriga in the official excavations of the Roman city and their environs. Many of them are fragments, but some present the name of the container (/panna/) and accounts of control of workshop. All are almost recorded in terra sigillata.

Key words: Grafitti, terra sigillata, panna, Segobriga, Hispania citerior.

Las excavaciones continuadas en Segobriga ${ }^{1}$ durante los últimos 12 años han permitido documentar un riquísimo conjunto epigráfico, principalmente del foro, del que se ha ido dando noticia en los últimos años. Menos atención hemos prestado a la epigrafía menor, al mundo de los grafitos cerámicos, cuya importancia se ha visto eclipsada por los sensacionales hallazgos de los pedestales del foro y las estelas de la necrópolis norte.

La primera serie de grafitos segobrigenses fue publicada hace más de 15 años por J. Sánchez-Lafuente (1991, 207-238), incluyendo entonces los hallazgos efectuados en la muralla y puerta norte entre 1986 y 1987. A ellos añadimos hace unos años algunos ejemplares más sobre tégulas (N..$^{\circ}$ inv. 2000, UE 5018, n. ${ }^{\circ} 33$ y 1999, UE 3014, n. $^{\circ} 6$ ), con ocasión de publicar las marcas sobre estos objetos que se iban recuperando en las excavaciones (Abascal, Cebrián y Riquelme, 2000, 187-197, Lám. VIII-9.3 y 9.4). Ahora retomamos con estas líneas esa labor, dando a

1. Las excavaciones en Segobriga forman parte del programa financiado por la Junta de Comunidades de Castilla-La Mancha y el Instituto Nacional de Empleo bajo la dirección de Juan Manuel Abascal, Martín Almagro-Gorbea y Rosario Cebrián. La redacción de este trabajo se ha realizado en el marco del proyecto HUM-2006-07904, financiado por el Ministerio de Educación y Ciencia. conocer un total de 243 fragmentos cerámicos con algún signo de escritura, que constituye una importante aunque fragmentaria serie.

Casi todos ellos proceden de las excavaciones regulares en la ciudad romana y en los edificios de espectáculos situados fuera de ella; la excepción son algunos fragmentos $\left(n \cdot{ }^{\circ} 240\right.$ 243) recuperados en las dos prospecciones llevadas a cabo en los alrededores de Segobriga: la de 1998, que fue sistemática y cubrió una importante superficie, y la de 2005 , circunscrita al Cerro Carraplín durante el estudio de los moldes de terra sigillata de Segobriga, por ser éste el lugar en que había aparecido el primer ejemplar (Sanfeliú y Cebrián, 2006, 159-175).

Habida cuenta del carácter exhaustivo de la serie, de la que sólo hemos excluído los ejemplares dudosos que no pasan de ser simples esgrafiados no alfabéticos, hemos optado por presentar el material agrupado en función de su zona de procedencia dentro de la ciudad, dato asociado a una fecha de hallazgo que figura entre paréntesis al comienzo de cada sección. A este respecto hay que advertir que la datación de los fragmentos recuperados raras veces habrá de coincidir con la de los edificios de procedencia, habida cuenta de que muchos de ellos pertenecen a niveles de amortización con materiales revueltos o a niveles de aterrazamiento 
con materiales sin contexto; esta advertencia es importante principalmente para la zona del foro y la basílica, donde toda la arquitectura fue expoliada en época tardo-romana y donde la extracción de materiales de construcción continuó hasta el siglo XVI. Lo mismo ocurre en el recién excavado circo, en el que los materiales proceden de los niveles de aterrazamiento de la zona para la construcción del edificio durante el siglo II; ello significa que estos paquetes de tierra contiene materiales separados a veces por intervalos de dos siglos. Con ello queremos decir que la indicación de procedencia sólo es una referencia topográfica para situar el hallazgo en el contexto urbano, pero en ningún caso estas piezas pueden considerarse de forma aislada como elementos de datación de los recintos.

Salvo algunos ejemplares bien conservados que son la minoría, la mayor parte de los textos son lacónicos fragmentos de nombres personales, muchas veces imposibles de restituir pero que irán cobrando sentido por su comparación con la riquísima serie epigráfica aún inédita procedente de la necrópolis principal de la ciudad.

Casi todos los textos presentados son grafitos post-cocción realizados con puntas secas de estiletes y buriles, destinados en la mayor parte de los casos a indicar la propiedad de los vasos como es habitual en este tipo de referencias. Estas marcas, cuya tosquedad revela con frecuencia la falta de experiencia de sus autores, figuran normalmente en vasos y platos de terra sigillata de los siglos I y II, es decir, en el servicio doméstico corriente en la ciudad durante esas dos centurias. El labio de los recipientes, la parte de la pared que queda sobre el anillo del pie y la parte inferior de la base son los escenarios preferidos por estos grabadores aficionados cuya pretensión no fue más allá de la singularización del recipiente de uso personal, ajenos completamente a cualquier pretensión estética. Ello explica las irregularidades visibles en el dibujo de una misma letra, las frecuentes formas de II para representar la $E$, el escaso empleo de los nexos e incluso la incorrecta forma de abreviar algunas palabras.

En el conjunto destacan las referencias al nombre del vaso como panna, citado como tal en tres ocasiones ( $n .^{\circ} 102,114$ y 234 . Cf. índice final) y cuya naturaleza se discute más adelante (cf. $n$. $^{\circ}$ 102). Por añadidura, el recipiente $n .^{\circ} 102$ contiene una cuenta de alfarero con indicación del número de recipientes fabricados $u$ horneados ( $\operatorname{Pan}(n)$ as $+[-] X X X I I$ y $[-] s \cdot C C C C C X)$, lo que refuerza nuestro caudal de datos sobre la producción cerámica de Segobriga, en esta ocasión relacionada directamente con la terra sigillata; el hallazgo de este fragmento entre las tierras acumuladas junto al lugar que ocupó el pórtico septentrional del foro es un buen indicador de la alteración de los niveles de la zona. También de los pórticos forenses procede un fragmento con la indicación pone fur! para evitar el robo de la pieza (n.0133).

Dado de la mayor parte de los grafitos son textos grabados post-cocción, se entenderá esto salvo que se indique lo contrario.

\section{Muralla norte (1997)}

1 (1997, UE 2001, n. ${ }^{\circ} 23$ ). Base de terra sigillata hispánica, forma Dr. 37. En el interior presenta multitud de pequeños trazos, muchos de ellos organizados en series de paralelas, que podrían constituir algún tipo de cuenta. El fragmento mide $6 \times 6 \mathrm{~cm}$ y los trazos oscilan entre 4 y $5 \mathrm{~mm}$.

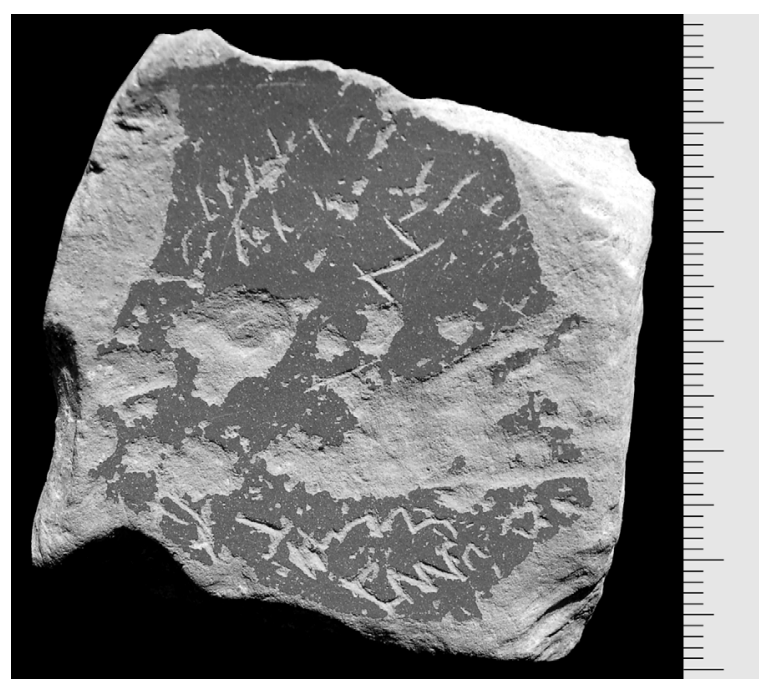

\section{Termas Monumentales (1997-1999)}

2 (1997, UE 1032, n. $\left.{ }^{\circ} 7\right)$. Base de terra sigillata hispánica; en el interior del pie presenta una letra aislada, una $\mathrm{M}$ cursiva, que debe formar parte de

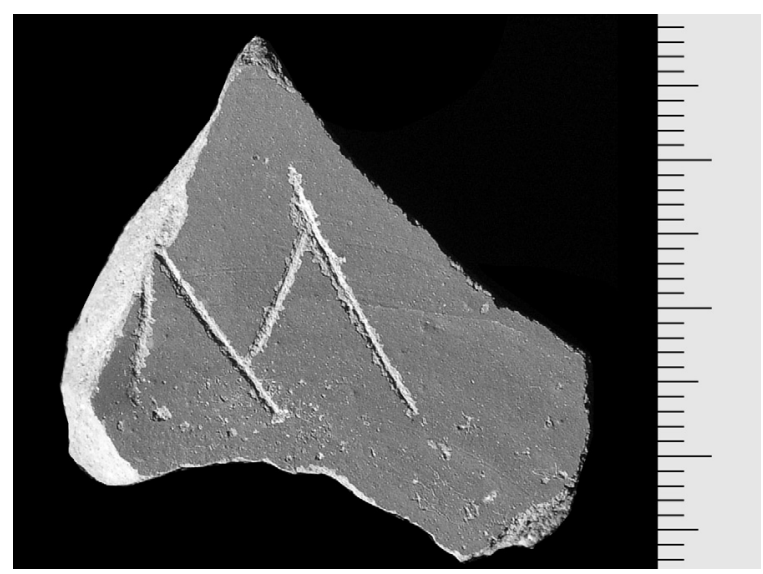


un texto mayor y que ocupa una superficie de 1,6 $x[1,9] \mathrm{cm}$.

3 (1997, UE 1100, n. 14 y 60). Dos fragmentos de la base de un mismo recipiente de terra sigillata hispánica y forma indeterminada. Alrededor del anillo inferior discurre un texto cuyas letras miden c. $1,5 \mathrm{~cm}$ de altura. Los únicos restos visibles dicen:
a) $+\mathrm{V}$. + es trazo oblicuo de M o R
b) PR+. + es trazo oblicuo.

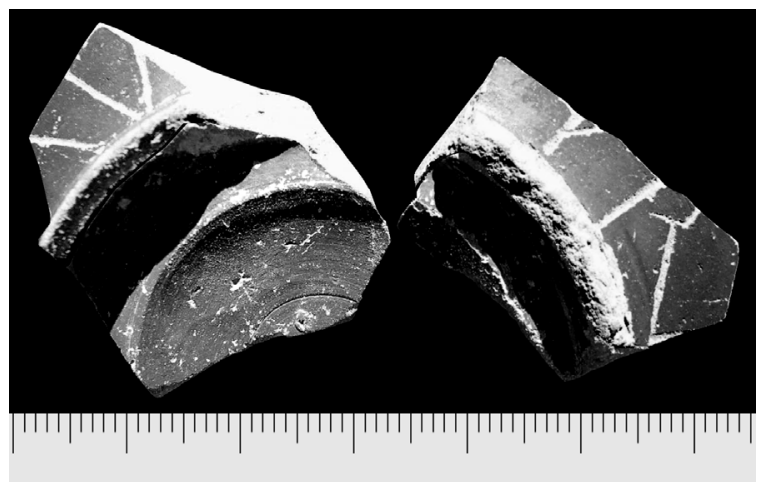

4 (1998, UE 1704, n. $\left.{ }^{\circ} 12\right)$. Borde de terra sigiIlata hispánica, forma Dr. 15/17. en el interior figura un grafito en forma de $E$ con trazo vertical prolongado de $0,9 \mathrm{~cm}$ de altura, aunque podría ser un anagrama y no una letra latina; en el exterior aparecen trazos muy tenues en forma de una doble $X$ en una superficie de 2,1 $x 0,9 \mathrm{~cm}$.

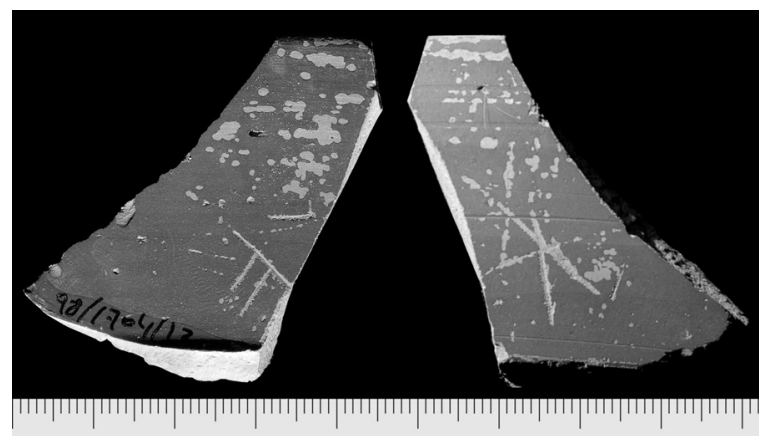

5 (1998, UE 1851, n. $\left.{ }^{\circ} 18\right)$. Fragmento de pared de un recipiente de terra sigillata hispánica. Al exterior presenta un texto casi horizontal con letras de $0,6 \mathrm{~cm}$ de altura y $[4,1] \mathrm{cm}$ de longitud. En el texto sólo se distingue lo siguiente: $[-]+M N V+\left(1 .^{a}+\right.$ es trazo oblicuo, quizá $\mathrm{V} ; 2^{a}$ + es trazo curvo quizá $\mathrm{C}$ u O). No puede descartarse la presencia de nexos NA o MA en el primer carácter, por lo que no se puede proponer una lectura.

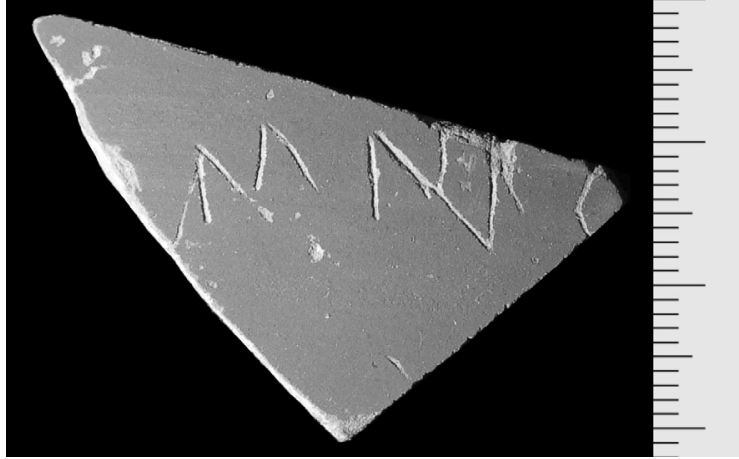

6 (1999, UE 403, n. ${ }^{9}$ 9). Fragmento de base de terra sigillata hispánica de forma indeterminada con sello interior. En el exterior, grafito con letras de $c .1 \mathrm{~cm}$ de altura. El texto dice: Ponti $(-) \mathrm{F}(-)$ ó Pontif(一)

En la primera de las opciones, PONTI podría ser abreviatura de un nombre como Pontianus, Pontinus o similar (Solin-Salomies, 1988, 381), aunque lo conservado permite múltiples combinaciones.

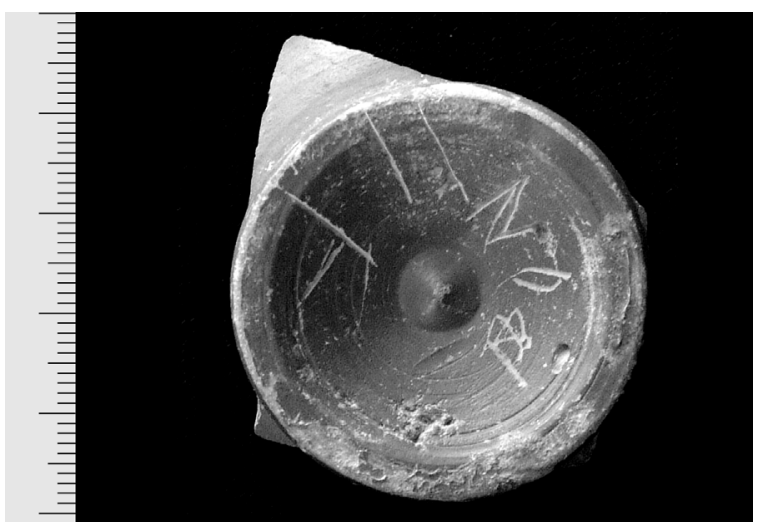

7 (1999, UE 403, n. $\left.{ }^{\circ} 13\right)$. Base de terra sigillata hispánica de forma no determinable; en su parte exterior presenta un grafito circular alrededor del anillo, con letras de $1 \mathrm{~cm}$ de altura y una longitud de $[1,5] \mathrm{cm}$, del que sólo se conserva lo siguiente: $[-] \mathrm{DR}[-]$. Tal vez las letras pertenezcan a

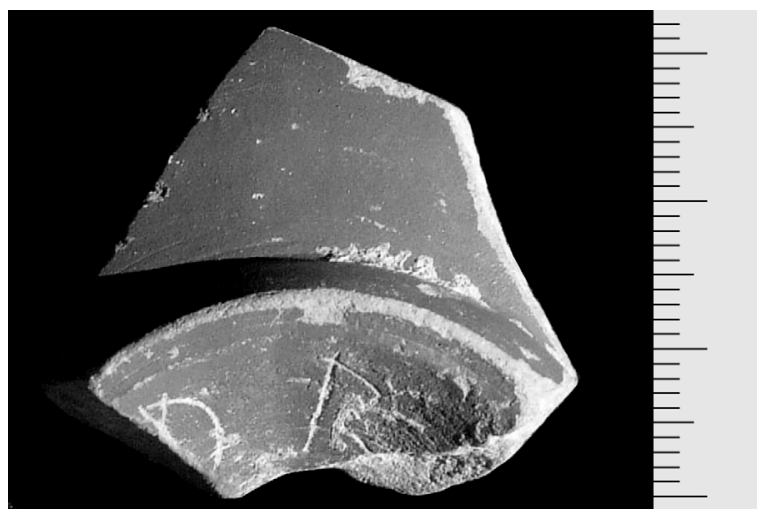


algún cognomen, lo que permitiría múltiples posibilidades de desarrollo.

8 (1999, UE 403, n. $\left.{ }^{\circ} 14\right)$. Base de terra sigillata hispánica con grafitos casi ilegibles al exterior (2 $x[2,1] \mathrm{cm})$ e interior $(1,9 \times[3] \mathrm{cm})$ debido al deterioro de la superficie.

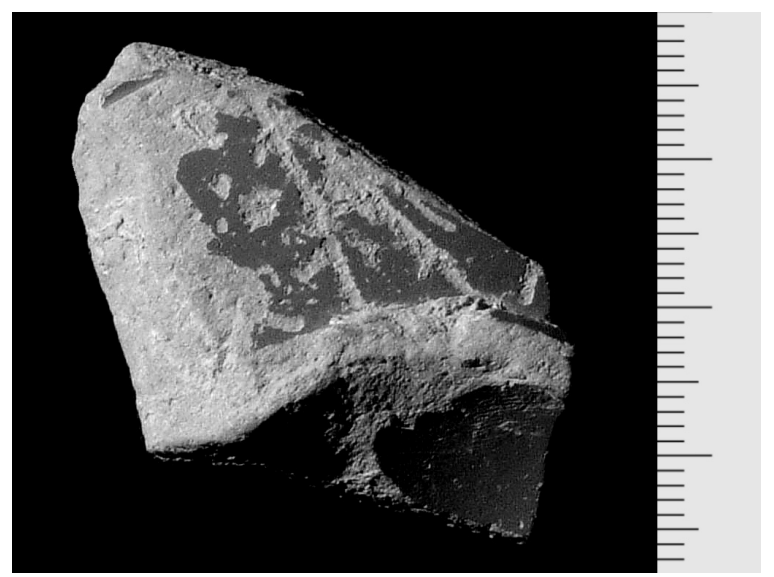

9 (1999, UE 1000, n. ${ }^{\circ}$ 319). Base de terra sigillata hispánica con grafito al interior en una superficie de $1,1 \times[2,4] \mathrm{cm}$. Aunque el primer trazo conservado parece una $F$, la rotura inferior puede enmascarar una $E$, con lo que no sería descartable una sucesión EVC[-] que daría pie a leer un nombre personal de origen griego, más que una forma FVC[-].

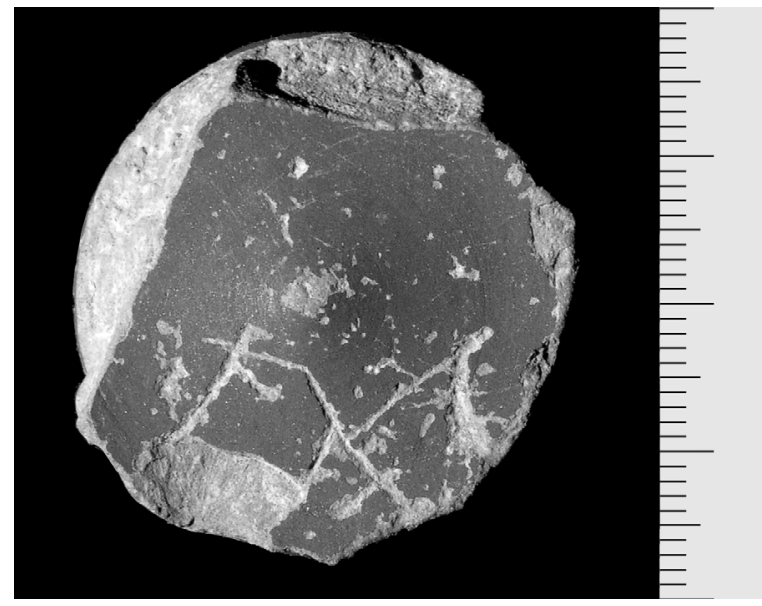

10 (1999, UE 1891, n. ${ }^{\circ}$ 3). Fragmento de pared de un cuenco de terra sigillata hispánica de forma no determinable. Al exterior presenta restos de un grafito en una superficie de $[1,1] \times[2,6]$ $\mathrm{cm}$. El primer trazo podría ser el vértice de una $\checkmark$ y más probablemente el pie derecho de una $\mathrm{N}$, mientras el tercero debe ser un trazo curvo de $O, C \circ G$, con lo que habría que entender [-]
NVC[-], [-]NVG[-], [-]NVO [-] o similar, sin que sea posible determinarlo.

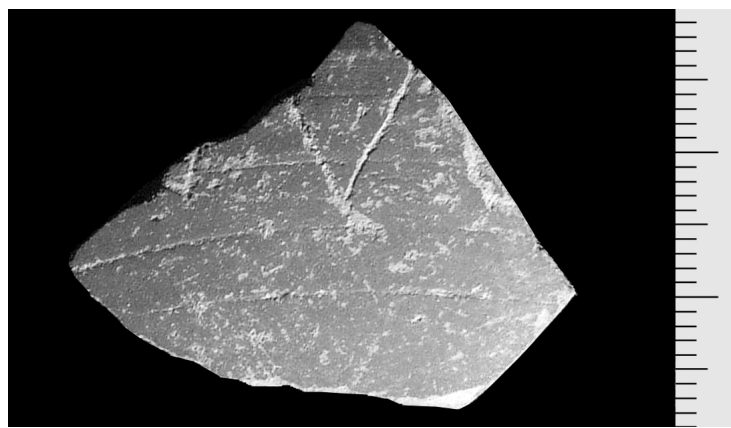

\section{Vertedero meridional de las Termas Monumentales (1998)}

11 (1998, UE 1600, n. 41 y 1998, UE 1644, n. ${ }^{\circ}$ 118). Dos fragmentos de una base de $4,5 \mathrm{~cm}$ de diámetro en terra sigillata hispánica, forma Dr. 37. Al exterior de la base aparecen radios irregulares.

12 (1998, UE 1600, n. ${ }^{\circ} 58$ ). Fragmento de pared de un vaso de terra sigillata hispánica, forma Dr. 37. En el interior de la pared aparecen restos de tres trazos que podrían pertenecer a un texto no reconocible, ocupando una superficie de $[1,6] \mathrm{x}$ $[1,8] \mathrm{cm}$.

13 (1998, UE 1600, n. ${ }^{\circ} 526$ ). Cuenco de terra sigillata hispánica brillante, forma 9 . En la pared exterior presenta tres trazos rectos convergentes en una superficie de 3,3 $3,4 \mathrm{~cm}$.

14 (1998, UE 1624, n. $\left.{ }^{\circ} 177\right)$. Base de terra sigillata hispánica, forma Dr. 27 que al interior presenta diversos trazos informes en una superficie de $0,8 \times[2,5] \mathrm{cm}$. No es posible reconocer signos alfabéticos.

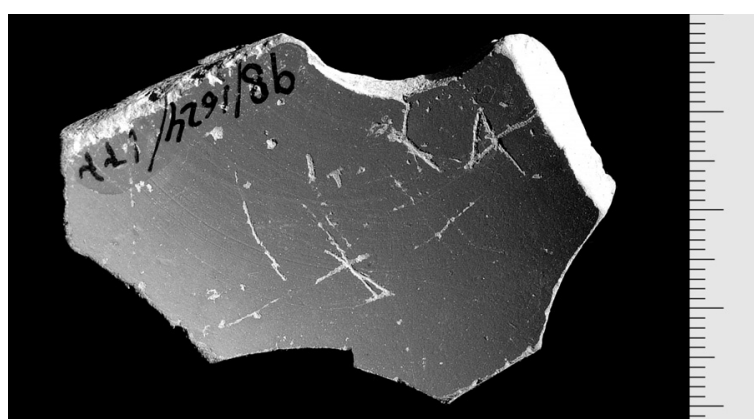

15 (1998, UE 1624, n. ${ }^{\circ} 225$ ). Fragmento de base de un recipiente de terra sigillata hispánica. En el exterior, grafito en forma de hoja de 
palma en una superficie de $1,2 \times 0,8 \mathrm{~cm}$; en el barniz de la base está impresa la huella digital del alfarero.

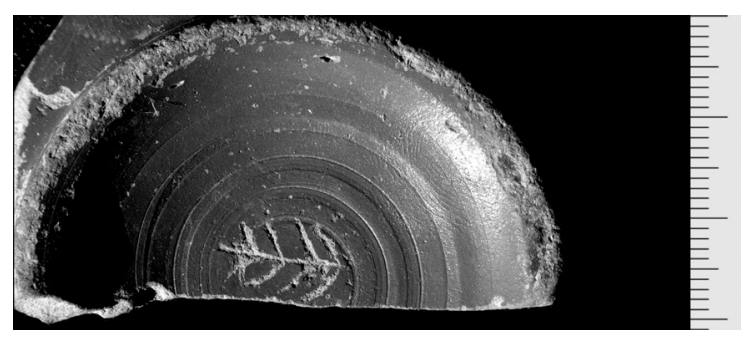

16 (1998, UE 1629, n. $\left.{ }^{0} 14\right)$. Fragmento de pared de un recipiente de terra sigillata sudgálica. $\mathrm{Al}$ exterior, conserva restos de un grafito en una superficie de $1 \times[1,8] \mathrm{cm}$, con el texto [-]ER[-]. La distancia entre las letras no permite determinar si hay alguna más, como parece probable a la derecha de la $\mathrm{R}$.

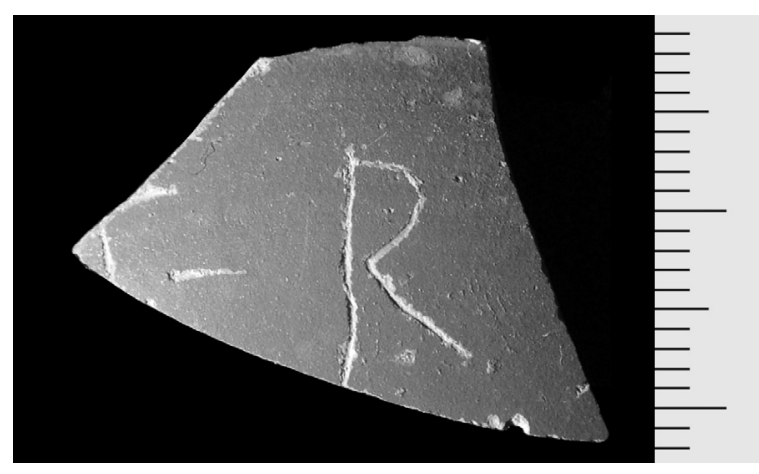

17 (1998, UE 1644, n. $\left.{ }^{\circ} 11\right)$. Base de terra sigillata hispánica, que presenta al exterior el extremo de una palabra, seguramente un nombre propio terminado en [-]is, en una superficie de 1 $x[2,4] \mathrm{cm}$. El primer trazo puede corresponder a una $\mathrm{A}$ (Thais, Lais, etc.), M (Phyramis, Pergamis, etc.) o quizá a una R (Charis, Apollinaris, Paris, etc.).

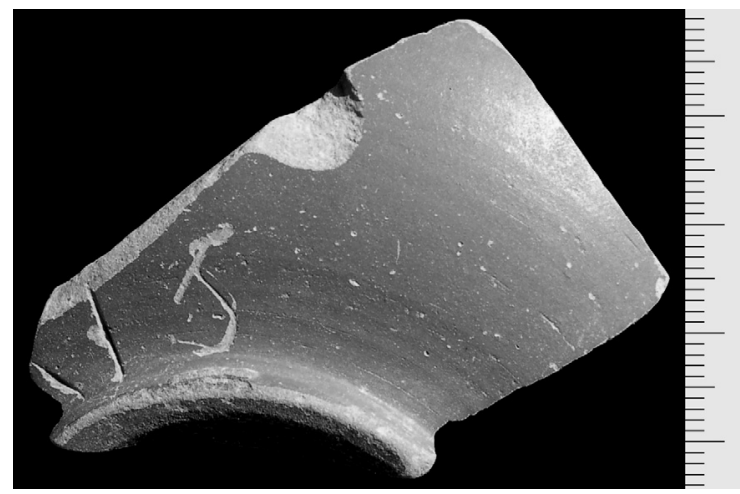

18 (1998, UE 1644, n. $\left.{ }^{\circ} 127\right)$. Base de terra sigillata hispánica con sello interior y restos de un grafito exterior no identificable en una superficie de $[0,9] \times[2,2] \mathrm{cm}$.

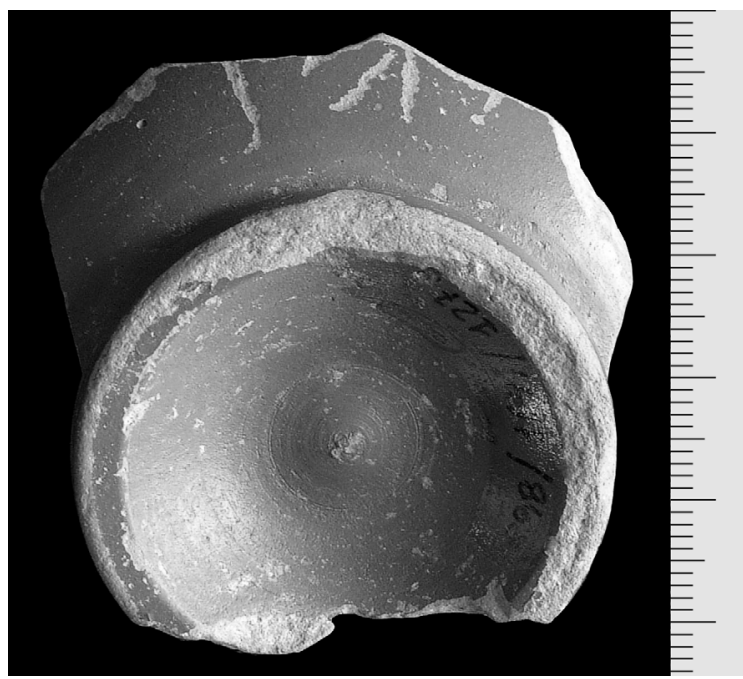

19 (1998, UE 1764, n. $\left.{ }^{\circ} 44\right)$. Fragmento de base de un recipiente de terra sigillata hispánica, forma Drag. 27. En el exterior, grafito en una superficie de $[1,3] \times 1 \mathrm{~cm}$, en forma de hoja de palma.

20 (1998, UE 1900, n. ${ }^{\circ}$ 54). Base de terra sigillata hispánica, forma Dr. 27. Al exterior de la pared presenta un aspa incisa en una superficie de 1 $\mathrm{x} 1 \mathrm{~cm}$.

21 (1998, UE 1900, n. ${ }^{\circ} 401$ ). Base de terra sigillata hispánica con sello impreso interior, en forma Dr. 27. Al exterior de la pared y junto a la base conserva el extremo de varios trazos incisos en una superficie de $[1,1] \times 7,5 \mathrm{~cm}$ que debieron pertenecer a un texto hoy ilegible.

22 (1998, UE 1900, n. ${ }^{\circ} 430$ ). Borde de terra sigillata hispánica, forma Dr. 27. En el exterior conserva restos de un grafito, aparentemente de una $\Pi$ de $[1,6] \times[1] \mathrm{cm}$.

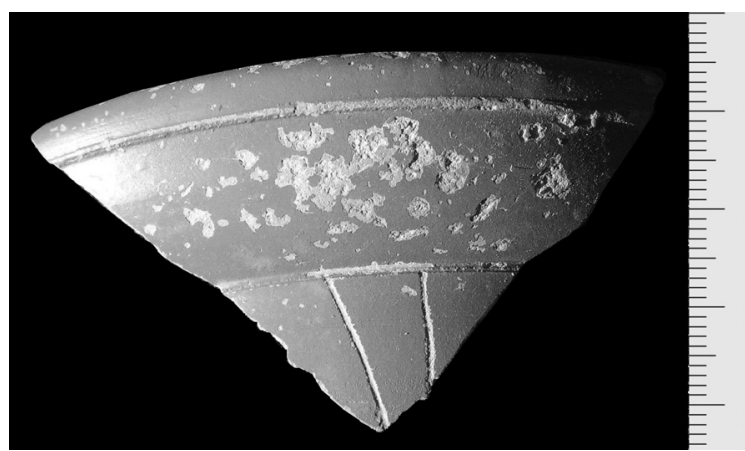


23 (1998, UE 1900, n. ${ }^{\circ} 431$ ). Base de terra sigillata hispánica, forma Dr. 37. Al exterior conserva sólo un signo que más que una $\mathrm{E}$ con el trazo central prolongado parece el signo silábico ibérico $\mathrm{TI}$, que ocupa una superficie de $1,6 \times[1,2]$ $\mathrm{cm}$.

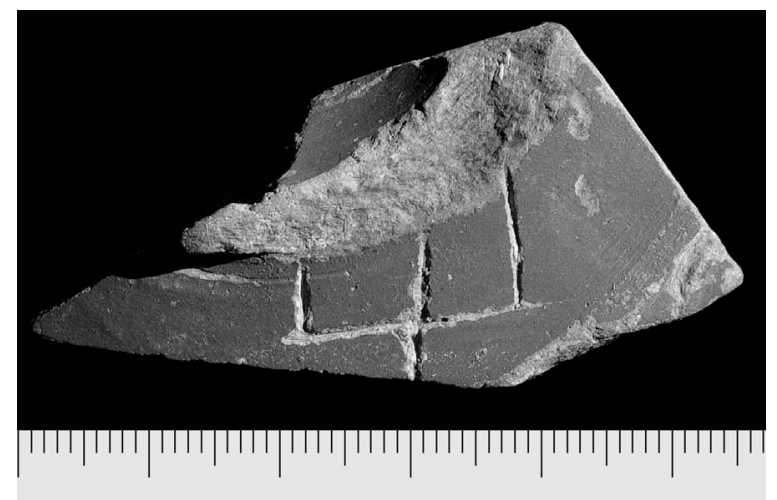

24 (1998, UE 1900, n. ${ }^{\circ} 432$ ). Base de botella de terra sigillata hispánica en cuya parte exterior figura una letra $\mathrm{N}$ de $1,7 \times 1,2 \mathrm{~cm}$.

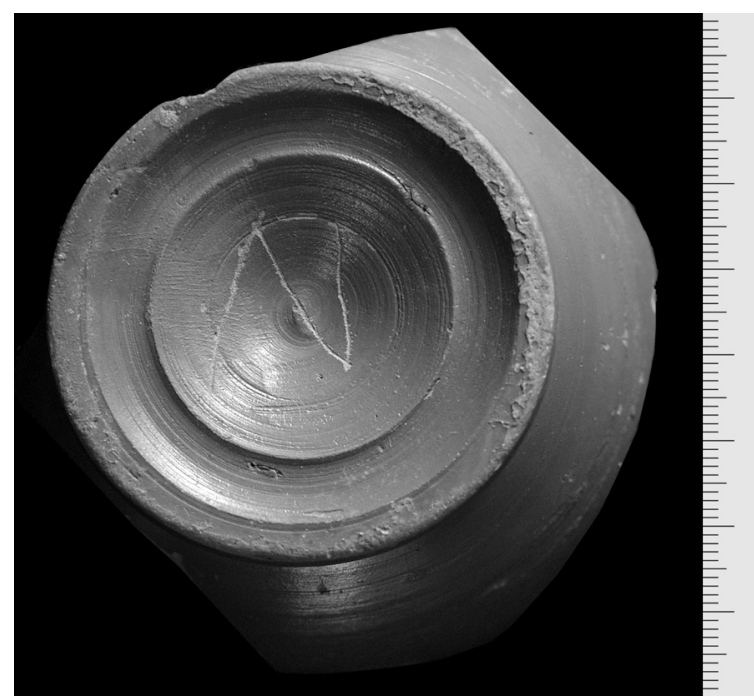

25 (1998, UE 1900, n. ${ }^{\circ} 937$ ). Borde de un urceus de cerámica común, que presenta al exterior del labio el extremo final de una palabra en la forma [-]NI sobre una superficie $0,9 \times[1,2] \mathrm{cm}$. Puede tratarse del genitivo de un nombre personal.

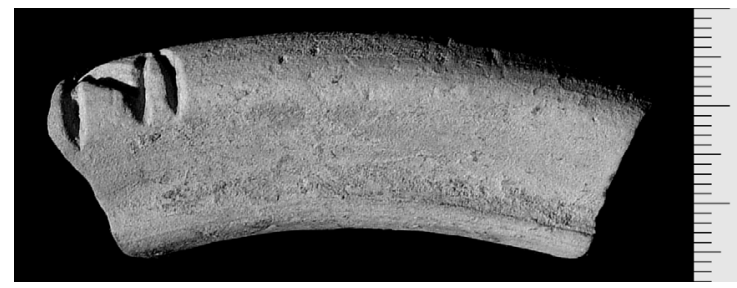

26 (1998, UE 1900, n. ${ }^{\circ}$ 1035). Borde de terra sigillata hispánica, forma Dr. 37. Al exterior presenta una larga sucesión de trazos en una superficie de $1,5 \times 2,8 \mathrm{~cm}$; aunque el primero de ellos parece una $\mathrm{N}$, los que le siguen parecen más parte de una cuenta que elementos de una palabra.

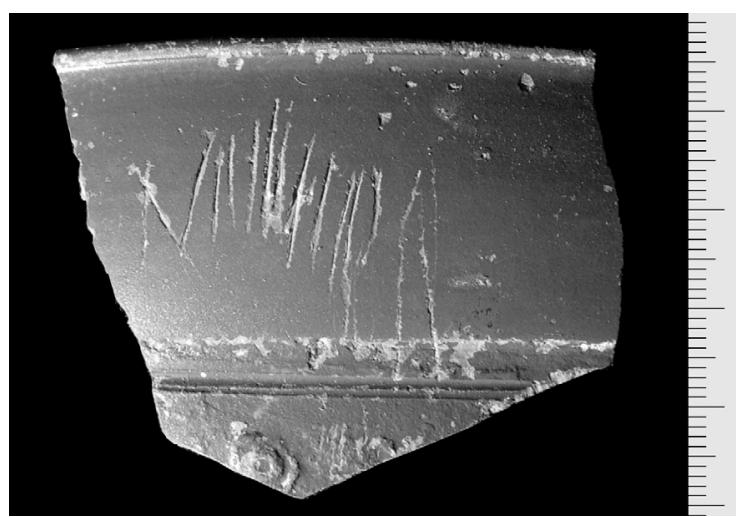

27 (1998, UE 1900, n. ${ }^{\circ}$ 1043). Base de un recipiente de terra sigillata hispánica con sello interior OF SEMPR. En el exterior presenta un grafito alrededor del pie, con letras de c. $1,3 \mathrm{~cm}$ de altura en el que puede leerse: A E I O V. La E presenta una aparente grafía griega.

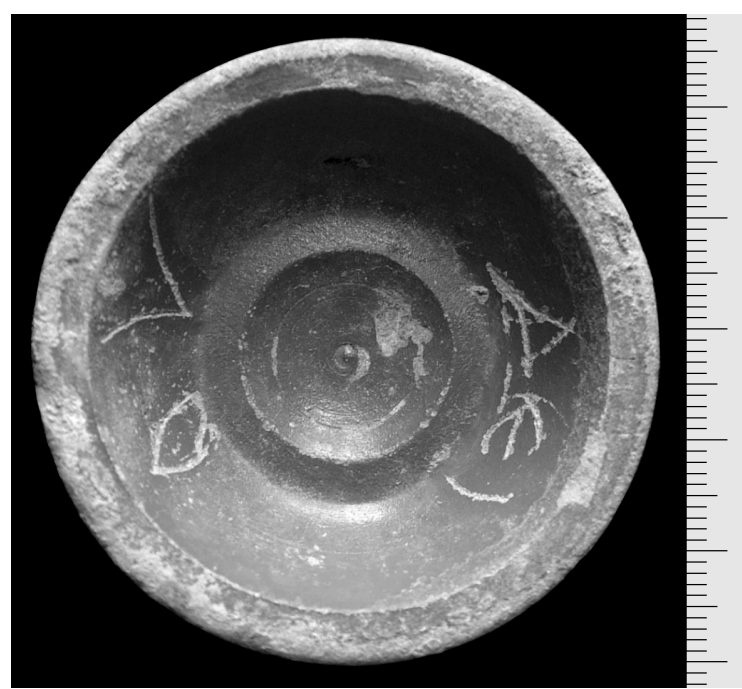

28 (1998, UE 1901, n. ${ }^{\circ} 166$ y 183). Base de un cuenco de terra sigillata hispánica, forma Dr. 37 , con grafito exterior entre la decoración y el anillo del pie; la altura de las letras es de $1,3 \mathrm{~cm}$, aunque la primera -casi perdida- es mayor. El texto dice: [-] Grati.

El trazo inferior de la $G$ es apenas perceptible en la parte izquierda de la pieza y la $A$ carece de travesaño. La forma es el genitivo del nombre personal Gratius, un nomen corriente en la Segobriga del siglo I d.C. y en otras ciudades 
próximas de la Meseta sur (Abascal, 1994, 147 y 2004, 142-143).

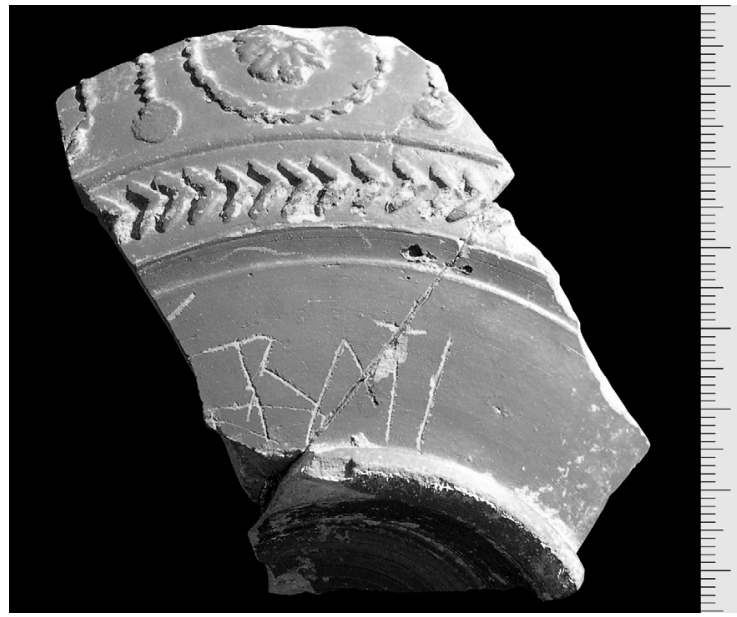

29 (1998, UE 1901, n. $\left.{ }^{0} 167\right)$. Base de un recipiente de terra sigillata hispánica con grafito exterior entre el anillo y la decoración en una superficie conservada de $0,8 \times[2,2] \mathrm{cm}$. Lo único visible dice [-]MAR[-], aunque tanto delante como detrás se perciben restos de trazos perdidos. Debe pertenecer a un nombre personal.

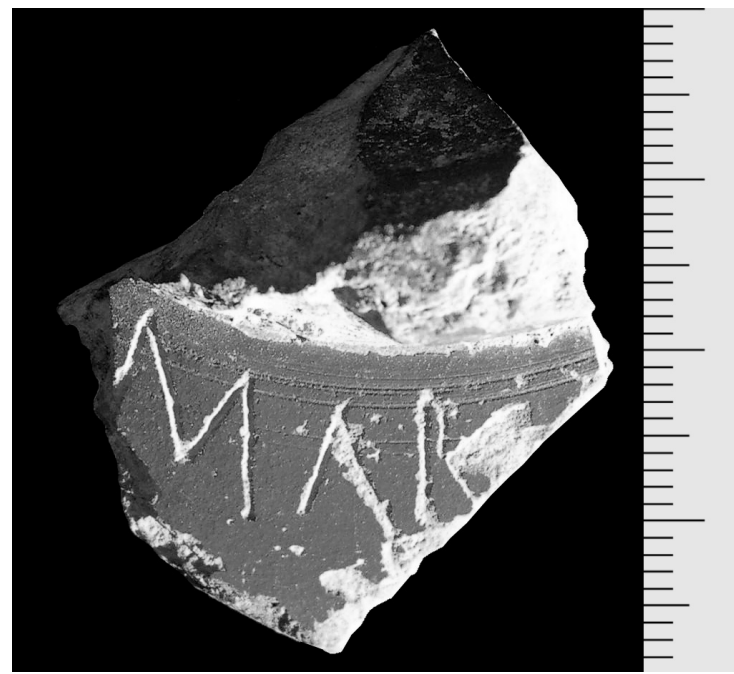

30 (1998, UE 1906, n. ${ }^{\circ}$ 283). Borde de un vaso de terra sigillata hispánica, forma Dr. 37. Bajo el

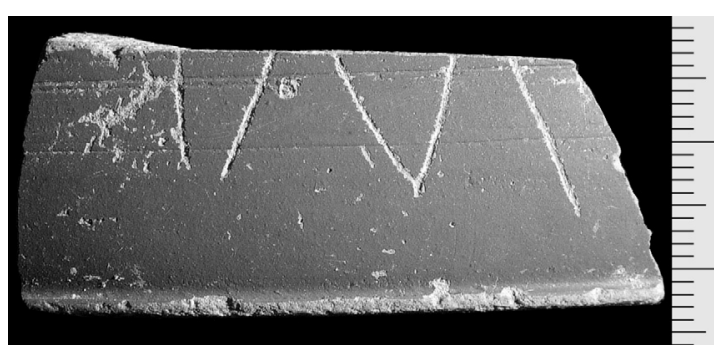

labio y en posición invertida figuran algunos trazos incompletos en los que parece identificarse una forma $[-] \mathrm{IM}[-]$ sobre una superficie de $[1,2]$ $x[3,5] \mathrm{cm}$. El deterioro de la parte izquierda impide garantizar la lectura.

31 (1998, UE 1906, n. ${ }^{\circ} 284$ ). Base de un recipiente de terra sigillata hispánica con sello OF T. ACCl. En su parte inferior presenta un grafito concéntrico junto al pie, con letras de c. $1,3 \mathrm{~cm}$ de altura y una longitud de $[3,4] \mathrm{cm}$. Sólo son visibles las letras SORI, precedidas de un trazo inclinado, quizá de $R$, con lo que podría suponerse aquí un genitivo o dativo del cognomen Cursor, en la forma [Cu]rsori[s] o [Cu]rsori, teniendo en cuenta que el nombre está atestiguado al menos dos veces en Hispania (Abascal, 1994, 341, de Córdoba y HEp 7, 108, de Medina de las Torres).

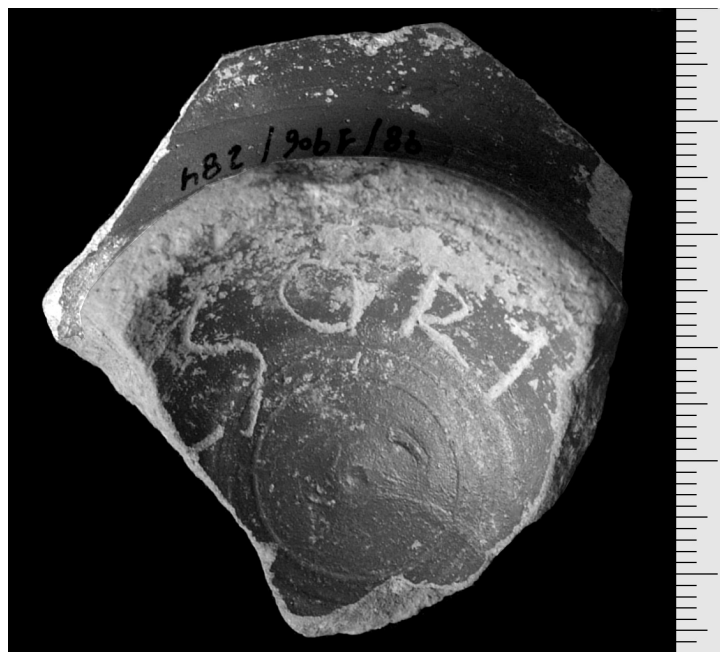

32 (1998, UE 1906, n. $\left.{ }^{\circ} 315\right)$. Borde de un vaso de terra sigillata hispánica, forma $\operatorname{Dr} .37$ bajo cuyo labio se lee [-]EST[-], con letras de $1,5 \mathrm{~cm}$ de altura en una superficie de $[3,5] \mathrm{cm}$ de longitud. Lo conservado debe ser parte de un nombre personal como [Mod]est[us], [F]est[us], [R]est[itutus] o similar, incluyendo las formas femeninas.

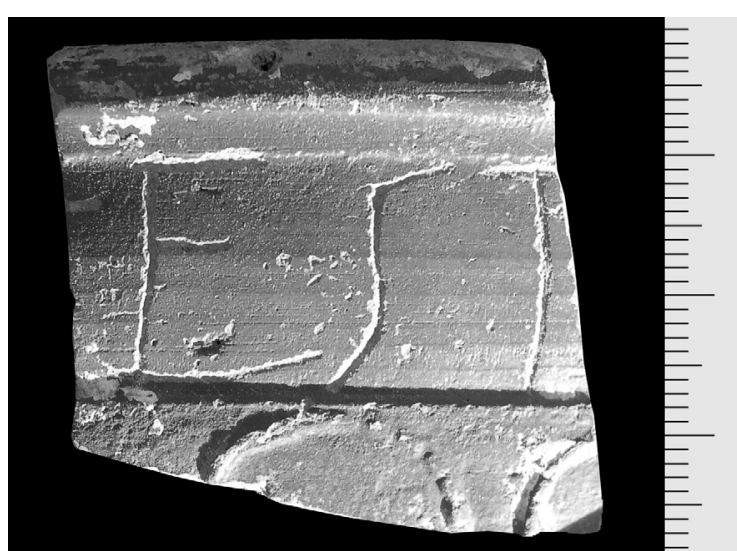


33 (1998, UE 1906, n. ${ }^{\circ}$ 1134). Borde de una urna de cerámica común, que conserva al exterior restos del final de un grafito en la forma [-] VII; lo conservado del texto mide $[1,6] \times[3,6] \mathrm{cm}$. Podría pertenecer al genitivo de nomina como Flavius, Cervius, Livius, Helvius, etc. Menos probable es que el segundo trazo sea una $L$, aunque no habría que descartar una forma [-]VLI, que abriría las puertas a lulius y otros nombre similares.

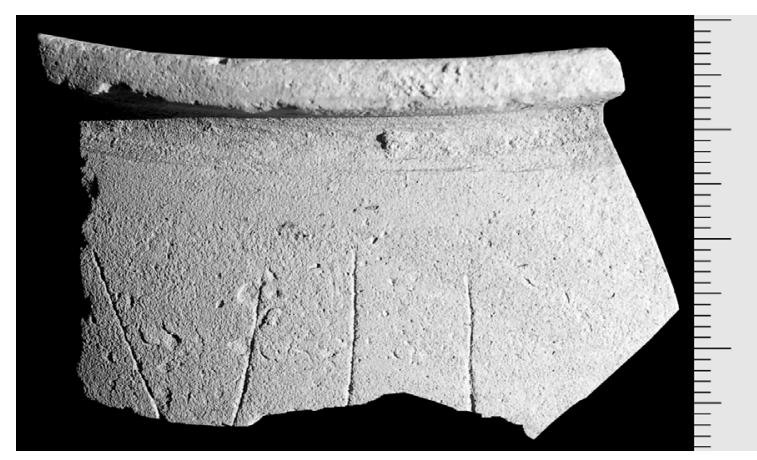

34 (1998, UE 1908, n. $\left.{ }^{\circ} 10\right)$. Fragmento de pared de un vaso de terra sigillata hispánica, en cuyo exterior conserva el extremo de la letra de un grafito no identificable de $[0,8] \mathrm{cm}$.

\section{Probable vivienda de Caius lulius Silvanus al oeste de las termas monumentales (1998- 1999)}

35 (1998, UE 1144, n. $\left.{ }^{\circ} 16\right)$. Base de un recipiente de terra sigillata hispánica, con restos de un grafito exterior junto al pie en una superficie de $[1,6] \times[2] \mathrm{cm}$. Del primer signo visible sólo queda el asta vertical, pudiendo ser tanto una I como $T$, $P$, etc.; el segundo es claramente una $E$, aunque ni delante ni detrás de ambos caracteres se percibe ningún trazo en lo conservado. No es posible determinar la naturaleza de esta forma $[-]+E[-]$.

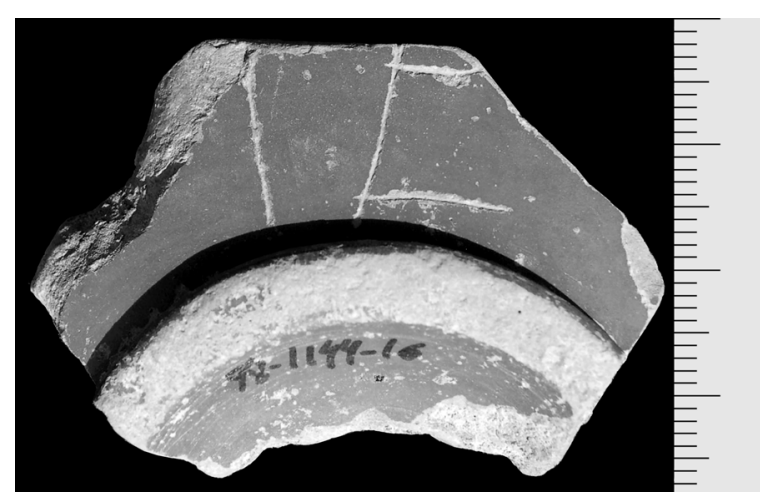

36 (1998, UE 1150, n. ${ }^{\circ} 56$ ). Dos fragmentgos de la base de un vasito de terra sigillata hispánica, forma Dr. 27. Al exterior y sobre el anillo del pie se conserva el final de una palabra con letras de $2,2 \mathrm{~cm}$ de altura y una longitud conservada de [3] $\mathrm{cm}$. Los trazos visibles permiten adivinar sin seguridad una forma [-]MV ó [-]MVS si, como parece, una $S$ muy estilizada coincide con la rotura de la pieza; podría tratarse del extremo de un nombre personal; menos probable es que en los primeros trazos pueda distinguirse $\mathrm{NI}$ en vez de $M$.

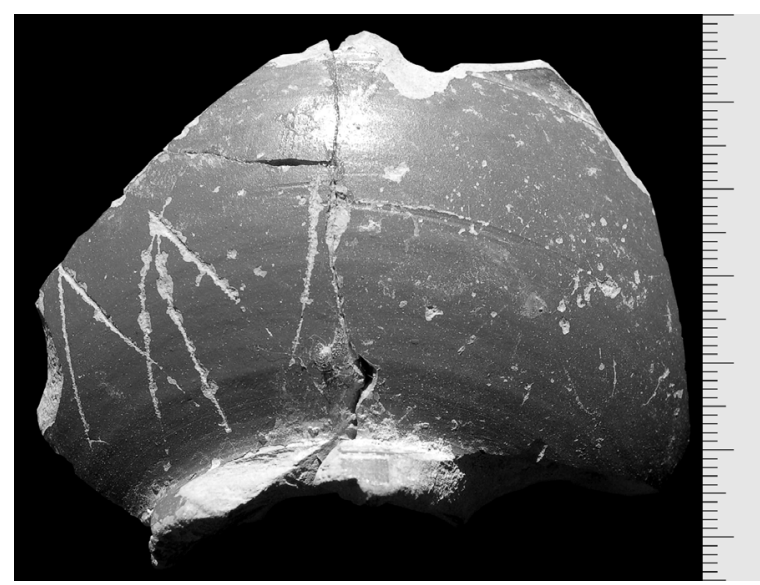

37 (1998, UE 1706, n. $\left.{ }^{\circ} 21\right)$. Fragmento de pared de un vaso de terra sigillata hispánica, que al exterior conserva restos de un grafito en el que parece distinguirse una $E$ de c. $1,5 \mathrm{~cm}$ de altura con el trazo vertical prolongado. Esta aparente lectura [-]E[-] no debe excluir otras posibilidades si se modifica la orientación del fragmento.

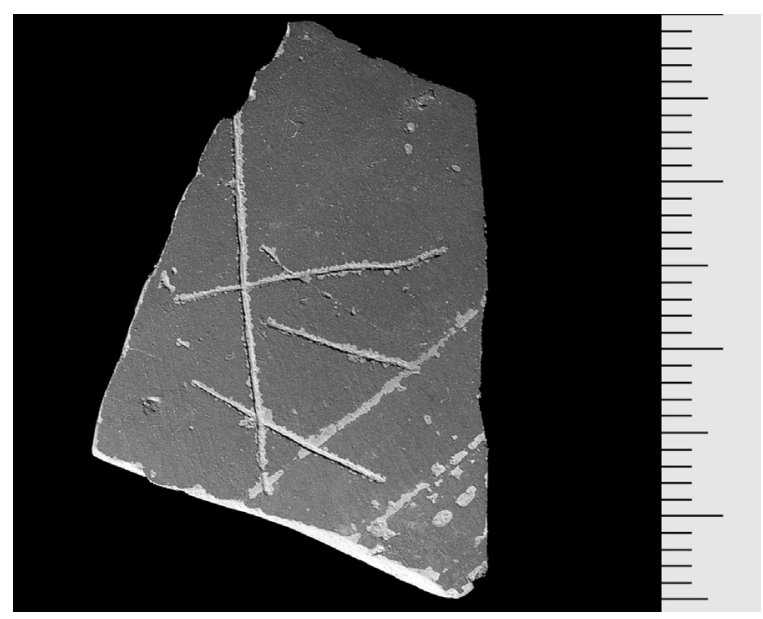


38 (1998, UE 1721, n. $\left.{ }^{\circ} 35\right)$. Fragmento de pared de un recipiente en cerámica común. Al exterior, en una superficie de $[4] \times[2,6] \mathrm{cm}$, presenta un grafito en forma de hoja de palma.

39 (1998, UE 1801, n. $\left.{ }^{\circ} 225\right)$. Fragmento de pared de un recipiente de terra sigillata hispánica, con restos de un grafito en su pared exterior sobre una superficie de $2,2 \times 0,6 \mathrm{~cm}$.

40 (1998, UE 1913, n. ${ }^{\circ} 7$ ). Borde de una urna de cerámica común con parte de un grafito exterior sobre el hombro. Las letras miden c. $1,2 \mathrm{~cm}$ de altura y ocupan una superficie de [5] $\mathrm{cm}$ de longitud. El texto dice CEM[-] o GEM[-], con la $E$ escrita como un doble trazo vertical, por lo que es probable que aluda a un nombre como Gem[ellus], Gem[inus] o similares, seguramente escrito aquí en genitivo.

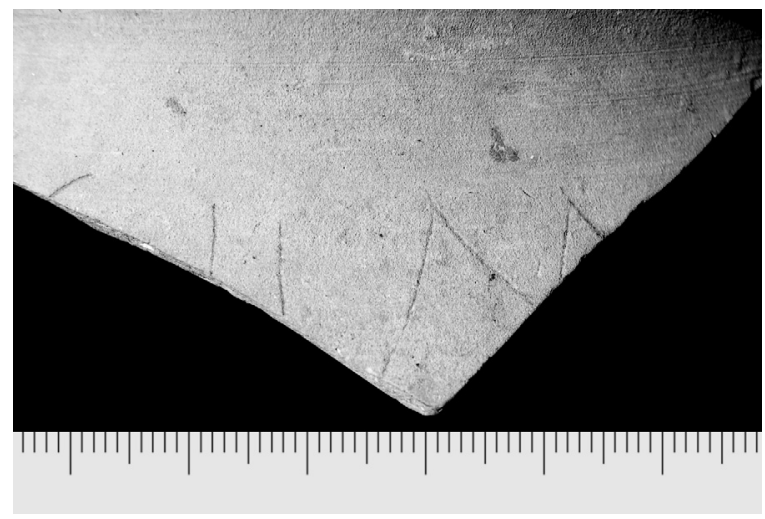

41 (1999, UE 1192, n. ${ }^{\circ}$ 32). Estancia 2. Base de un recipiente de terra sigillata hispánica. Sobre el anillo del pie se encuentran varios trazos rectos de unos $0,4 \mathrm{~cm}$ y en una longitud de $1,4 \mathrm{~cm}$, que podrían pertenecer al inicio de una palabra si no son elementos decorativos.

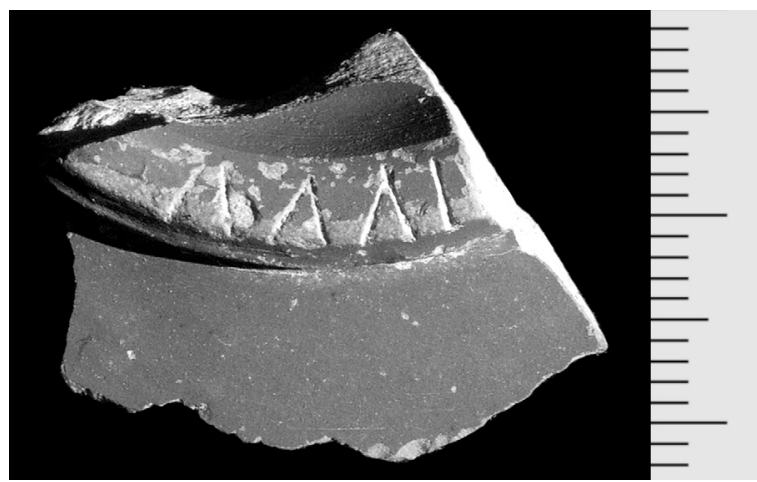

42 (1999, UE 1245, n. ${ }^{\circ} 2$ y 15). Estancia 2. Vasito de terra sigillata hispánica, forma Dr. 27, que presenta al exterior un grafito que lo rodea con letras de c. $1,7 \mathrm{~cm}$. El texto dice: Apolei llas o Ilas Apolei. Apolei es el genitivo del nomen Ap(p) uleius, bien representado en Hispania (Abascal, 1994, 83-84) en su forma Apoleius; Ilas es una forma simplificada del nombre griego Hylas (Solin 1982, 520), también conocido en la Península Ibérica (Abascal 1994, 388). De este modo, habría que entender que el vaso pertenece a Hylas, siervo de Apuleius. En los dos casos, la A está dibujada con travesaño oblicuo y no horizontal.

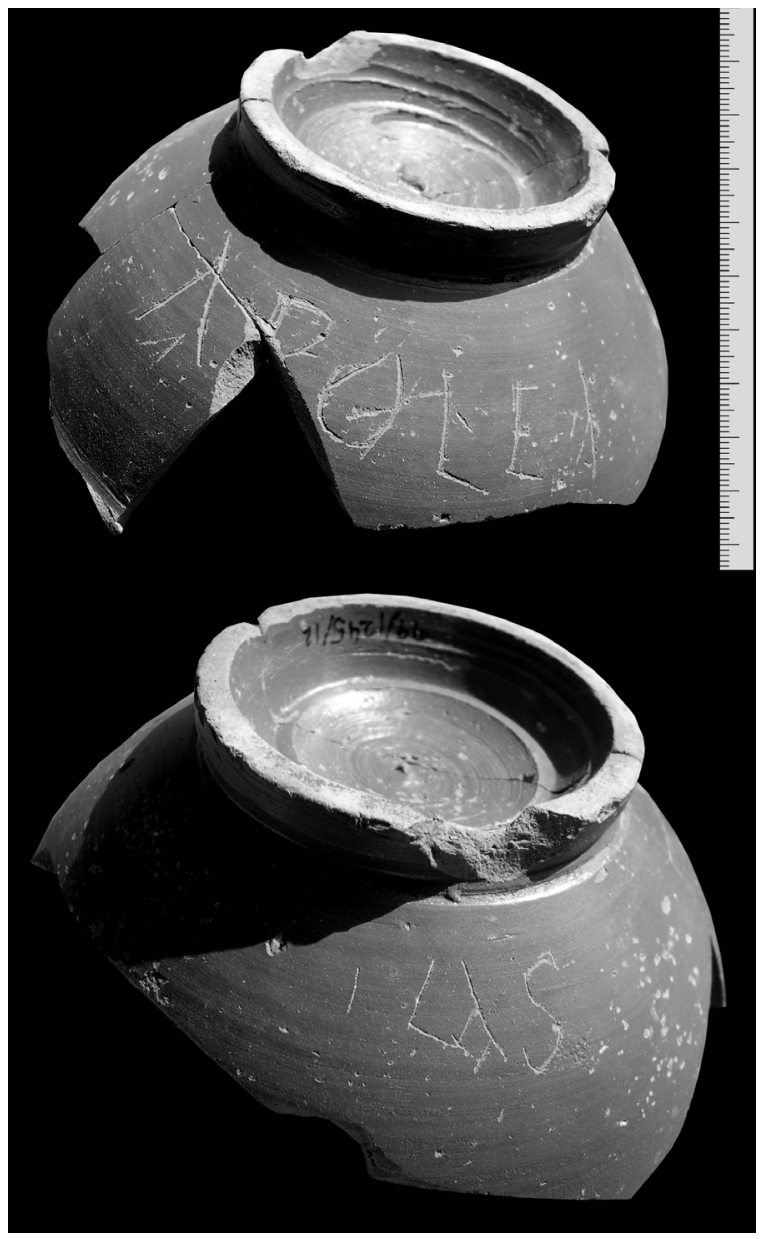

43 (1999, UE 1249, n. 8 al 11). Estancia 2. Botella de cerámica común partida en varios fragmentos, sobre cuyo hombro aparece escrito un grafito con letras de c. $4,6 \mathrm{~cm}$ de altura en una longitud conservada de [17] $\mathrm{cm}$. La primera letra del texto es, con seguridad, la M, mientras hay que suponer que lo escrito continuaba tras la $\mathrm{O}$ que puede reconocerse en la fractura final. El texto Marto[-] como nombre personal sugiere la forma Martorius, conocida en una inscripción cristiana de Tarragona (Alföldy, 1995, n. ${ }^{\circ}$ 991) o la también infrecuente Martolus (Solin - Salomies 1988, 359). Lo fragmentario del texto y la 
imposibilidad de decidir si hubo una interpunción tras la T impide proponer otras posibilidades de lectura.

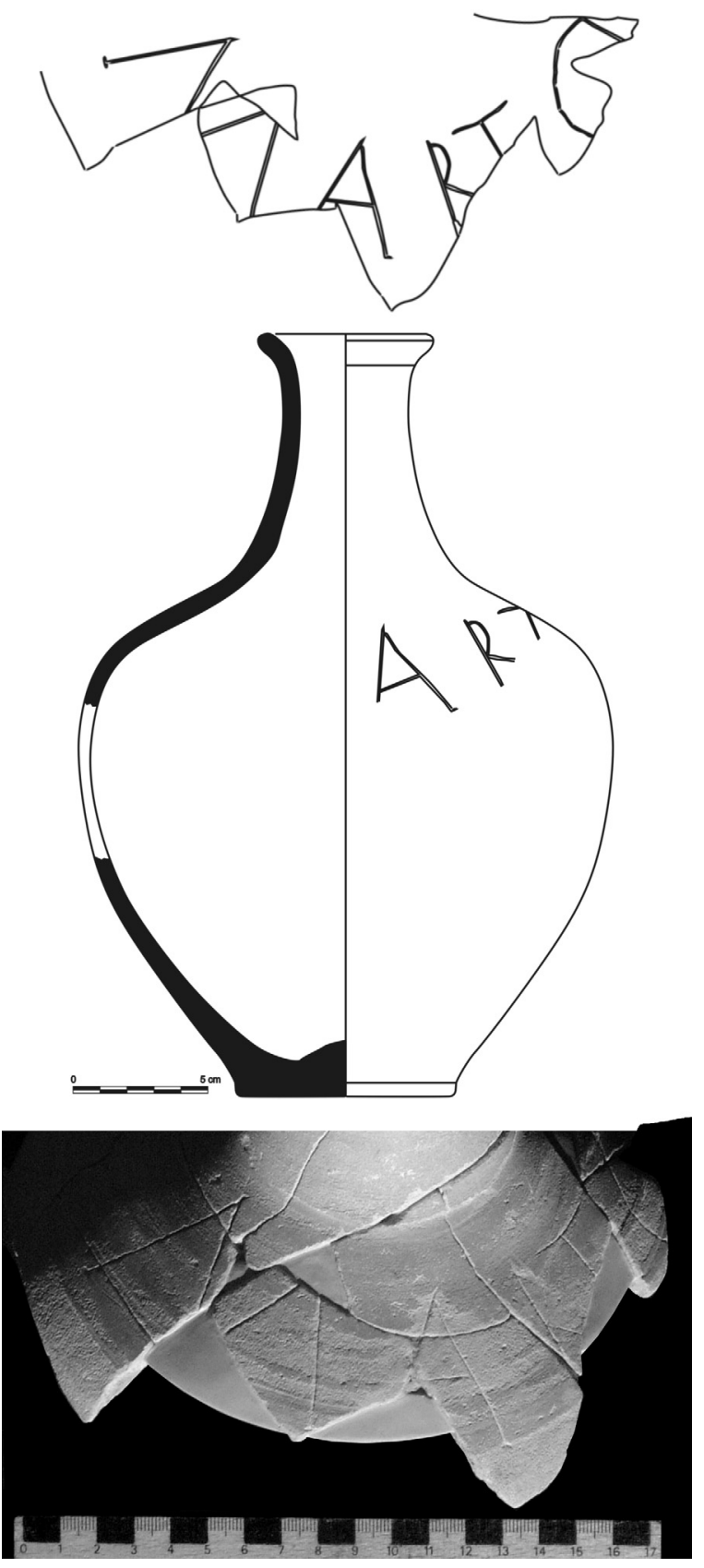

44 (1999, UE 1862, n. ${ }^{\circ}$ 58). Estancia 4. Base de terra sigillata itálica. Al exterior, ocupando una superficie de $1 \times 2 \mathrm{~cm}$, presenta tres trazos verticales paralelos.

45 (1999, UE 1864, n. $\left.{ }^{\circ} 74\right)$. Estancia 4. Fragmento de pared de un plato de terra sigillata hispánica, forma Dr. 15/17, en cuya pared exterior se conserva el final de un grafito en una superficie de $[1,1] \times[2] \mathrm{cm}$. El texto dice [-]NA, que podría pertenecer a la voz [pan]na o a un nombre personal no determinable por lo corriente de la terminación.

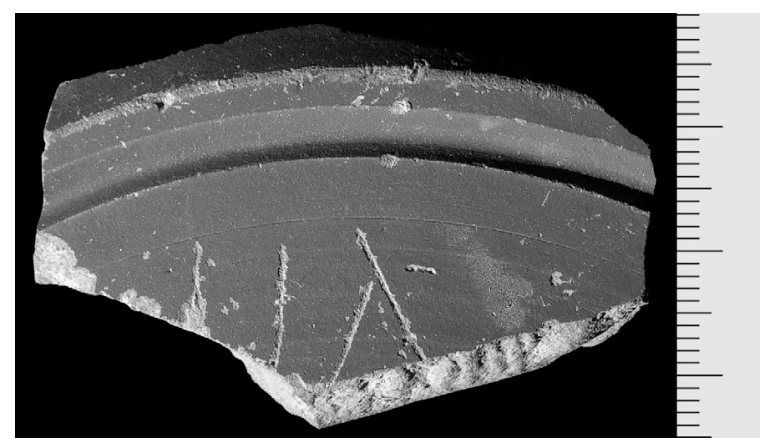

\section{Muralla oriental (1998-2000)}

46 (1998, UE 105, n. ${ }^{\circ} 58$ ). Base de un vaso de terra sigillata hispánica, en cuyo exterior, por encima del anillo del pie, se conserva el final de un grafito con letras de $1,5 \mathrm{~cm}$ de altura en una longitud de $[2,4] \mathrm{cm}$. El texto dice [-]VNI, lo que debe corresponder al genitivo de un nombre personal. Las direcciones de trazado descartan una combinación MYI como parece distinguirse a primera vista por la excesiva proximida de la $\mathrm{V}$ y la $\mathrm{N}$ y el incorrecto trazado de ésta última.

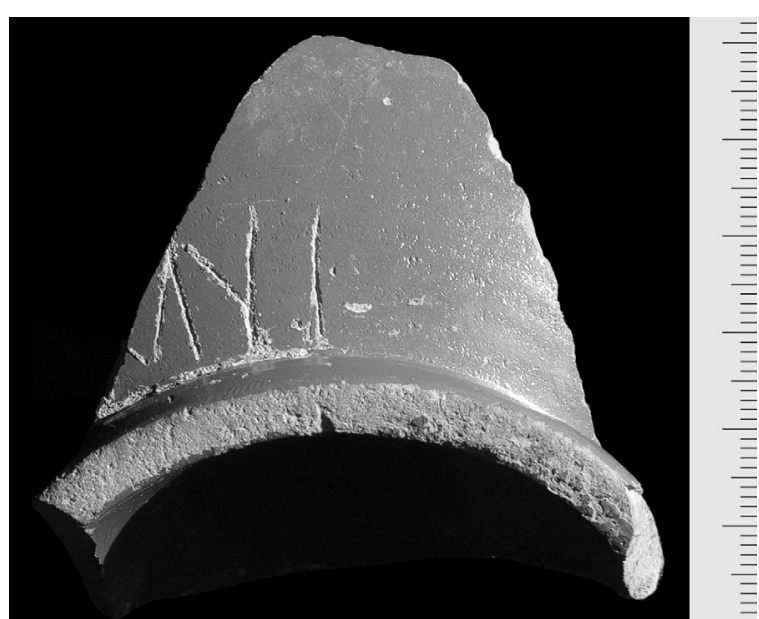

47 (1998, UE 105, n. $\left.{ }^{\circ} 66\right)$. Borde un recipiente de terra sigillata sudgálica, forma Halt. 15b. Al exterior y bajo el labio conserva parte de un grafito con loetras de $0,7 \mathrm{~cm}$ en una longitud de $[2,1] \mathrm{cm}$. El texto dice [-]ANV[-]. Debe tratarse en buena lógica de parte de un nombre personal, aunque ello no puede confirmarse. 


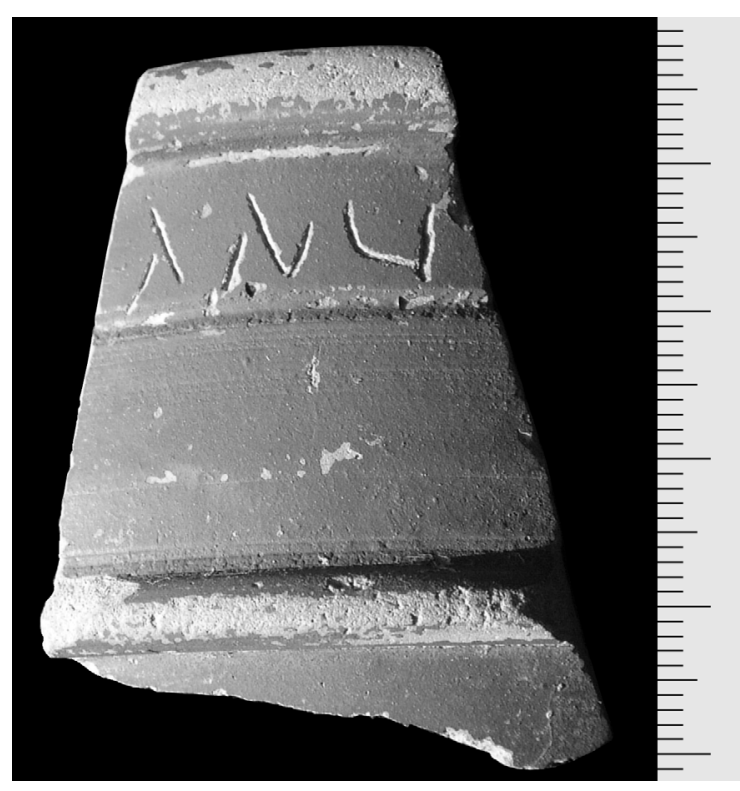

48 (1998, UE 139, n. ${ }^{\circ}$ 2). Fragmento de pared de una copita de terra sigillata hispánica, forma Dr. 27 , con varios trazos oblicuos paralelos y exteriores de interpretación imposible en una superficie de [2] $\times[1,9] \mathrm{cm}$.

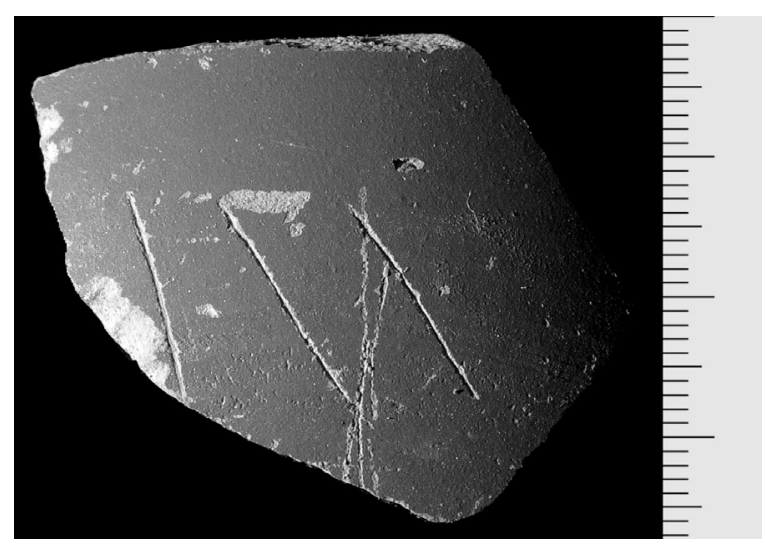

49 (1998, UE 171, n. $\left.{ }^{\circ} 4\right)$. Base de un vaso de terra sigillata hispánica, que al exterior y junto al anillo del pie conserva varios caracteres aparentemente no conexos en una superficie de $1,3 \mathrm{x}$ $3,6 \mathrm{~cm}$. Entre ellos puede reconocerse una $M$ invertida y un nexo TE al final de palabra.

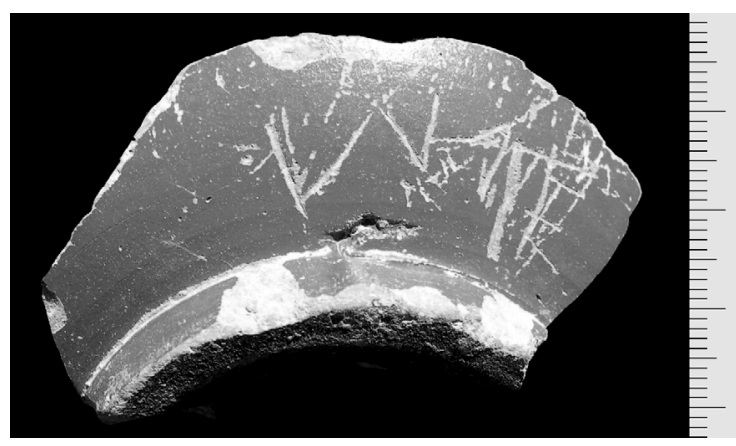

50 (1998, UE 230, n. ${ }^{\circ}$ 5). Base de un recipiente de terra sigillata hispánica, con parte de un grafito en la pared exterior por encima del pie, ocupando un espacio de $[1,6] \times[3] \mathrm{cm}$. En lo conservado puede leerse $[-] \mathrm{OCl}+[-]$, siendo la cruz el inicio de una letra que parece iniciarse con un asta vertical y que podría ser una N. Según eso, podría tratarse de una forma declinada de un nombre personal como Brocinus, Crocine o Docinia, todos ellos atestiguados en Hispania. No es descartable que que el tercer trazo sea una $T$, excesivamente cercano a la $C$, lo que abriría las puertas a nombres como Octavius y similares. En la parte inferior de la base presenta un aspa de ocho brazos también incisa tras la cocción.

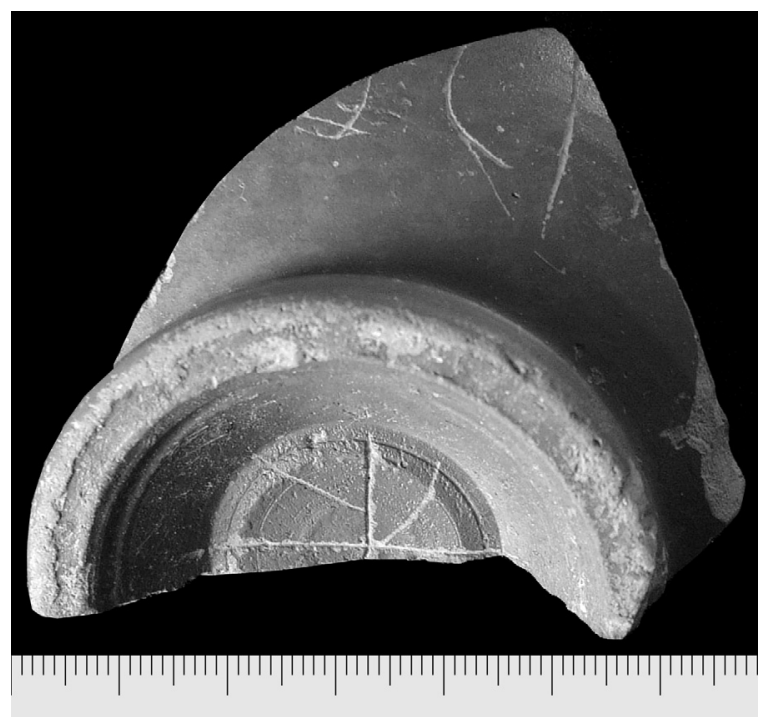

51 (1999, UE 95, n. 66 ). Fragmento de pared de un recipiente de cerámica común que conserva al exterior parte de un grafito en el que sólo puede leerse [-]A, que constituye el final de una palabra; la letra mide $3 \mathrm{~cm}$ de altura.

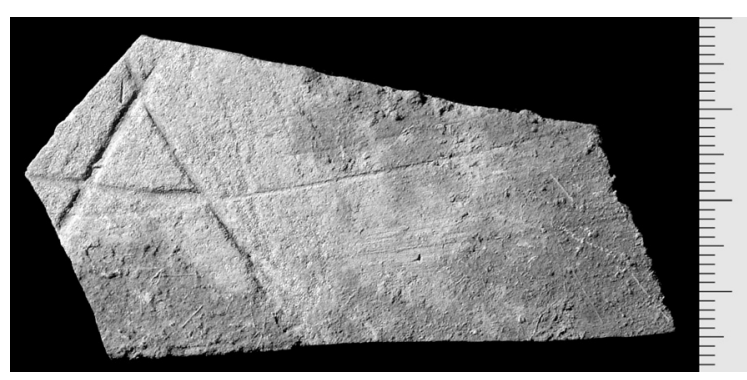

52 (2000, UE 2730, n. $\left.{ }^{\circ} 88\right)$. Fragmento de pared de una jarra de cerámica común con parte de un grafito exterior con letras de $1,7 \mathrm{~cm}$ de altura y una longitud conservada de [3] $\mathrm{cm}$. El texto dice 
[-]MA, siendo de destacar la forma de la última letra, con un travesaño oblicuo en la A.

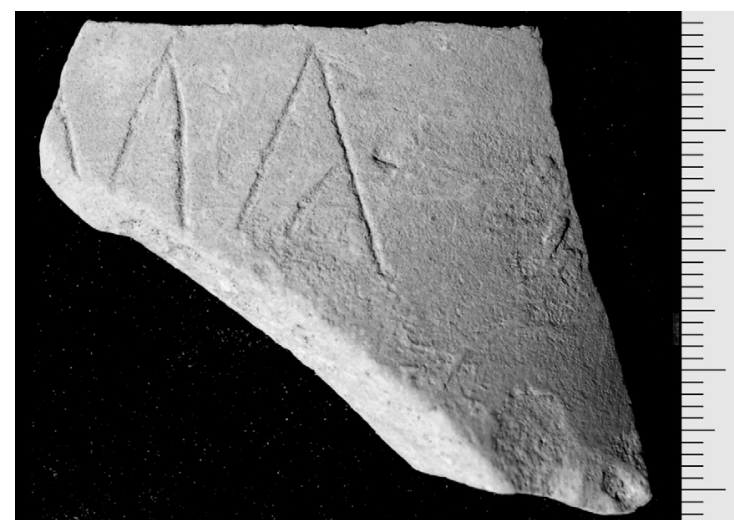

\section{Termas flavias junto al teatro (1999)}

53 (1999, UE 2050, n. ${ }^{\circ} 52$ ). Base de un plato de terra sigillata sudgálica que conserva al exterior el inicio de un grafito con dos caracteres de c. 1,1 $\mathrm{cm}$ de altura. El texto dice CV[-], lo que admite muchas posibilidades de desarrollo incluso si se restringe la búsqueda a una forma declinada de un nombre personal.

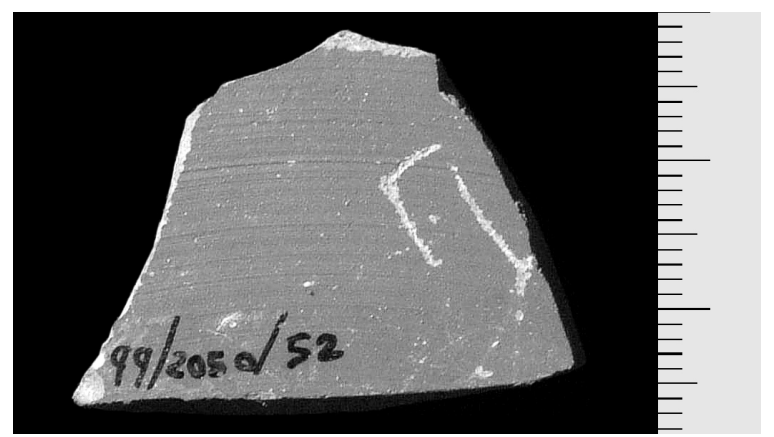

54 (1999, UE 2061, n. ${ }^{\circ} 28$ ). Fragmento de base de un recipiente de terra sigillata itálica de forma indeterminada con sello interior CRISE. En el exterior, presenta un grafito bien conservado con letras de c. $2 \mathrm{~cm}$ de altura, cuyo texto dice $\mathrm{M}(-) \mathrm{O}(-) \mathrm{P}(-) \mathrm{S}(-)$. Dada la seguridad de la lectura, no habría inconveniente en asignar el recipiente al siervo de un personaje cuyos tria nomina comenzaran por las iniciales $\mathrm{M}$. O. P., tal como $\mathrm{M}$ (arcus) $\mathrm{O}$ (ctavius) $\mathrm{P}$ (aternus) o similares, en cuyo caso, el grafito debería decir algo así como $\mathrm{M}(\operatorname{arci}) \mathrm{O}(-) \mathrm{P}(-) \mathrm{s}($ ervi), para indicar la propiedad del objeto.

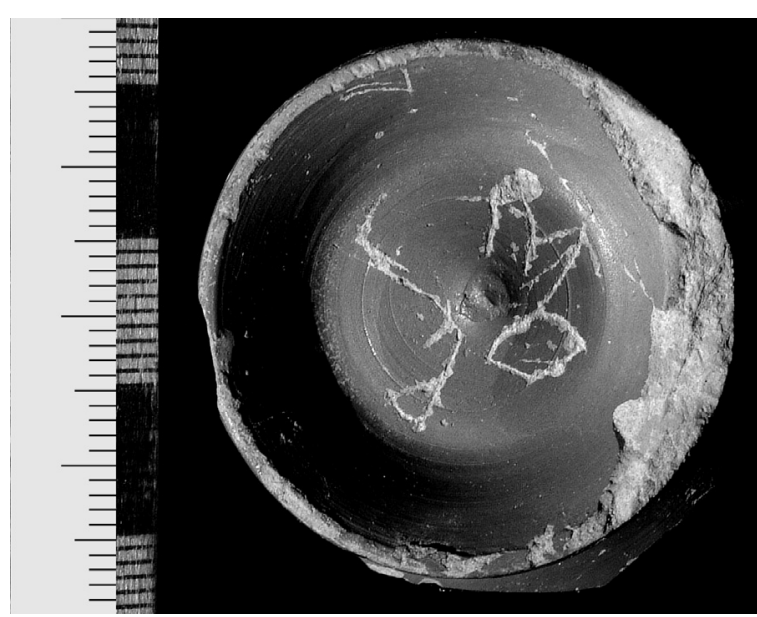

55 (1999, UE 2089, n. $\left.{ }^{\circ} 69\right)$. Fragmento de pared de un contenedor de grandes dimensiones, en cuya pared exterior figura un grafito ante-cocción del que sólo se conserva la parte inferior de una $X$ que debió medir unos $4,5 \mathrm{~cm}$ de altura. Dado el soporte y el tipo de letra, se trata a buen seguro de parte de la indicación de la capacidad del recipiente, tal y como es frecuente en dolia y otro tipo de contenedores, por lo que habría que imaginar que pudo ser un valor en modios o fracciones de éstos.

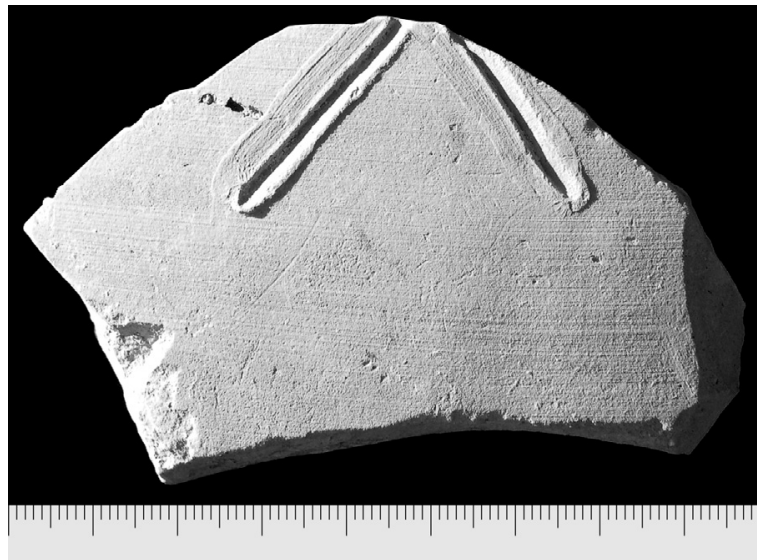

56 (1999, UE 2118, n. ${ }^{\circ}$ 3). Base de un recipiente de terra sigillata hispánica en cuya pared, junto al anillo del pie y en posición invertida, figura la denominación en genitivo de su propietario con letras de $0,9 \mathrm{~cm}$ de altura y en una longitud conservada de $[5,4] \mathrm{cm}$. El texto dice Vegeti Bu[-]; no es posible identificar el segundo elemento. Hay que destacar la escritura de la E con doble trazo vertical. 


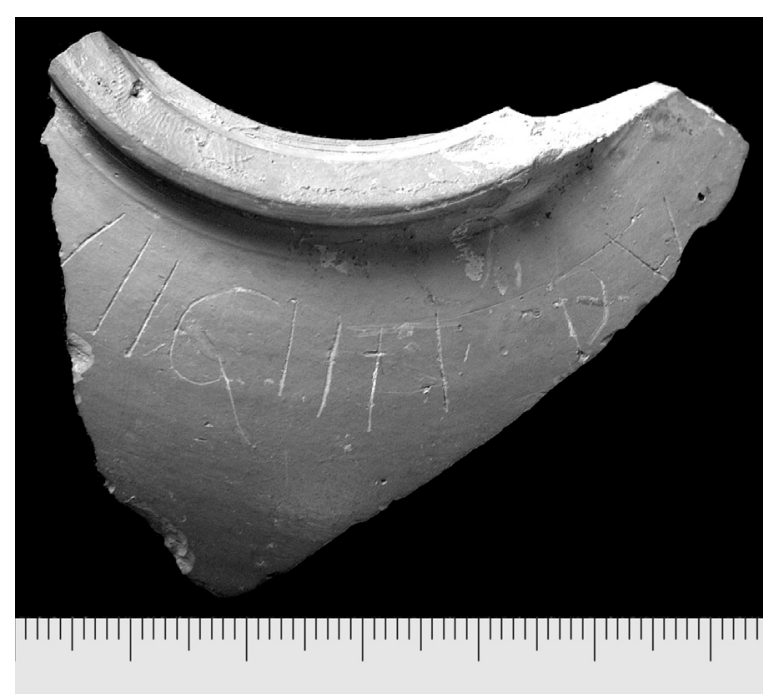

57 (1999, UE 2197, n. $\left.{ }^{\circ} 4\right)$. Fragmento de pared de un plato en terra sigillata sudgálica con gradfito en la pared interior con letras de $1,1 \mathrm{~cm}$ de altura en una longitud conservada de $[1,9] \mathrm{cm}$. En el texto se lee $\mathrm{VE}+[-]$, siendo la cruz el trazo curvo de la izquierda de una letra como G, o, G, etc.; en consecuencia, hay que imaginar que se trata de parte de un nombre personal, quizá en genitivo, en la forma Veg[-].

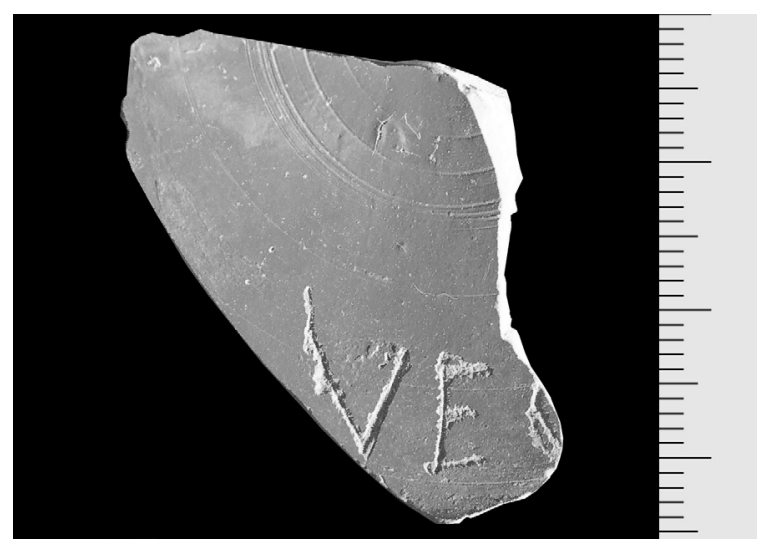

58 (1999, UE 2254, n. ${ }^{\circ} 18$ ). Fragmento de borde de un gran contenedor de cerámica común, con un grafito ante-cocción en la pared exterior; sus letras miden $4,5 \mathrm{~cm}$ de altura y ocupan una franja de $[10,5] \mathrm{cm}$ de longitud. Lo conservado dice [-] EBVR[-]. La E está escrita con un doble trazo vertical y la $V$ y $R$ forman un nexo. Es posible que estos trazos escondan una forma declinada del nombre personal Reburrus o del diminutivo Reburrinus.

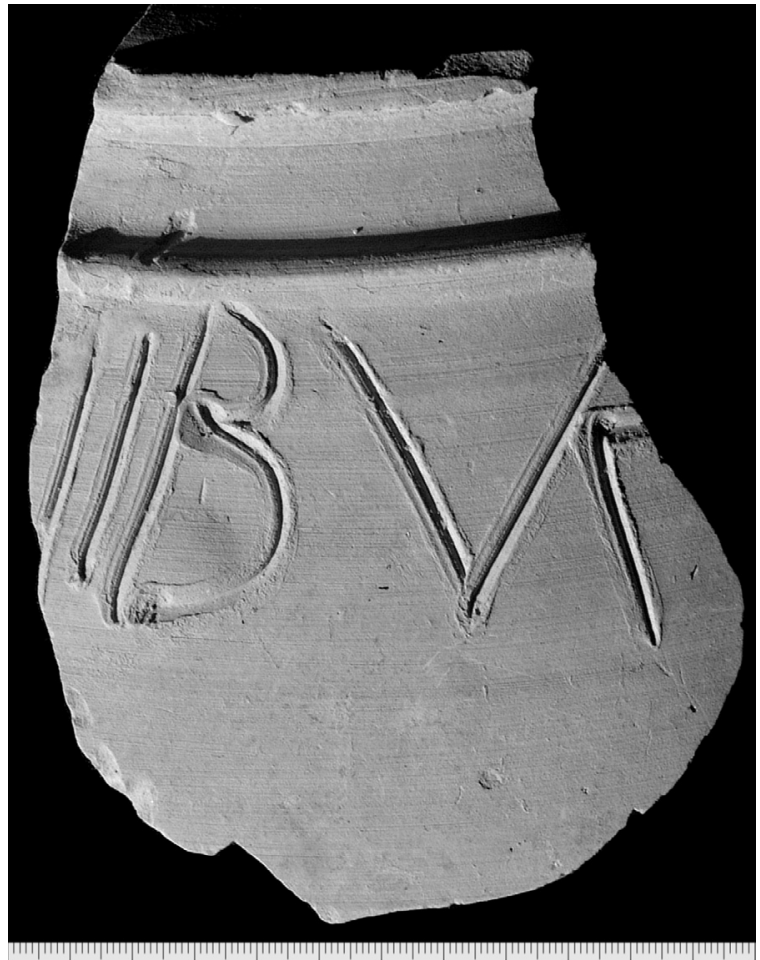

59 (1999, UE 2511, n. $\left.{ }^{\circ} 11\right)$. Base de terra sigillata sudgálica, forma Dr. 27. Al exterior presenta un aspa de $0,8 \times 0,6 \mathrm{~cm}$.

60 (1999, UE 2515, n. ${ }^{\circ} 60$ ). Hombro de una tinaja de cerámica común con restos de lañado en su extremo izquierdo. Al exterior presenta un grafito ante-cocción con letras de $3 \mathrm{~cm}$ de altura. Los caracteres están muy separados y hay un nexo $R E$; seguramente la $R$ es la letra inicial del texto, que debía continuar tras la $\mathrm{C}$. Lo visible dice Rec[-], quizá relativo al nombre personal Rectugenus o Retugenus, que ya conocíamos por la producción tegularia de la ciudad (Abascal, Cebrián y Riquelme, 2000).

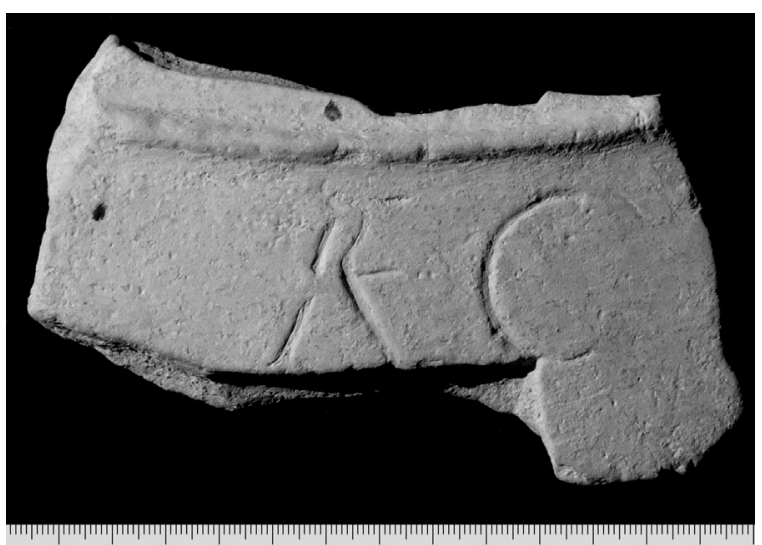


61 (1999, UE 2520, n. ${ }^{\circ}$ 4). Fragmento de pared de un vaso de cerámica pintada romana de época flavia. En la pared exterior, sobre la franja de pintura roja, lleva inciso el comienzo de un grafito con letras de $1,2 \mathrm{~cm}$ de altura. El texto dice $\operatorname{Vir}[-]$, seguramente parte de un nombre personal declinado.

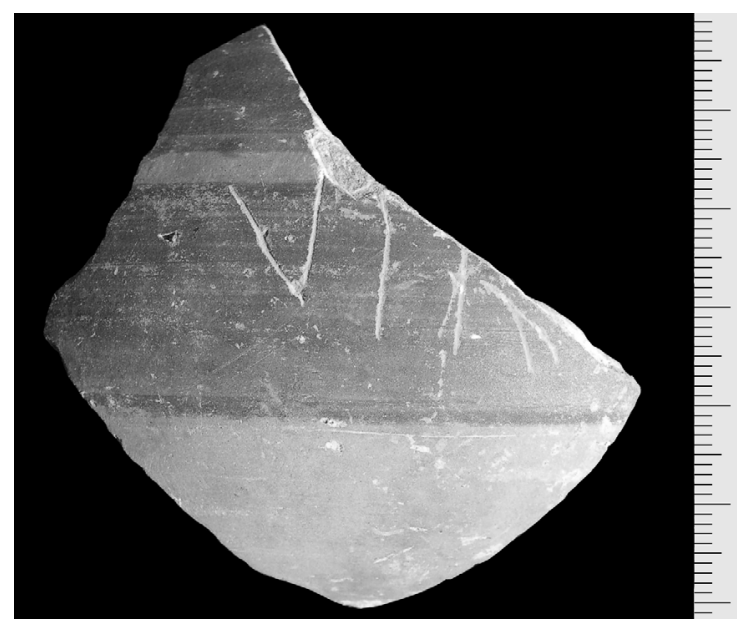

62 (1999, UE 2520, n. ${ }^{\circ} 5$ ). Borde de un cuenco engobado al exterior en color vinoso. Sobre el borde, y en posición invertida, conserva una letra $M$ aislada, seguids aparentemente de una interpunción, por lo que puede ser el extremo final de un texto. La letra mide $1,5 \mathrm{~cm}$ de altura.

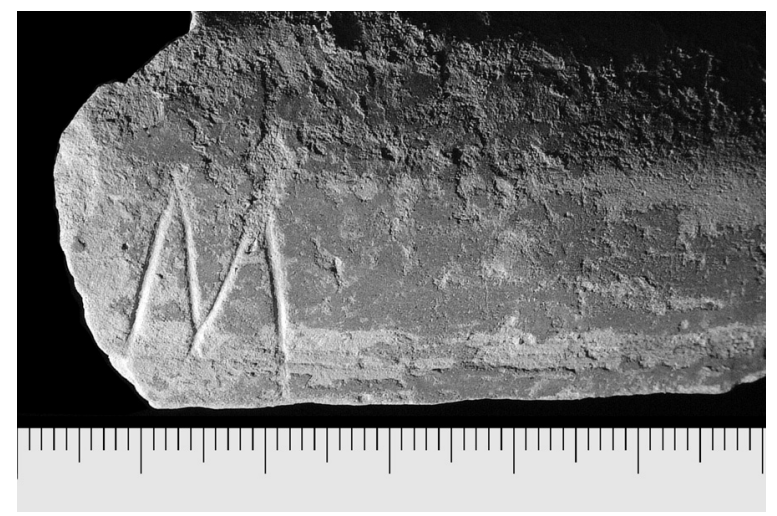

63 (1999, UE 2546, n. ${ }^{\circ} 110$ ). Fragmento de pared de una tinaja con restos de lañado en el lado derecho; conserva al exterior la parte final de un grafito ante-cocción imposible de identificar en su totalidad, del que sólo puede leerse [-]MIA, con letras de $2,9 \mathrm{~cm}$ de altura seguidas de la perforación de la laña.

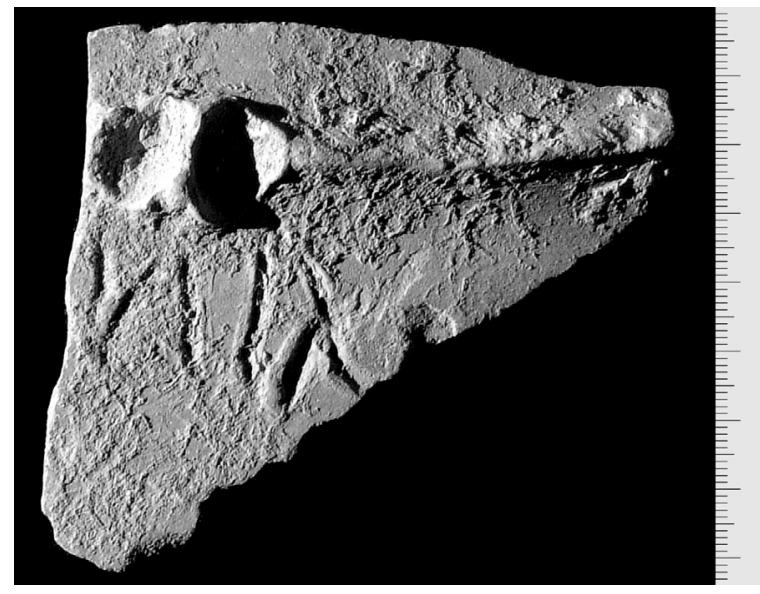

64 (1999, UE 2546, n. ${ }^{\circ} 103$ y 111). Dos fragmentos del hombro de un recipiente de cerámica común con parte de un texto cuyas letras miden $\mathrm{c}$. $4,5 \mathrm{~cm}$ de altura y que discurre horizontalmente. La parte conservada dice [-]MVESV[-], con la E escrita con un doble trazo vertical.

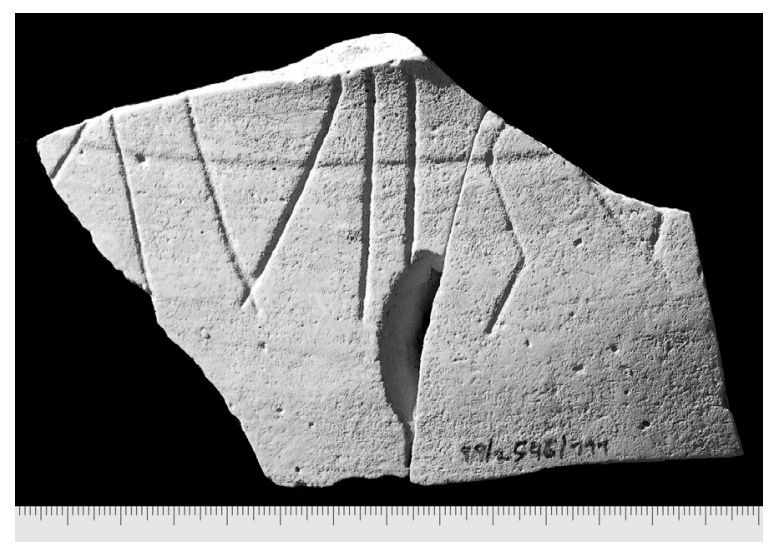

\section{Torre octogonal de la muralla oriental (1999)}

65 (1999, UE 58, n. $\left.{ }^{\circ} 24\right)$. Fragmento del hombro de una urna de cerámica pintada de la primera mitad del siglo I d.C. Entre dos líneas de color vinoso se conserva la parte final de un texto cuyas letras miden $3 \mathrm{~cm}$ de altura y ocupan una superficie de $[2,9] \mathrm{cm}$. El texto dice [-]OS. 


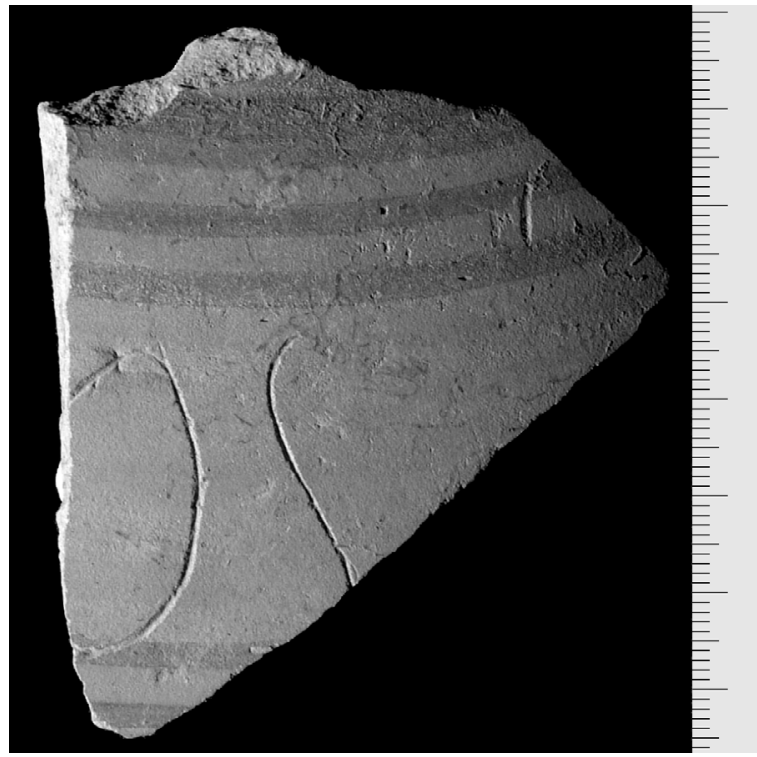

66 (1999, UE 85, n. $\left.{ }^{\circ} 56\right)$. Base de terra sigillata hispánica. Presenta en la parte inferior, al exterior, cuatro trazos verticales paralelos en una superficie de 1,1 $\times 1,1 \mathrm{~cm}$; en el interior, la letra $\mathrm{V}$, con unas dimensiones de $1,5 \times 1,4 \mathrm{~cm}$.

\section{Edificio de acceso escalonado, quizá de culto imperial, al oeste del foro (1999-2000)}

67 (1999, UE 3010, n. $\left.{ }^{\circ} 315\right)$. Base de terra sigillata hispánica; en el interior de la base presenta un grafito en forma de aspa de 1,9 cm de longitud.

68 (2000, UE 3000, n. ${ }^{\circ}$ 592). Fragmento de pared de un recipiente de terra sigillata hispánica, que al exterior de la pared presenta un grafito en forma de aspa de $1 \times 0,7 \mathrm{~cm}$.

69 (2000, UE 3000, n. 1014). Base de cerámica común, quizá de un jarro o mortero. Al exterior queda el extremo final de un grafito con letras de c. $1,1 \mathrm{~cm}$ de altura, en el que sólo puede leerse [-]ICO, quizá parte de un nombre personal en nominativo como Nico, Helico, Pelico, etc., todos ellos documentados en Hispania.

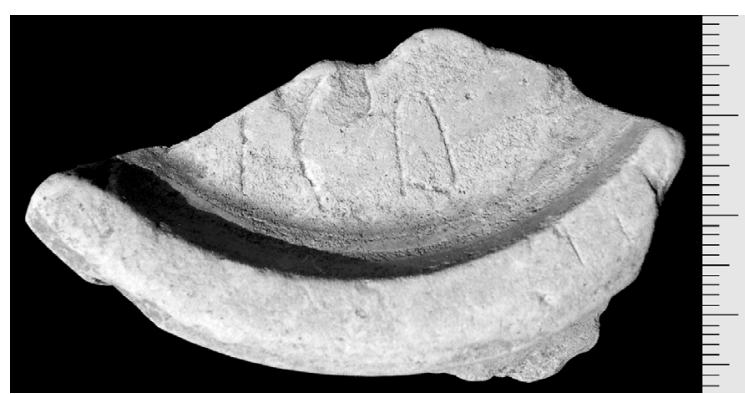

70 (2000, UE 3000, n. ${ }^{\circ} 3626$ ). Fragmento de base de un vaso en terra sigillata sudgálica, forma Drag. 37, con sello interior [-] $\cdot$ - CAR $(-)$. Al exterior y junto al anillo del pie conserva parte de un nombre personal en genitivo en la forma Clari [- ?], con letras de $1,9 \mathrm{~cm}$ de altura y una longitud de $5,8 \mathrm{~cm}$. Aunque la rotura afecta a la cuarta letra, no parece haber dificultad en restituir el cognomen Clarus (Solin - Salomies 1988, 314; Abascal, 1994, 329); cabe la posibilidad de que el texto continuara en la parte perdida.

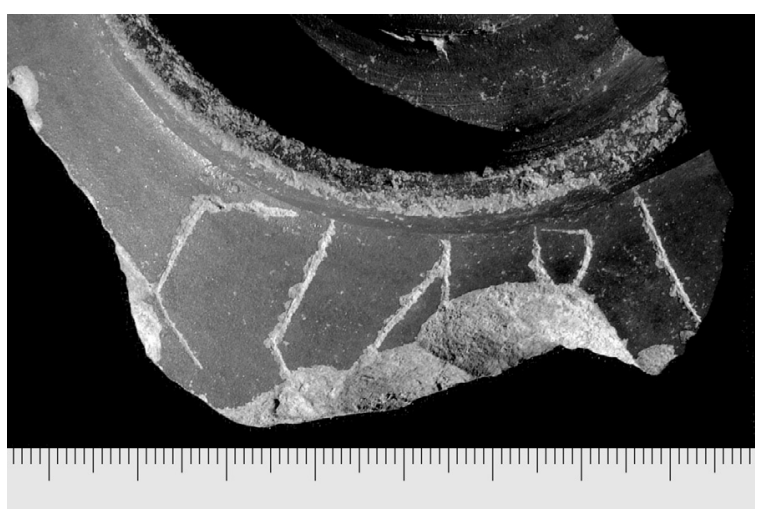

71 (2000, UE 3064 , n. ${ }^{\circ}$ 2). Borde de terra sigillata hispánica, forma Dr. 27, con grafito en el exterior en forma de aspa sobre una superficie de $3 \times 2,1$ $\mathrm{cm}$.

72 (2000, UE 3123, n. $\left.{ }^{\circ} 116\right)$. Borde de terra sigillata hispánica, forma Dr. 37. En la pared exterior presenta un grafito con algunos trazos ilegibles; en el interior aparece una doble aspa inscrita en un cuadrado, con unas dimensiones de $2 \times 1,8$ $\mathrm{cm}$.

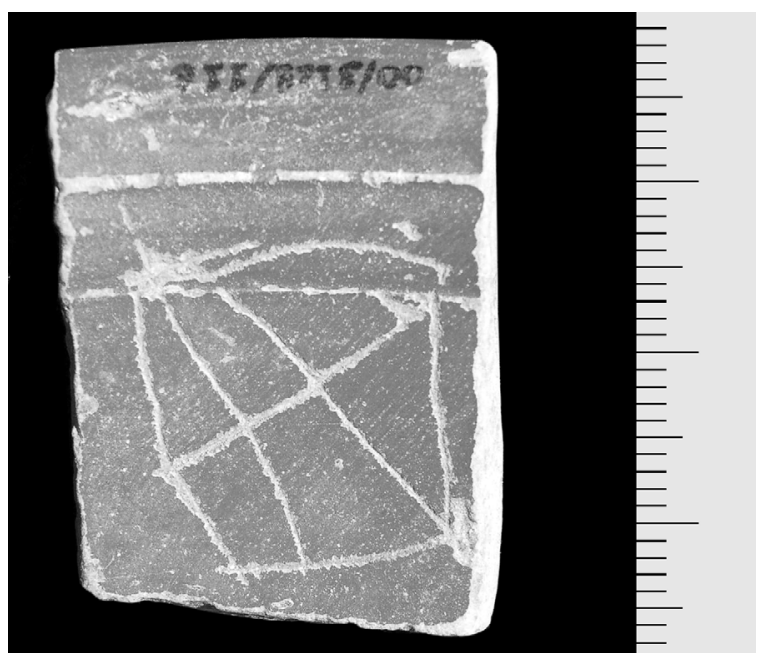


73 (2000, UE 3137, n. $\left.{ }^{0} 164\right)$. Fragmento de borde de un cuenco Drag. 37 de terra sigillata hispánica. En la pared exterior, grafito en forma de hoja de palma en una superficie de 1,5 x 1,3 cm.

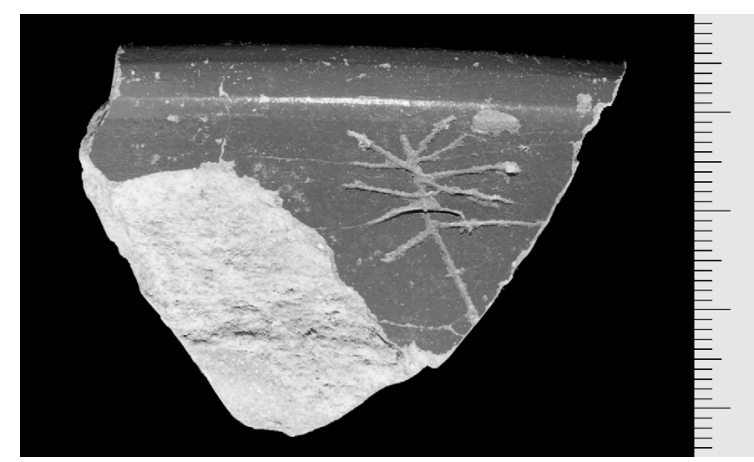

74 (2000, UE 3147, n. ${ }^{16}$ ). Base de terra sigillata hispánica. Al exterior de la base presenta incisas dos líneas paralelas en una superficie de $1,5 \times[1,1] \mathrm{cm}$.

75 (2000, UE 3209, n. $\left.{ }^{\circ} 2\right)$. Base de un recipiente de terra sigillata hispánica que en la parte inferior conserva un grafito en el que puede leerse Protae, con letras de c. $1 \mathrm{~cm}$ de altura. Protae es genitivo de Prota, una forma insólita del nombre griego femenino Prote (Solin 1982, 1042). La E final está dibujada con dos trazos paralelos. El empleo del genitivo indica la posesión del vaso.

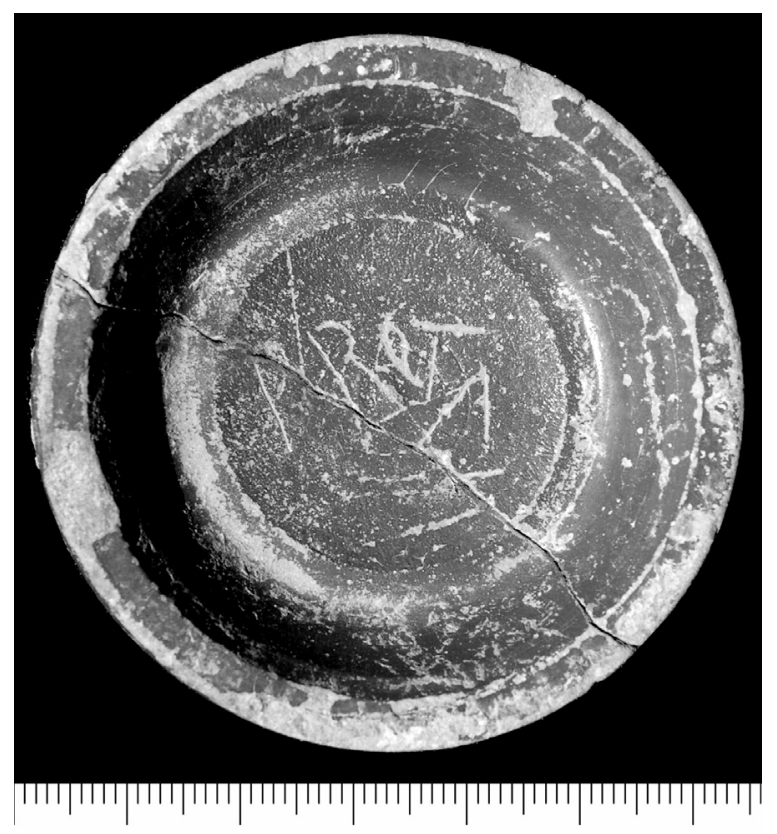

76 (2000, UE 3227, n. $\left.{ }^{\circ} 13\right)$. Base de un vaso de terra sigillata hispánica con restos de un gradito en el que sólo puede leerse [-]ILIC+[-], con le- tras de $1,5 \mathrm{~cm}$ de altura. La cruz final es resto de un trazo no identificable. En el interior de la base presenta otro grafito en forma de aspa de 1,2 $\mathrm{x}$ $1,4 \mathrm{~cm}$. La L está dibujada con un trazo vertical y otro oblicuo.

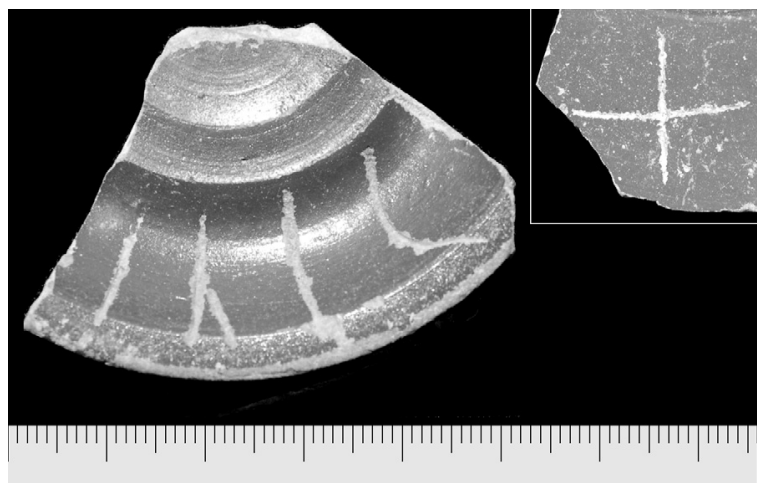

77 (2000, UE 3227, n. $\left.{ }^{\circ} 34\right)$. Base de un recipiente de terra sigillata hispánica, forma Dr. 27 con sello EX OF [-], que al interior presenta un grafito en forma de aspa de $1,2 \times 0,7 \mathrm{~cm}$.

78 (2000, UE 3227, n. $\left.{ }^{\circ} 165\right)$. Base de un plato de terra sigillata hispánica, forma Dr. 15/17, con sello OF [-]. En el interior, junto al sello, se conserva una parte de un grafito, con grandes letras de $2,5 \mathrm{~cm}$ de altura. El texto dice Salvae, genitivo del cognomen femenino Salva (Kajanto, 1982, 232), seguido de una pequeña aspa. Las dos $A$ carecen de travesaño y la $S$ es inicial es de proporciones mayores que el resto de los caracteres.

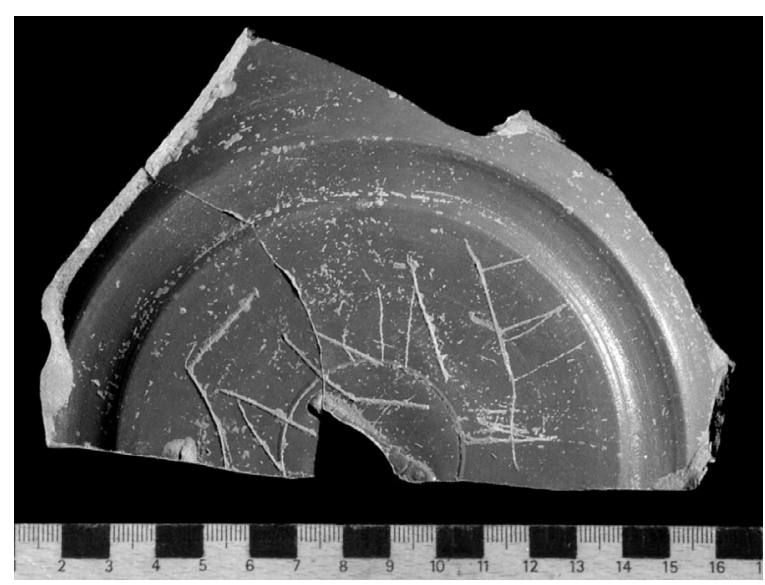

79 (2000, UE 3227, n. ${ }^{\circ} 251$ ). Borde de un cuenco de terra sigillata hispánica, forma Rit. 08. Sobre la pared exterior, con letras de c. $0,9 \mathrm{~cm}$ de altura y en una longitud de $1,5 \mathrm{~cm}$, se lee con claridad GIA ó SIA, aparentemente sin pérdidas de texto por los extremos. 


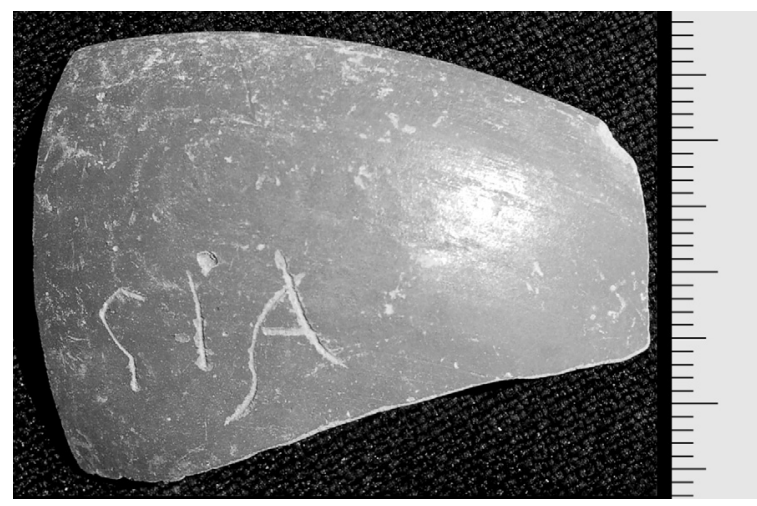

80 (2000, UE 3227, n. $\left.{ }^{\circ} 271\right)$. Base de un vaso de terra sigillata hispánica, forma Dr. 27. Al exterior presenta un grafito con letras de c. 0,9 $\mathrm{cm}$ de altura; la primera, incompleta y de mayor tamaño, podría ser una I precedida de una $R$; al final, ligeramente separada, se encuentra la parte izquierda de una probable $P$. En tal caso, habría que leer algo como Riosci p[anna ?], aunque habría que esperar aquí mejor Rosci, como genitivo del nomen Roscius.

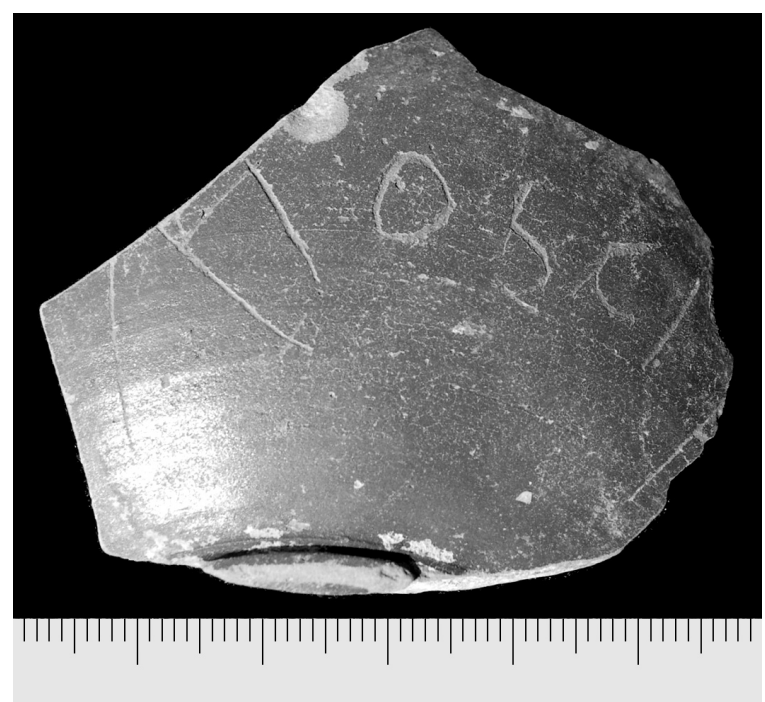

\section{Necrópolis musulmana situada entre el teatro y el Museo antiguo (2000).}

81 (2000, UE 811, n. ${ }^{\circ}$ 94). Fragmento de pared de un recipiente de terra sigillata hispánica con restos de un texto no identificable.

82 (2000, UE 815, n. $\left.{ }^{\circ} 126\right)$. Fragmento del disco y margo de una lucerna de finales del siglo I o comienzos del II d.C. Sobre el margo conserva restos de un grafito no identificable.

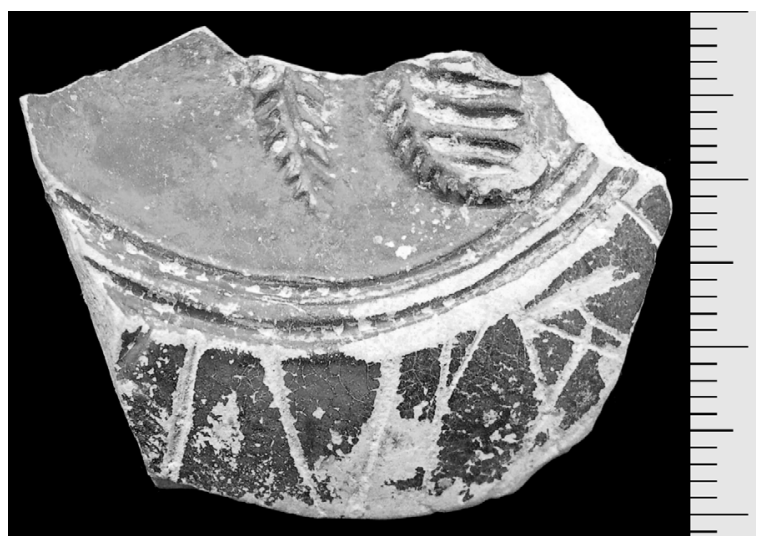

83 (2000, UE 850, n. $\left.{ }^{\circ} 553\right)$. Base de un recipiente de terra sigillata hispánica que conserva restos de un grafito con letras de c. $0,8 \mathrm{~cm}$ de altura. A la izquierda se ve parte de una $S$ rota en la arista de la pieza; a la derecha, un asta vertical y el arranque de la curva de una $D$. El texto dice [-]SOD[-]. El texto permite tanto una forma declinada del cognomen Prosodus como cualquier otra solución más compleja.

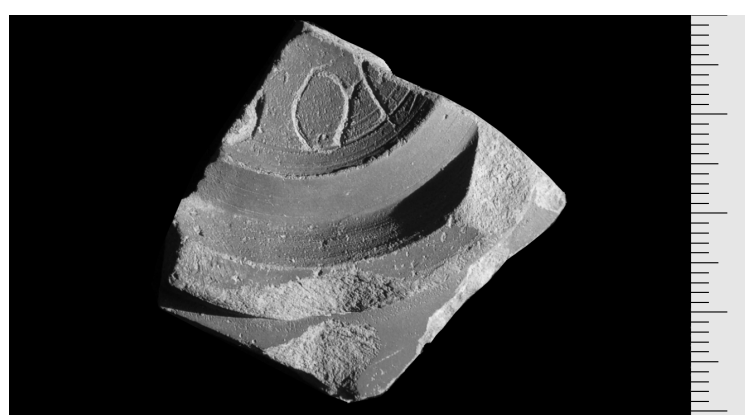

84 (2000, UE 852, n. $\left.{ }^{\circ} 600\right)$. Base de un recipiente de terra sigillata hispánica con restos de un gradito junto al anillo del pie; sólo subsisten tres astas verticales incompletas de $[0,8] \mathrm{cm}$ de altura en una longitud de [2] $\mathrm{cm}$.

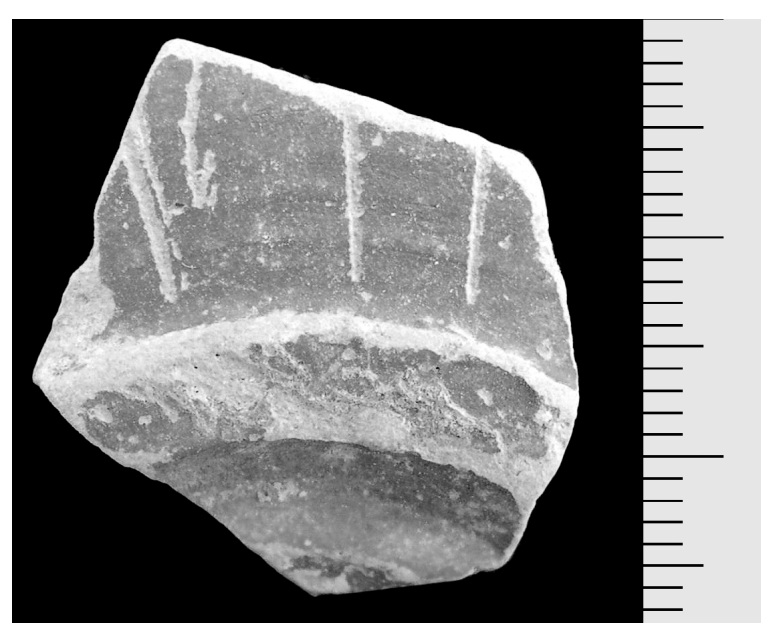


85 (2000, UE 852, n. $\left.{ }^{\circ} 897\right)$. Base de una jarra de cerámica común con la pared exterior bruñida. Sobre ella se ve parte de un grafito cuyas letras incompletas miden $[1,9] \mathrm{cm}$ de altura y ocupan una longitud de $[3,5] \mathrm{cm}$. Se distingue claramente una $S$, seguida de una $\mathrm{V}$ y de una probable $M$, en el caso de que éste sea el sentido de la lectura, de lo que no hay garantías.

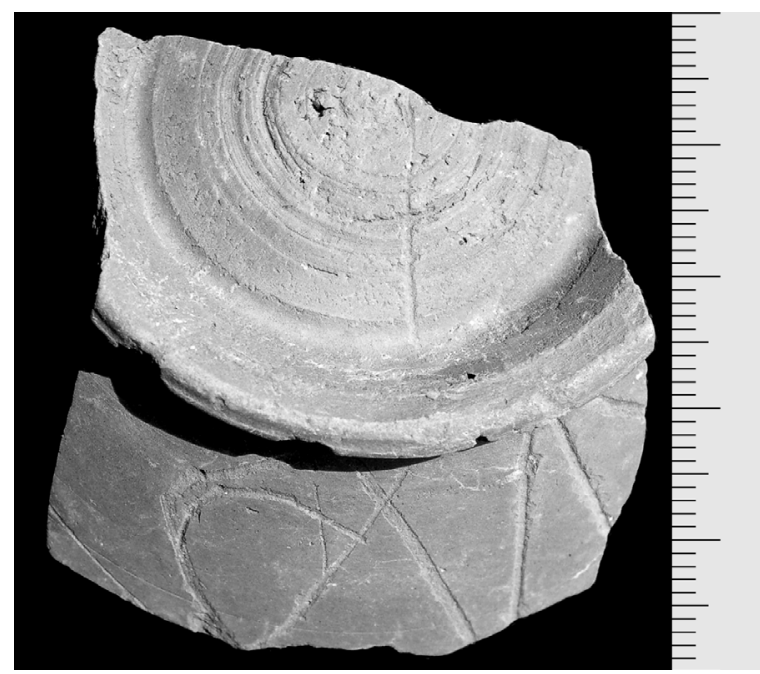

86 (2000, UE 855, n. $\left.{ }^{\circ} 13\right)$. Base de un recipiente de terra sigillata hispánica, en cuya pared exterior queda el extremo final de un grafito con letras de $1,2 \mathrm{~cm}$ de altura, muy bien dibujadas; la penúltima, una probable $\mathrm{R}$, se ha perdido con la caída del barniz, pese a lo cual parece distinguirse bien su trazo inclinado; por delante de ella hay dos trazos verticales que podrían ser la expresión de una $E$. En tal caso, habría que entender aquí [-] ERP; no es posible dar sentido a esta lectura, en la que no es probable que se esconda el final de la abreviatura de un nombre personal como Euterpe, Perpetuus o similar.

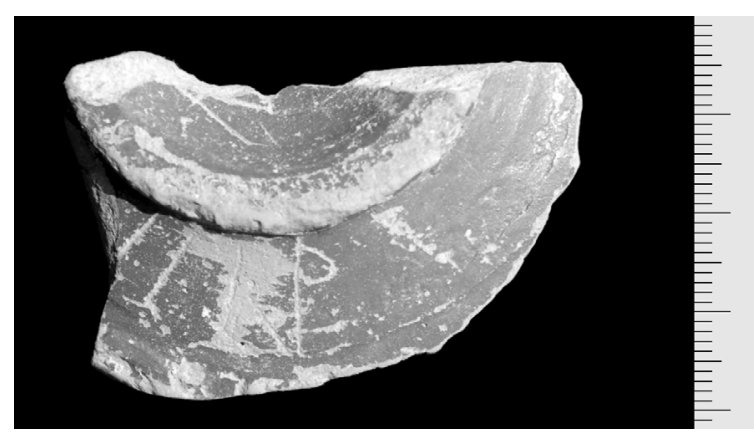

87 (2000, UE 855, n. $\left.{ }^{\circ} 19\right)$. Base de un cuenco de terra sigillata hispánica; junto al anillo, con letras de $1,5 \mathrm{~cm}$ de altura, se lee el inicio de un grafito en el que sólo puede verse RA[-]. La R está dibujada con el ojo muy pequeño y la A carece de travesaño.

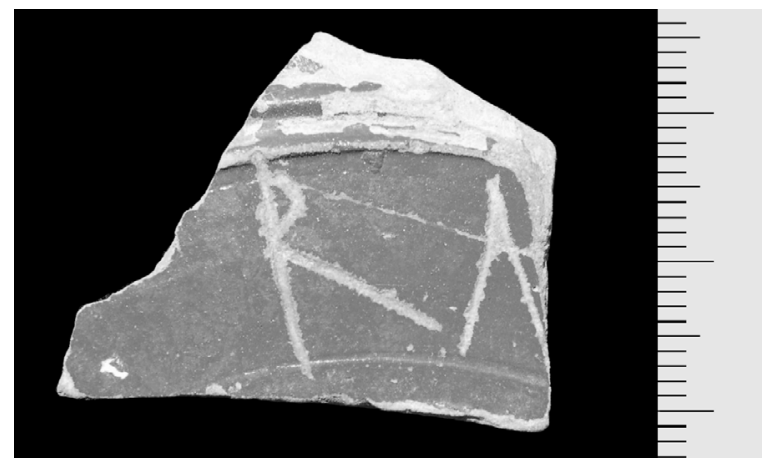

88 (2000, UE 856, n. $\left.{ }^{\circ} 494\right)$. Fragmento de pared de un recipiente muy deteriorado de terra sigillata hispánica; conserva el final de un grafito con letras de $1,7 \mathrm{~cm}$ de altura, que ocupa un espacio horizontal de $[2,2] \mathrm{cm}$. La primera letra completa es una $R$ de trazos angulados, seguida de una doble asta vertical y precedida de un trazo oblicuo quizá perteneciente a una V. En tal caso, habría que leer [-]VRII, es decir, un genitivo de nombres como Mercurius, Asturius, Saturius, etc.

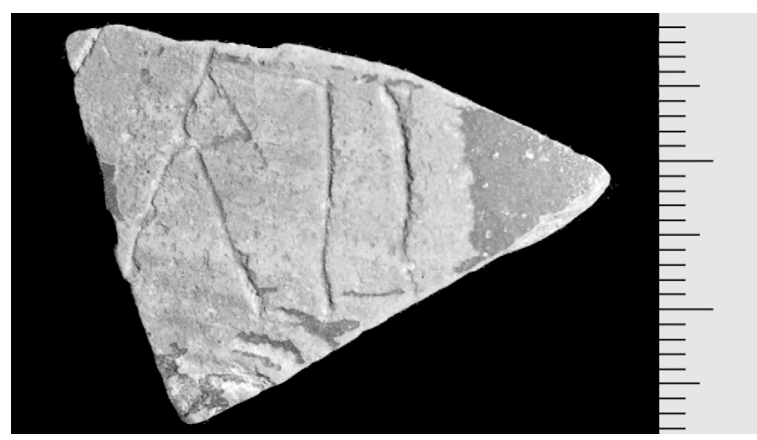

89 (2000, UE 874, n. $\left.{ }^{\circ} 6\right)$. Fragmento de base de un recipiente de terra sigillata hispánica. En la pared exterior, presenta un grafito que incluye una hoja de palma y un aspa en una superficie de $[2,2] \times[3] \mathrm{cm}$.

90 (2000, UE 885, n. $\left.{ }^{\circ} 23\right)$. Base de un plato de terra sigillata hispánica brillante. En el interior de la base conserva la parte final de un grafito que ocupa una superficie de $[0,6] \times 1,5 \mathrm{~cm}$. La primera letra completa es una $L$ con trazo inferior oblicuo, precedida del asta derecha de una probable $\mathrm{V}$; la tercera y cuarta letra son I y $\mathrm{E}$ respectivamente, con lo que habría que leer [-]VLIE, quizá un genitivo femenino en la forma [-]uli(a)e. 


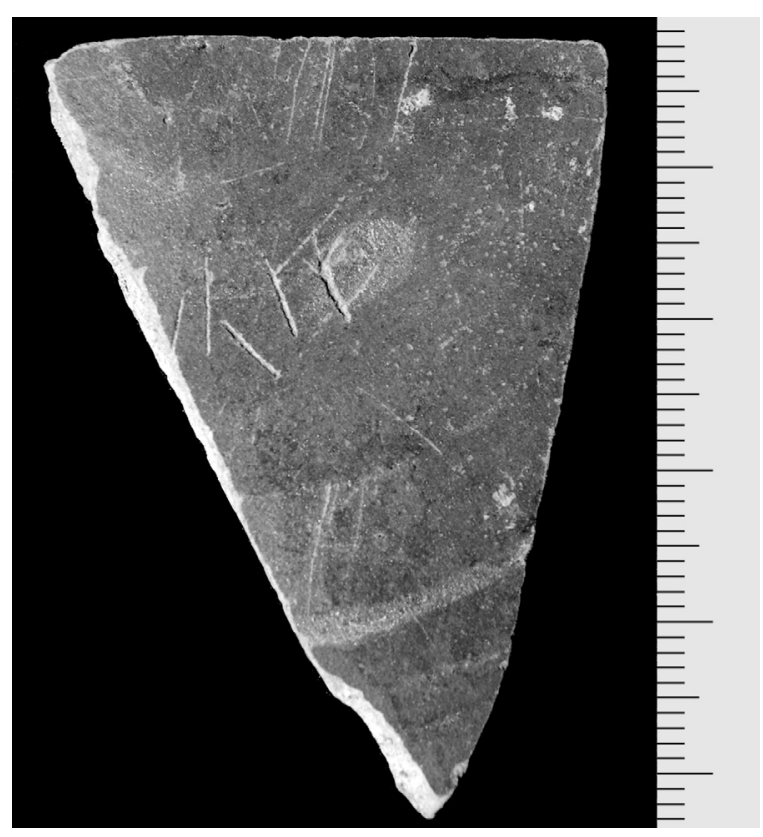

91 (2000, UE 888, n. ${ }^{\circ}$ 3). Base de un plato de terra sigillata hispánica, forma Dr. 24/25. En el exterior de la base aparecen los extremos irreconocibles de un grafito en una superficie de $[0,4]$ $x[0,6] \mathrm{cm}$.

\section{Necrópolis tardo-romana del camino hacia el Centro de Interpretación (2000)}

92 (2000, UE 6001, n. $\left.{ }^{\circ} 407\right)$. Fragmento de base de un cuenco de terra sigillata hispánica, forma Dr. 37, con parte de un grafito no identificable en el que parece distinguirse con claridad una $R$ seguida de una $\mathrm{N}$, sin que sea posible dar una solución al texto.

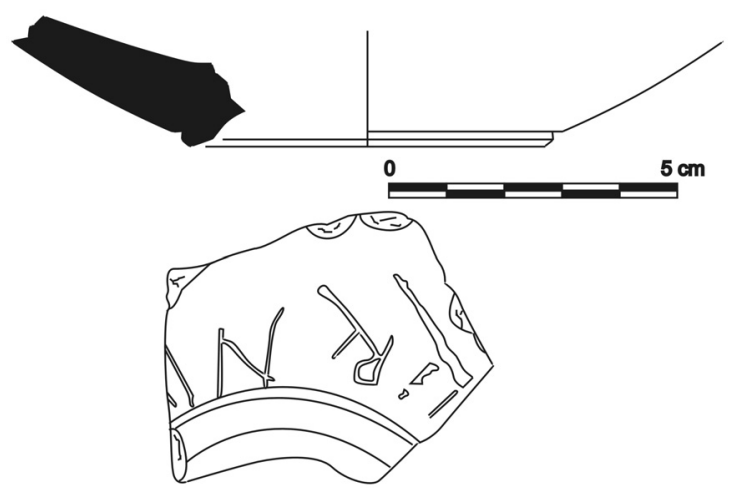

93 (2000, UE 6009, n. $\left.{ }^{\circ} 23\right)$. Fragmento de pared de un vaso de terra sigillata sudgálica, forma Dr. 27. Al exterior de la pared presenta un aspa de $1,1 \times[1] \mathrm{cm}$.
94 (2001, UE 6000, n. ${ }^{\circ} 749$ ). Fragmento de pared de un vaso de terra sigillata hispánica, forma Dr. 27. Al exterior conserva restos de un grafito en el que puede distinguirse una $\mathrm{T}$ y el arranque de la letra que le sigue, todo en una superficie de $[0,7] \times 1,9 \mathrm{~cm}$.

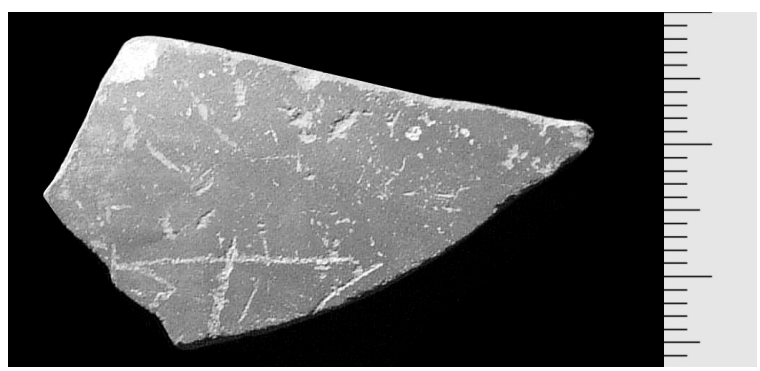

Pórtico Norte del Foro (2000)

95 (2000, UE 5000, n. $\left.{ }^{\circ} 26\right)$. Base de terra sigillata hispánica con restos de una letra, quizá una $\mathrm{C}$, en la pared exterior.

96 (2000, UE 5001, n. $\left.{ }^{\circ} 268\right)$. Fragmento de pared de una forma cerrada de terra sigillata hispánica. Al exterior, sobre una superficie de $0,4 \mathrm{x}$ $[1,7] \mathrm{cm}$., conserva restos del final de una palabra, cuyo primer carácter es irreconocible en la fractura; en todo caso, lo visible parece un nominativo masculino, quizá parte de un nombre personalen la forma [-]+NVS.

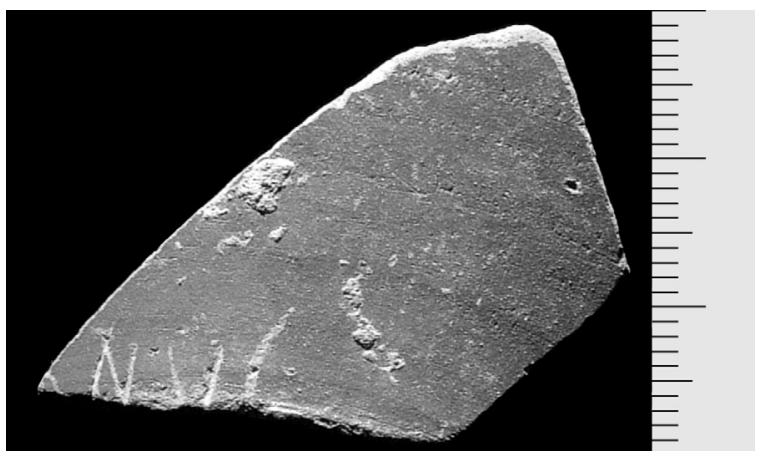

97 (2000, UE 5001, n. ${ }^{\circ}$ 269). Fragmento de la base de un cuenco de terra sigillata hispánica, muy deteriorado, que en la parte inferior presenta varios trazos pertenecientes a un grafito de lectura no precisable. 


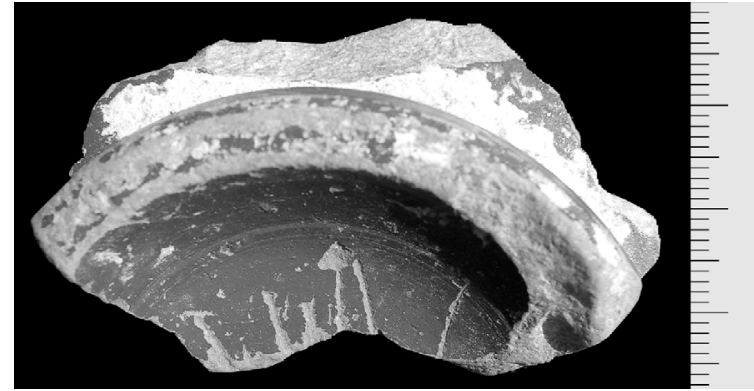

98 (2000, UE 5007, n. ${ }^{\circ}$ 4). Base de un cuenco de terra sigillata hispánica, que conserva junto al anillo del pie el inicio de un grafito con letras de $c$. $1,1 \mathrm{~cm}$ de altura, en una longitud de $[2,6] \mathrm{cm}$. El texto, aunque incompleto, no ofrece dudas para la lectura ARIM[-], que recuerda al cognomen latino Ariminus (Solin - Salomies, 1988, 295). La A tiene el trazo interior en posición oblicua.

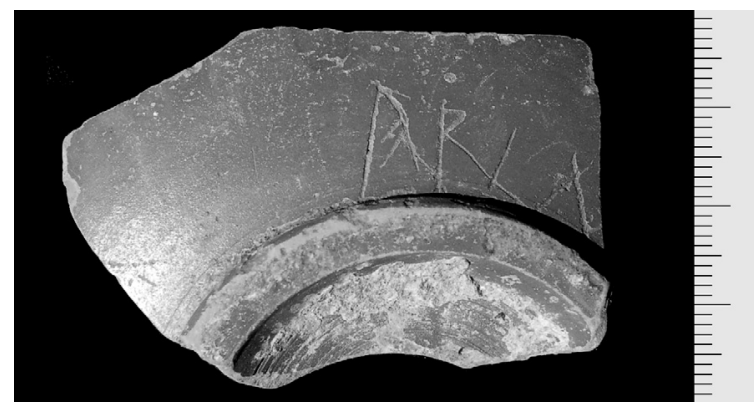

99 (2000, UE 5045, n. ${ }^{\circ} 9$ ). Base de un recipiente de terra sigillata hispánica. En la parte inferior se distingue una $\mathrm{P}$ enlazada con algún otro elemento y con restos de letras en la rotura derecha. No es posible determinar la relación entre estos caracteres.

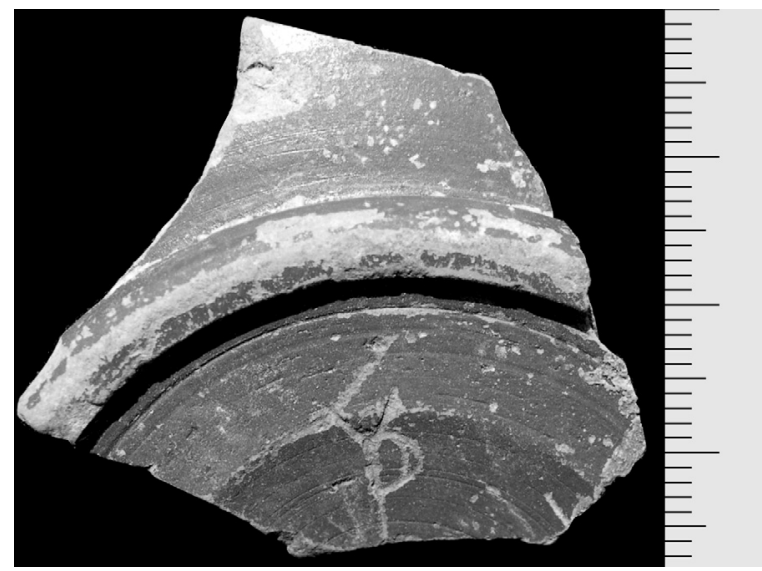

100 (2000, UE 5070, n. ${ }^{\circ} 61$ ). Borde de un vaso de terra sigillata hispánica, forma Dr. 37. Al exterior de la pared presenta cinco trazos oblicuos paralelos.
101 (2000, UE 5078, n. $\left.{ }^{\circ} 1\right)$. Borde y pared de una fuente de tipo rojo pompeyano, en cuya superficie exterior conserva un grafito completo, afectado en parte por la rotura del recipiente. Las letras miden c. $1 \mathrm{~cm}$ de altura y el texto dice VICTO. Hay que suponer que es abreviatura del nombre personal Victor (Solin - Salomies, 1988, 422).

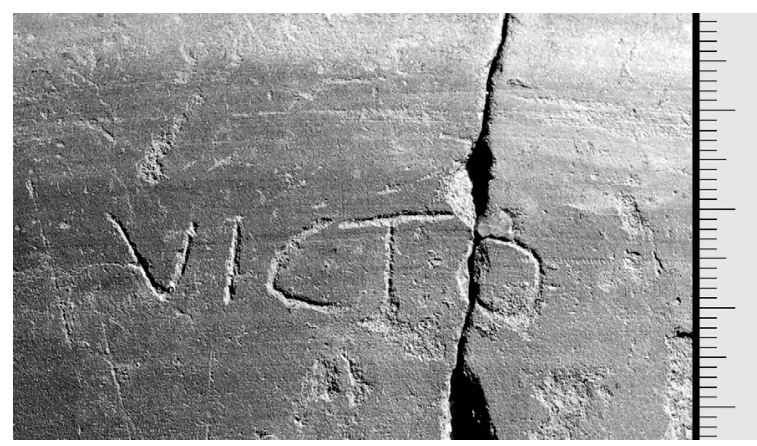

102 (2000, UE 5080, n. ${ }^{\circ} 3$ ). Fragmento de un plato de terra sigillata hispánica, forma Hispánica 07 , con grafitos exteriores e interiores realizados antes de la cocción.

Al exterior, sobre la pared, figura la expresión Pan(n)as+ [-]XXXII, con caracteres de c. $0,9 \mathrm{~cm}$ de altura; la cruz indica el extremo de una letra no determinable.

Al interior, con letras similares y en un espacio de $[5,1]$ de longitud, se lee [-]s - CCCC$\mathrm{CX}$; dado que en el texto anterior el numeral va acompañado de un acusativo plural, habría que suponer aquí idéntica circunstancia, por lo que la $S$ sería la desinencia del plural de un tipo cerámico no determinable, quizá [Catino]s, que es un recipiente corrientemente anotado en este tipo de cuentas de alfar (Marichal, 1988).

La forma panna alude a un recipiente de tamaño medio para bebida (Hilgers, 1969, 237; Marichal 1988, 89), parangonable con las formas Drag. 29, 37 y Ritt. 8 y muy corriente durante los siglos I y II d.C. (Abascal - López de los Mozos, 1993, 362).

Su presencia en Segobriga guarda relación con la producción cerámica documentada repetidamente en el lugar, incluída la de terra sigillata, como se ha dado a conocer recientemente (Sanfeliú y Cebrián, 2006). 


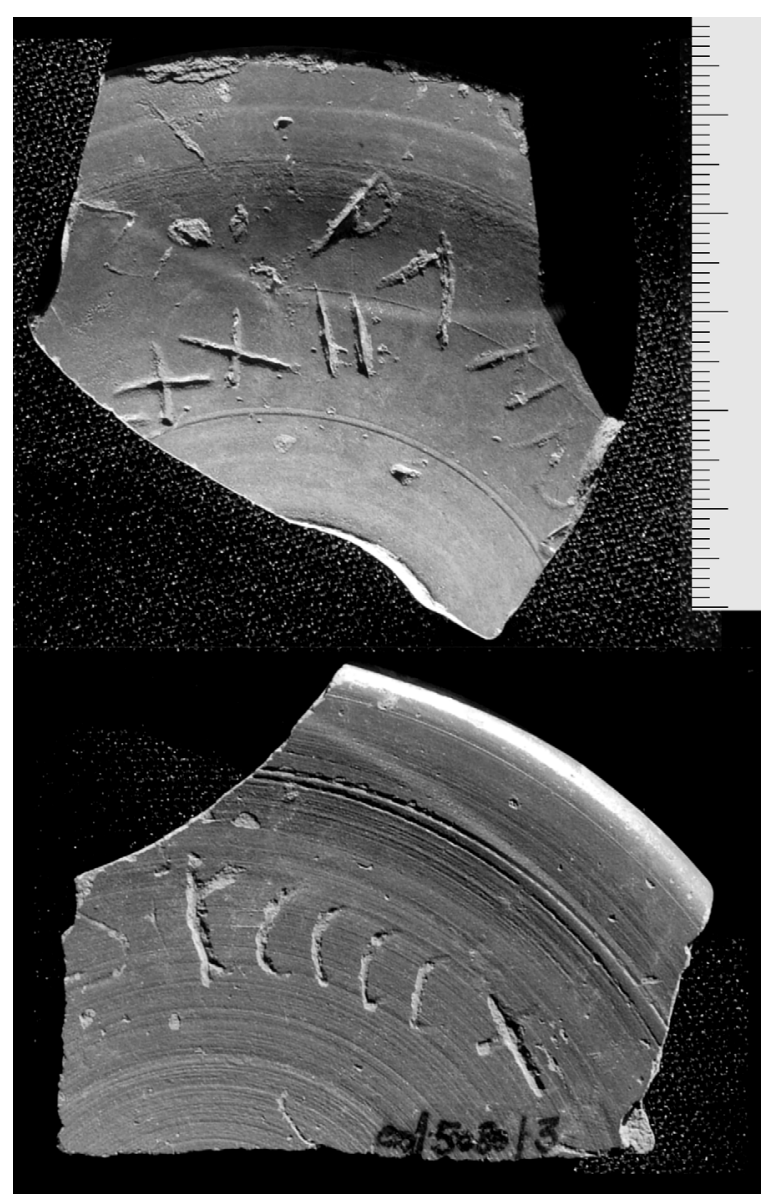

Plaza del Foro (2001)

103 (2001, UE 5000, n. $\left.{ }^{\circ} 1100\right)$. Base de un vaso de terra sigillata hispánica, forma Dr. 27. En la parte exterior aparece una letra $\mathrm{R}$ incisa en una superficie de $3 \times 0,7 \mathrm{~cm}$.

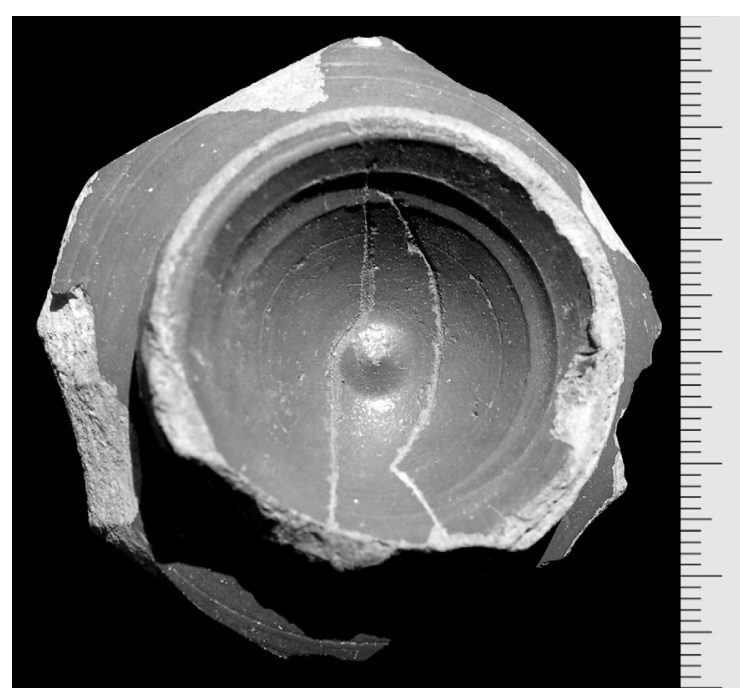

104 (2001, UE 5000, n. $\left.{ }^{\circ} 1303\right)$. Operculum cerámico fragmentado que presenta al axterior una letra $\mathrm{E}$ de $3,3 \mathrm{~cm}$ de altura.

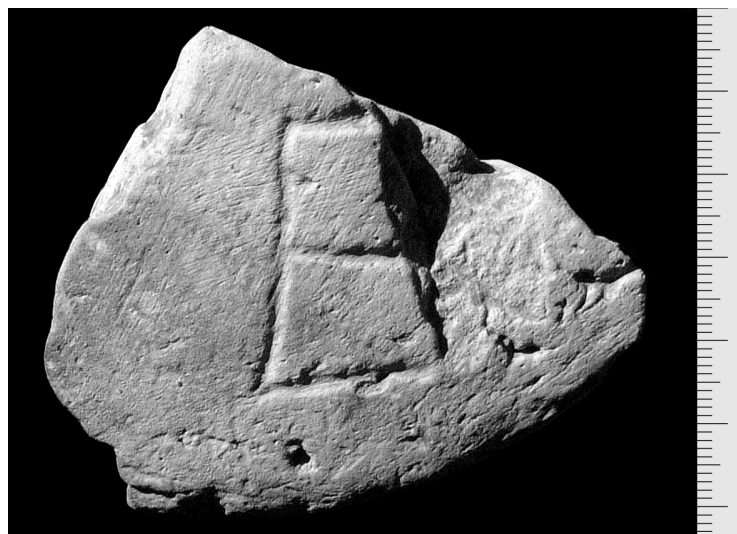

105 (2001, UE 5000, n. ${ }^{\circ}$ 1459). Borde de una pelvis de cerámica común sobre el que se lee [-]XX[-], probablemente como indicador de capacidad; miden $4 \mathrm{~cm}$ de altura y ocupan una superficie de [7] $\mathrm{cm}$.

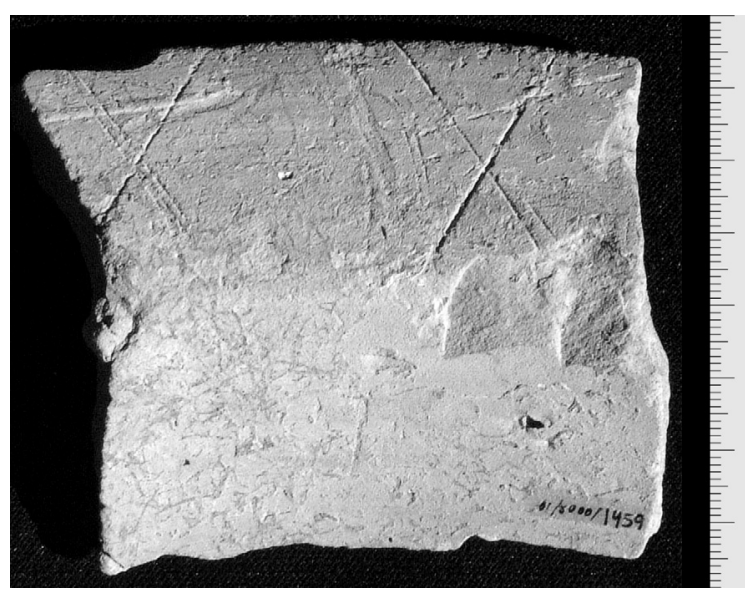

106 (2001, UE 5000, n. ${ }^{\circ} 2278$ ). Base de una copa de terra sigillata hispánica en cuyo interior aparece un grafito en una superficie de $[3,1] \times 1,5$ $\mathrm{cm}$, que quizá pueda identificarse con la letra $\mathrm{E}$, aunque esto no es seguro.

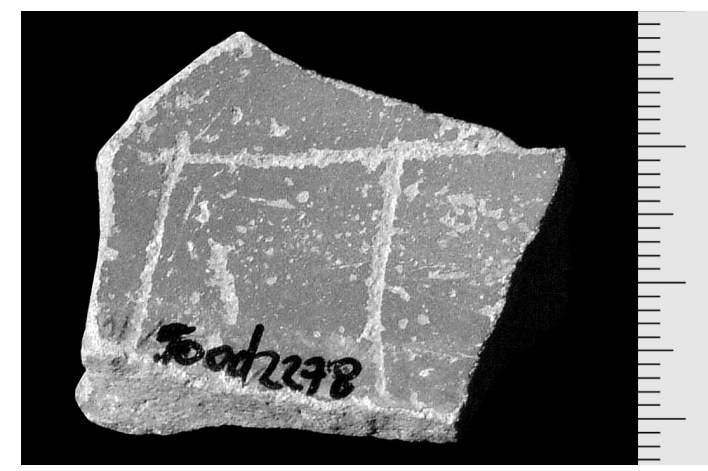

107 (2001, UE 5120, n. ${ }^{\circ} 2$ ). Base de un plato de terra sigillata sudgálica en cuyo interior aparece un grafito en forma de aspa de [3] x 3,6 cm. 
108 (2001, UE 5126, n. ${ }^{\circ}$ ). Base de un cuenco de terra sigillata hispánica; junto al anillo del pie se encuentra el texto THEM[-], con letras de 0,8 $\mathrm{cm}$ de altura. Se trata del inicio de un nombre griego no determinable.

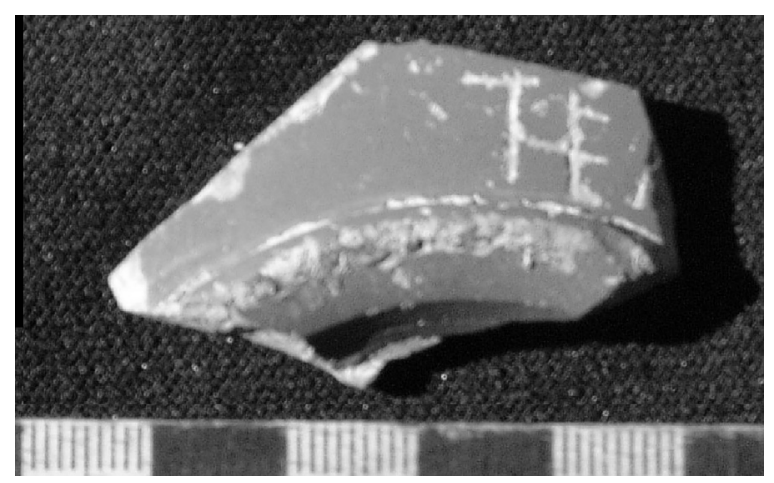

109 (2001, UE 5131, n. $\left.{ }^{\circ} 24\right)$. Base de una jarra de cerámica común en la que puede leerse el grafito $\mathrm{CA}[-]$ con letras de $1 \mathrm{~cm}$ de altura. Podría tratarse de un nombre personal.

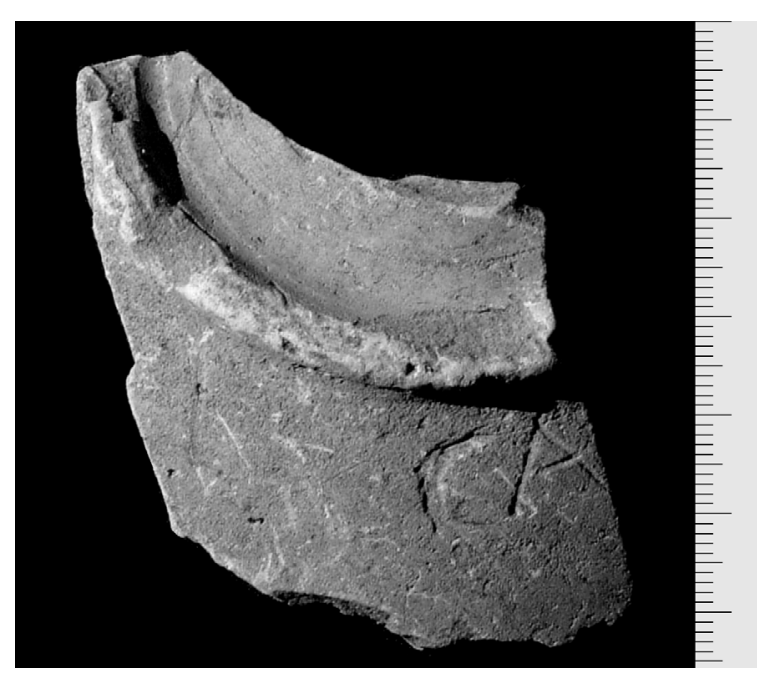

110 (2001, UE 5133, n. ${ }^{\circ}$ 2). Borde de un cuenco de terra sigillata hispánica, forma Dr. 37 , que presenta bajo el labio el extremo final de un grafito en la forma [-]TI, con letras de $1,2 \mathrm{~cm}$ de altura. Debe ser el genitivo de un nombre personal masculio.

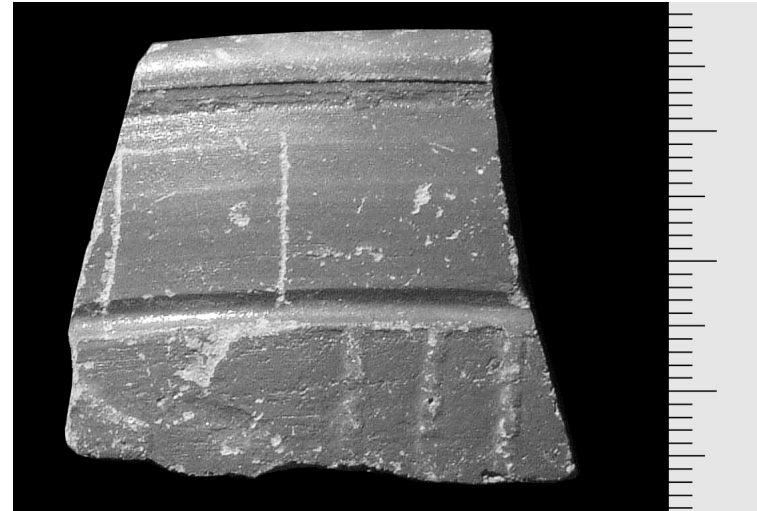

111 (2001, UE 5168, n. ${ }^{\circ} 88$ ). Borde de un vaso de terra sigillata hispánica, de forma Hispánica 1. Al exterior y bajo el labio aparece la parte superior de una sucesión de caracteres en donde podría leerse [-]CCl ó [-]CCL, quizá como parte de una cuenta de alfar. La superficie ocupada por el texto mide $[0,8] \times[3,19 \mathrm{~cm}$.

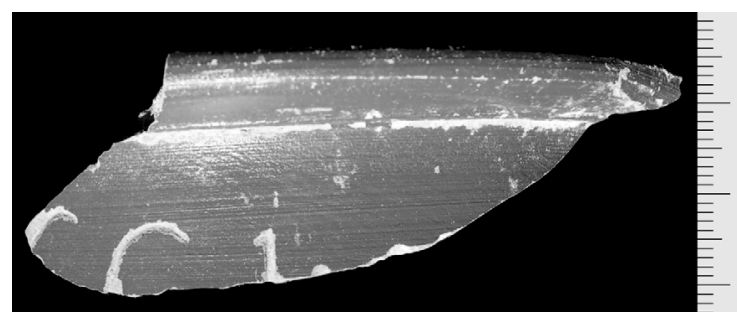

112 (2001, UE 5168, n. $\left.{ }^{\circ} 175\right)$. Borde de terra sigillata hispánica, forma Dr. 37, que presenta al exterior un grafito en forma de aspa de $1,9 \times[3,1]$ $\mathrm{cm}$.

113 (2001, UE 5223, n. ${ }^{\circ}$ 1). Base de un plato de terra sigillata hispánica que al interior conserva restos de astas de un grafito irreconocible de $[2,6] \times[2,9] \mathrm{cm}$.

114 (2001, UE 5353, n. ${ }^{\circ} 7$ ). Fragmento de pared de un cuenco de terra sigillata hispánica, forma Dr. 37. Al exterior se conserva parte de un texto en la forma [P]anna[-], con letras de $0,8 \mathrm{~cm}$ de altura. El nombre hace referencia a la denominación del propio cuenco, y debería ir precedido de un nombre en genitivo de su propietario, dado que la calidad de la ejecución permite descartar una anotación de alfar. 


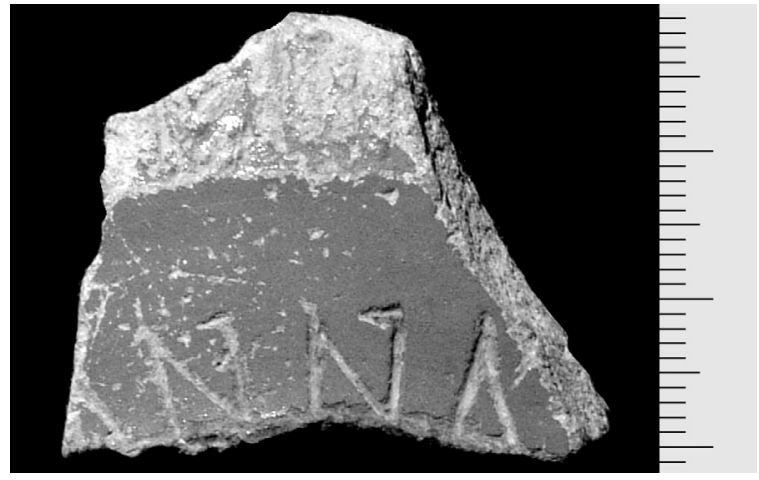

115 (2001, UE 5391, n. ${ }^{\circ}$ 239). Borde de una fuente de terra sigillata hispánica brillante, tipo 9 . Sobre el labio presenta una serie de seis trazos paralelos de $0,8 \mathrm{~cm}$ de altura en una superficie longitudinal de $[1,9] \mathrm{cm}$, que deberían indicar un cómputo desconocido.

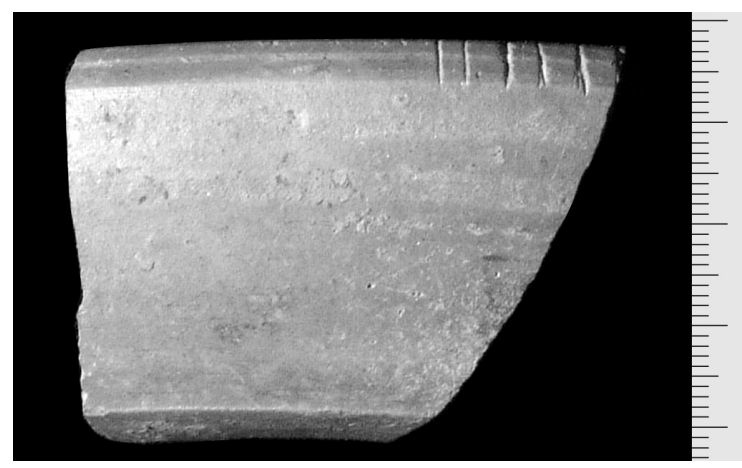

116 (2001, UE 5440, n. $\left.{ }^{\circ} 4\right)$. Base de un recipiente en terra sigillata aretina, con sello interior en dos líneas [-]P. MESS / [-]AM PIO. En la parte exterior de la base conserva un grafito fragmentario en el que sólo puede distinguirse una $\mathrm{V}$ de c. $0,7 \mathrm{~cm}$ de altura.

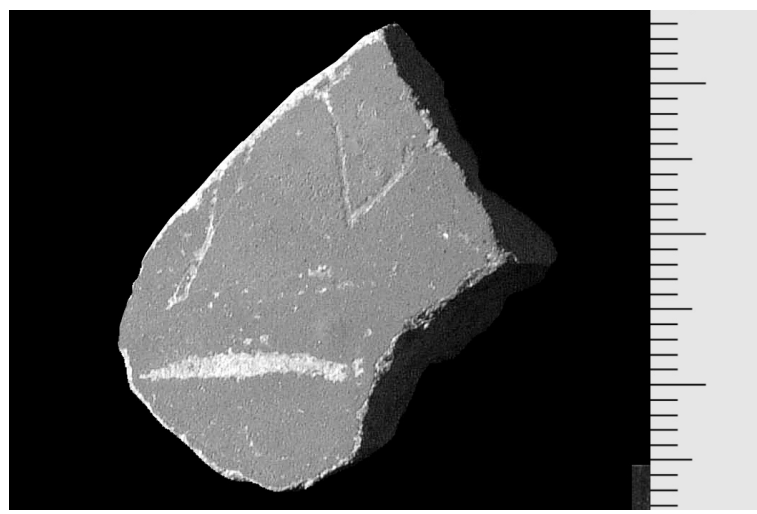

117 (2001, UE 5440, n. ${ }^{\circ} 21$ ). Base de una copa en terra sigillata hispánica con restos de un grafito irreconocible en el exterior.

\section{Pórticos oriental y sur del foro (2002)}

118 (2001, UE 930, n. ${ }^{\circ}$ 5). Base de una copita de terra sigillata hispánica en cuyo exterior se conservan los extremos de varios trazos paralelos pertenecientes a un grafito irreconocible.

119 (2002, UE 5580, n. ${ }^{\circ} 88$ ). Borde de una jarra de cerámica común con un grafito exterior en el que sólo se distingue una letra $V$ de $1 \mathrm{~cm}$ de altura.

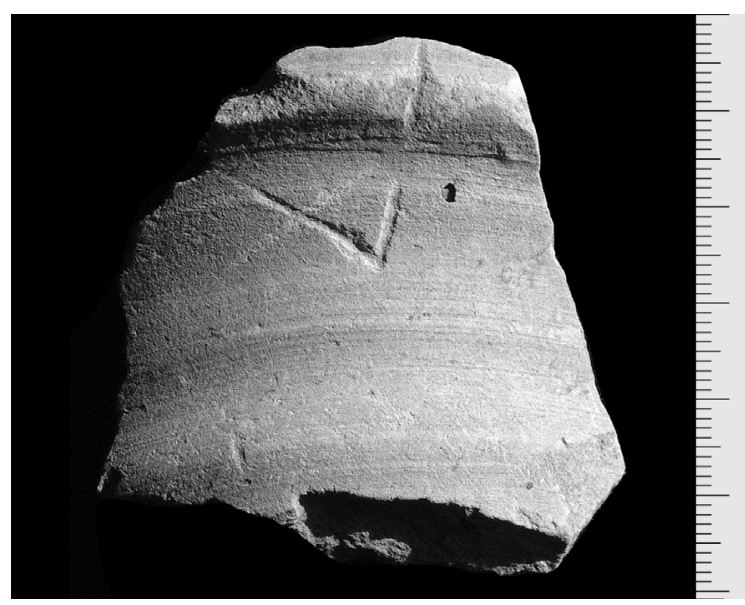

120 (2002, UE 5582, n. ${ }^{\circ} 14$ ). Base de un plato de terra sigillata hispánica, con grafito en forma de palma en el interior y restos de un texto en el exterior sobre una superficie de $[0,8] \times[1,6] \mathrm{cm}$; en este último sólo se lee [-] $\mathrm{VI}$, seguramente un nombre personal en genitivo.

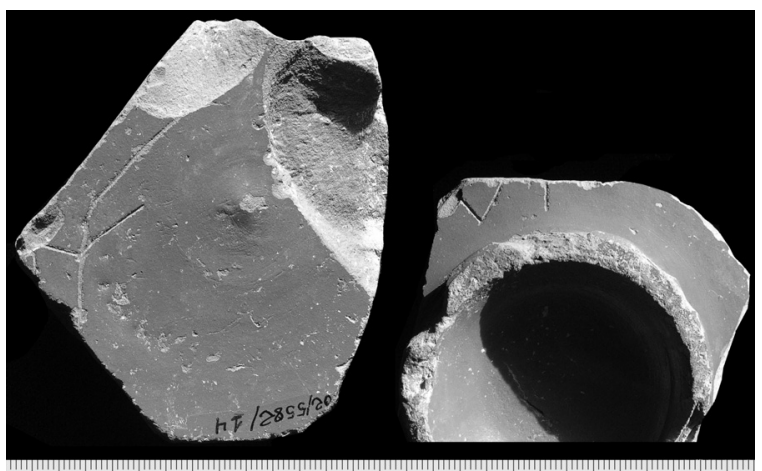

121 (2002, UE 5588, n. ${ }^{\circ} 7$ ). Base de un plato de terra sigillata hispánica que, en el interior del pie, presenta el comienzo de un grafito en el que puede leerse $\mathrm{E}+[-]$, con letras de $1 \mathrm{~cm}$ de altura; el segundo trazo puede ser una $\mathrm{L} o$ una $\mathrm{I}$. 


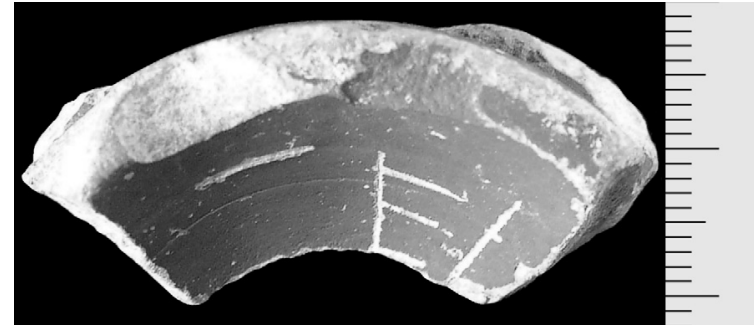

122 (2002, UE 5619, n. ${ }^{13}$ ). Fragmento de pared de una botella de cerámica común con un grafito en forma de aspa de $3,5 \mathrm{~cm}$ de longitud al exterior.

123 (2002, UE 5640, n. ${ }^{\circ}$ 72). Borde de un recipente de terra sigillata hispánica tardía (Mayet, pl. CCXLIV), que presenta en el interior del labio tres trazos verticales paralelos de $1,3 \mathrm{~cm}$ de longitud.

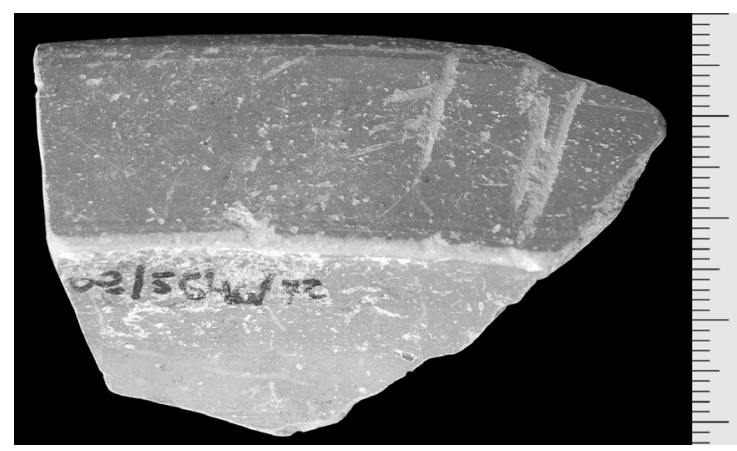

124 (2002, UE 5650, n. 3 ). Fragmento de pared de un recipiente de terra sigillata hispánica en cuyo exterior queda parte de un grafito irreconocible de $0,7 \times 1,8 \mathrm{~cm}$.

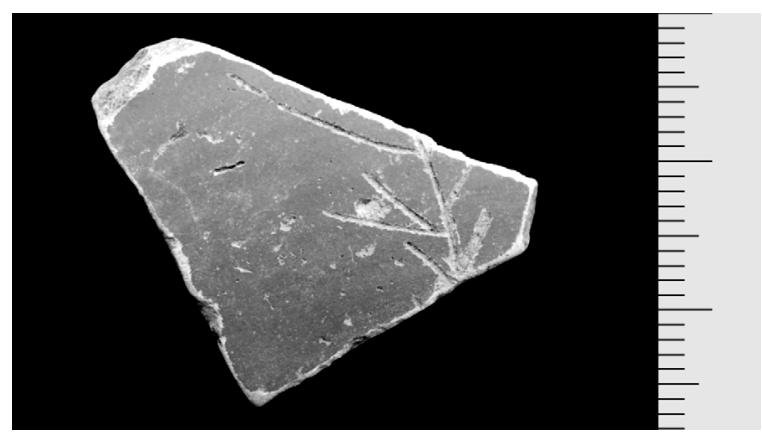

125 (2002, UE 5668, n. ${ }^{\circ}$ 5). Fragmento de pared de un recipiente de terra sigillata hispánica. Al exterior, figura un grafito en forma de hoja de palma con una longitud conservada de $2 \mathrm{~cm}$.

126 (2002, UE 5678, n. $\left.{ }^{\circ} 5\right)$. Base de terra sigillata hispánica con sello. En el exterior de la base figura un grafito en forma de aspa de $2 \mathrm{~cm}$ de longitud.
127 (2002, UE 5699, n. $\left.{ }^{\circ} 21\right)$. Base de terra sigillata hispánica. En el interior del pie figura el comienzo de un grafito en la forma Satur[-], con letras de c. 1,1 cm de altura.

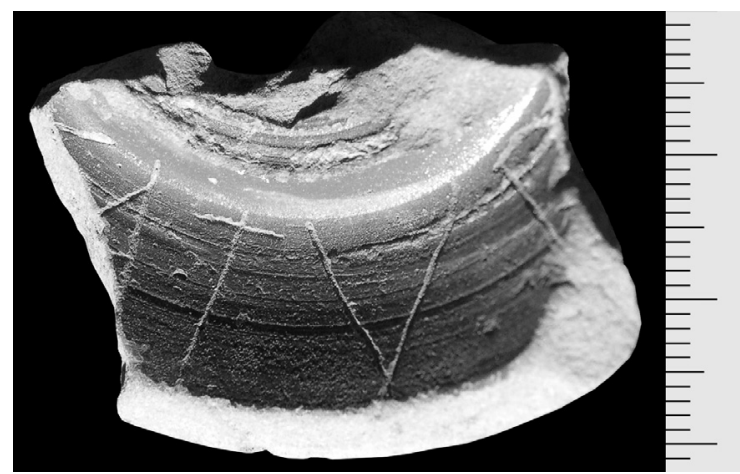

128 (2002, UE 5699, n. ${ }^{\circ}$ 122). Borde de un recipiente en terra sigillata hispánica, forma Dr. 29 (?). Al exterior y bajo el labio puede leerse [-]+SV, con letras de c. $1,1 \mathrm{~cm}$ de altura, ocupando 2,7 cm en posición horizontal. La cruz inicial corresponde al resto de una letra, quizá otra $\mathrm{V}$ aunque sin garantías. La S está muy retocada pues inicialmente el autor del grafikto colocó allí una I.

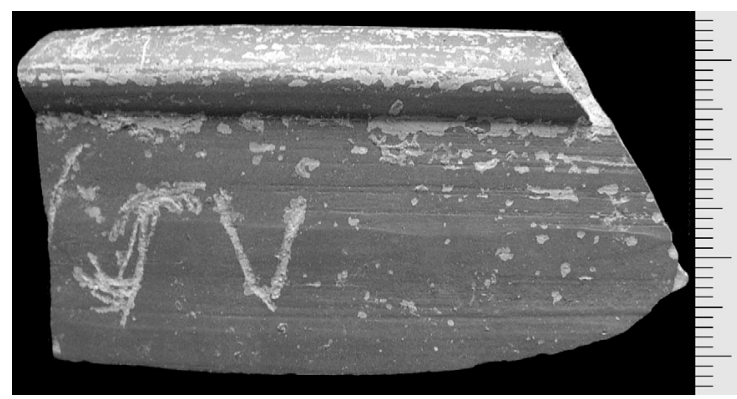

129 (2002, UE 5699, n. $\left.{ }^{\circ} 185\right)$. Borde de un vaso de terra sigillata hispánica, forma Dr. 27 , que presenta al exterior restos de un grafito, con una letra $\mathrm{N}$ de $1,5 \mathrm{~cm}$ de altura.

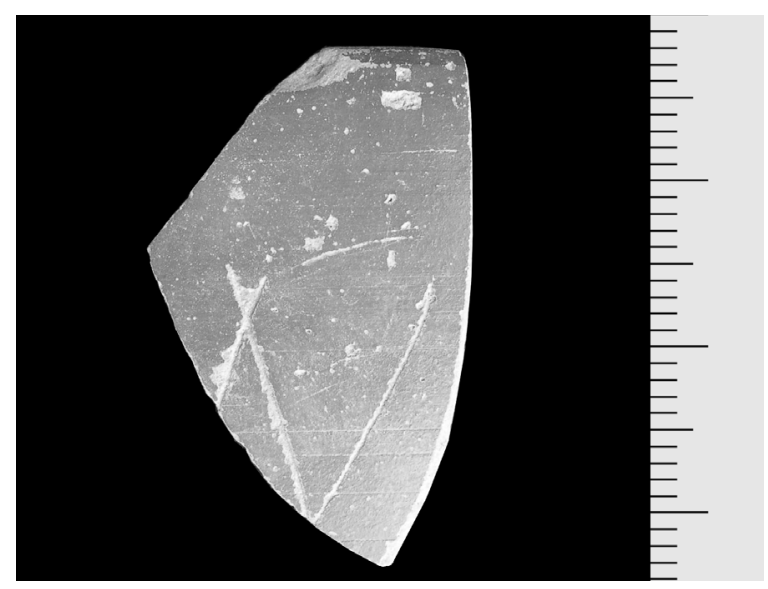


130 (2002, UE 5749, n. $\left.{ }^{\circ} 25\right)$. Borde de un cuenco de terra sigillata hispánica, forma $\operatorname{Dr}$. 29 , que presenta bajo el labio parte de un grafito en la forma [-]ANEA[-], con letras de $1,5 \mathrm{~cm}$ de altura. Hay nexo NE muy bien marcado. Lo conservado difícilmente se ajustaría a un nombre personal si se confirma la rotura de los extremos, aunque conocemos el nombre femenino Annea en una inscripción de Talavera de la Reina (CIL II 904)

131 (2002, UE 5760, n. ${ }^{\circ} 4$ ). Fragmento de pared de un recipiente de terra sigillata hispánica con restos de un grafito irreconocible en la pared exterior.

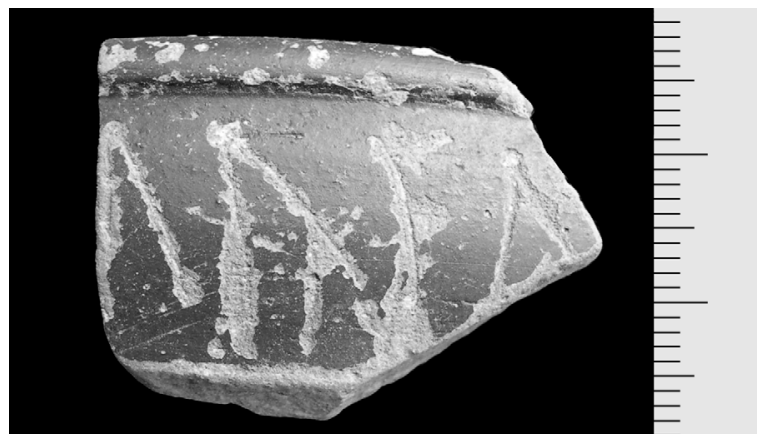

132 (2002, UE 5760, n. ${ }^{\circ} 15$ y $16+2002$, UE-5761, n. ${ }^{\circ} 76+2002$, UE 5776, n. ${ }^{\circ} 3+2003$, UE 7040 , n. ${ }^{\circ} 3$ ). Varios fragmentos de pared de un mismo recipiente de terra sigillata hispánica recuperador en la misma zona pero en diferentes momentos de las excavaciones. Todos ellos están decorados con series de tres líneas paralelas que se entrecortan formando espacios libres de forma romboidal en los que se alojan unos motivos casi circulares y de identidad desconocida. No es posible determinar el tipo de motivo que representan.

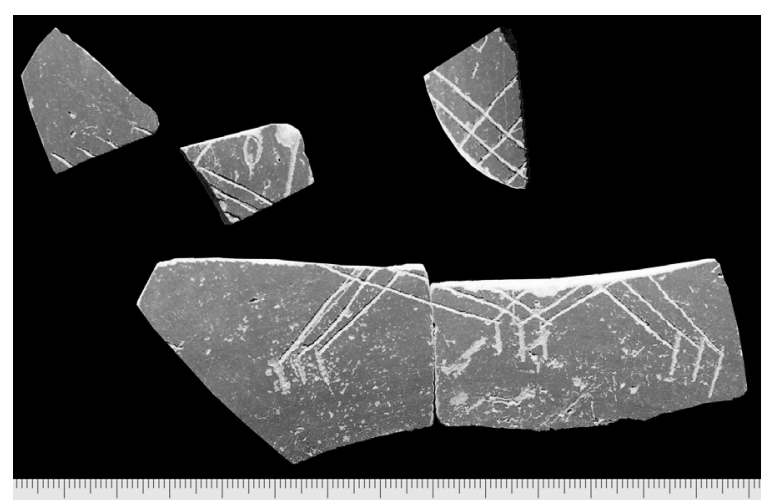

133 (2002, UE 5761, n. ${ }^{\circ} 25+2002$, UE 5776, n. ${ }^{\circ}$ 5). Tres fragmentos del borde de un vaso de terra sigillata hispánica, forma Dr. 27.
Al exterior, con letras de $1.4 \mathrm{~cm}$ de altura $y$ en una longitud de $[5,6] \mathrm{cm}$, se lee $[-]$ pone $f u[r]$. Las instrucciones sobre la necesidad de dejar los recipientes en un determinado sitio o de no robarlos son frecuentes en el ámbito temático de los grafitos (cf. por ejemplo Mayer 1999, 127128; Sánchez-Lafuente - Rascón y Polo, 1999, $597, n .^{\circ} 217$ ). El paralelo exacto al nuevo grafito de Segobriga se encuentra en otro de Complutum (Alcalá de Henares), en donde puede leerse Saroni pone fur (Stylow, 1998, 202, n. ${ }^{\circ} 29$ ), que acertadamente traduce su último editor como "¡Déjalo, ladrón”. Según esa estructura, delante de lo conservado habría que esperar el nombre del propietario en genitivo.

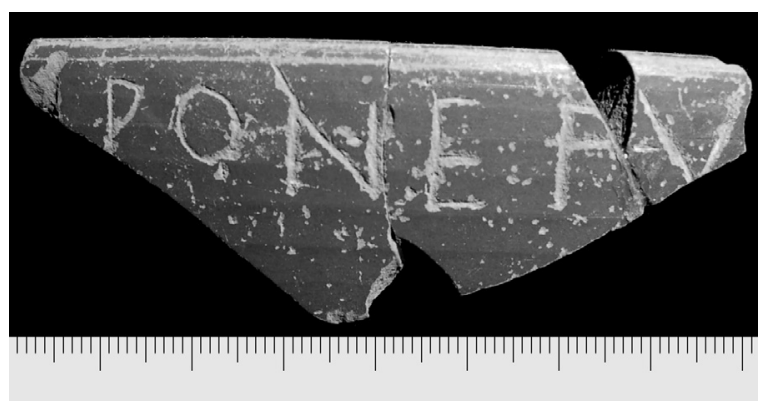

134 (2002, UE 5761, n. $\left.{ }^{\circ} 26\right)$. Borde de un vaso en terra sigillata hispánica, forma Dr. 27 , que conserva al exterior el extremo de un grafito en la forma [-]N con letras de $1,5 \mathrm{~cm}$ de altura.

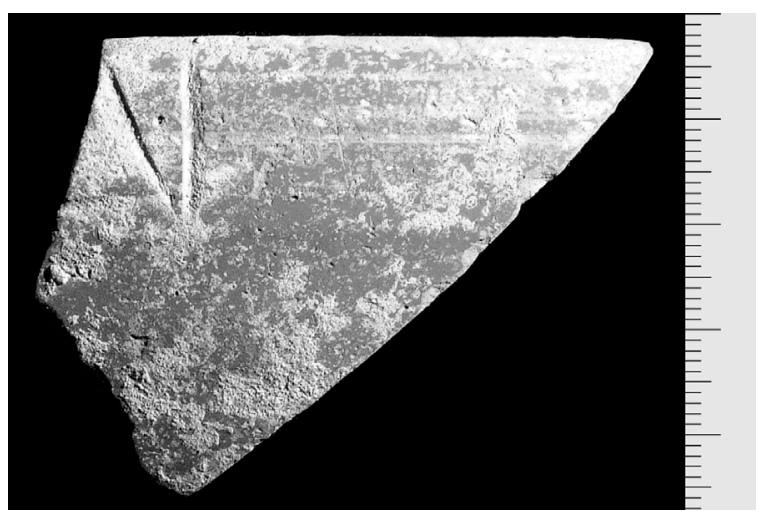

135 (2002, UE 5766, n. ${ }^{\circ} 17$ ). Borde de un vaso en terra sigillata hispánica, forma Dr. 27 , que presenta al exterior y junto al labio el grafito LV[-], con letras de $1,8 \mathrm{~cm}$ de altura. 


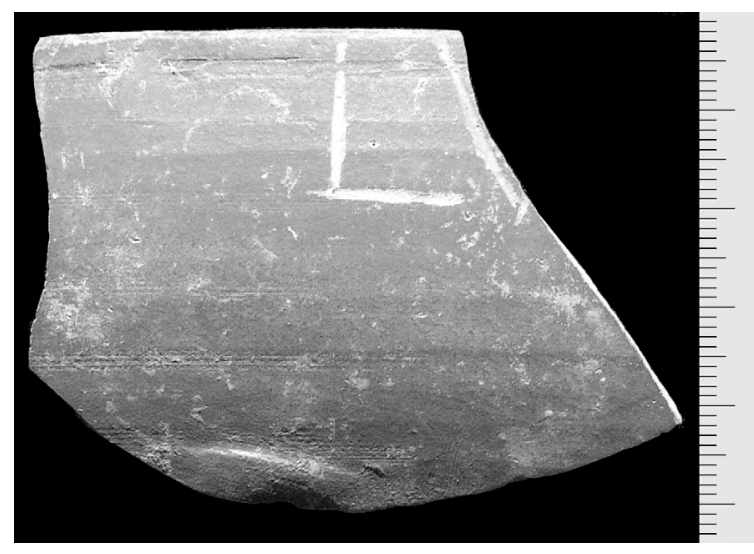

136 (2002, UE 5776, n. ${ }^{4}$ ). Borde de un vaso en terra sigillata hispánica, forma Dr. 27, que presenta al exterior los restos de un grafito irreconocible de $1,7 \times[2,9] \mathrm{cm}$.

\section{No existe.}

138 (2002, UE 5776, n. ${ }^{\circ} 30$ ). Fragmento de pared de un recipiente de terra sigillata hispánica con restos de cuatro líneas paralelas oblicuas.

139 (2002, UE 5811, n. $\left.{ }^{\circ} 11\right)$. Fragmento de base de un plato de terra sigillata hispánica, en cuyo exterior figura junto al anillo del pie un grafito de $3,2 \mathrm{~cm}$ de longitud con letras de $0,9 \mathrm{~cm}$ de altura. El texto dice: Lucifer. El cognomen es sobradamente conocido (Kajanto, 1982, 288) incluso en Hispania (Abascal, 1994, 404).

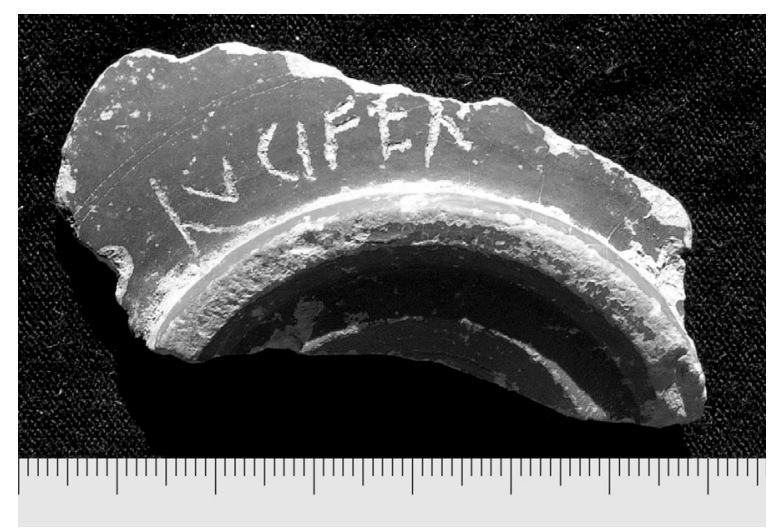

140 (2002, UE 5821, n. $\left.{ }^{\circ} 2\right)$. Base de un recipiente de terra sigillata hispánica en cuya parte inferior se conserva parte de un grafito en una superficie de $[0,6] \times[1,5] \mathrm{cm}$. Lo visible puede ser el extremo de las letras A y $\mathrm{T}$ o un nexo NT.

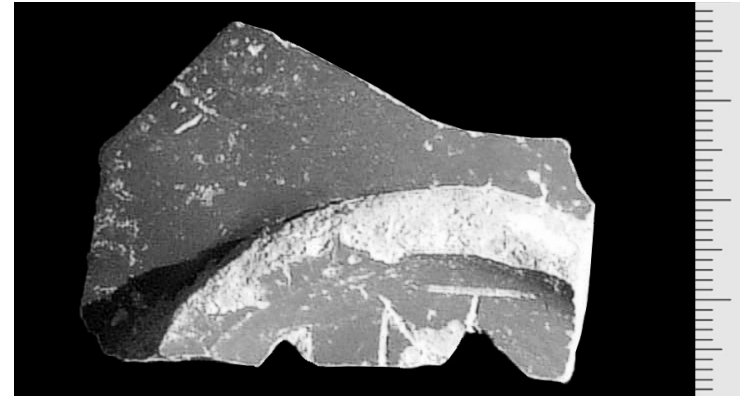

141 (2002, UE 5917, n. ${ }^{\circ} 3$ ). Fragmento de pared de una tinaja que presenta al exterior un grafito ante-cocción con letras de $4,7 \mathrm{~cm}$ de altura. Lo conservado sólo dice [-]XII +[-], en donde la cruz representa un resto de letra que puede ser de una $\mathrm{B}, \mathrm{R}$ o incluso $\mathrm{K}$; debe tratarse de una indicación de capacidad del recipiente.

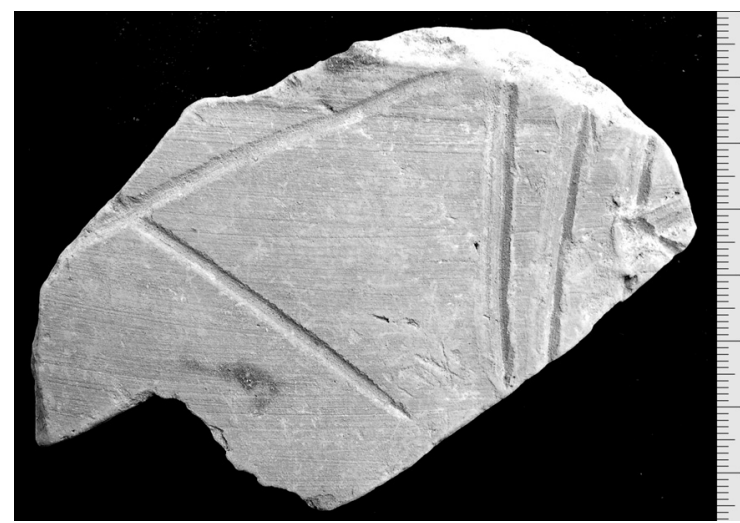

142 (2002, UE 5921, n. ${ }^{\circ} 7$ ). Base de un plato de terra sigillata hispánica en cuyo interior se encuentra un grafito incompleto en la forma [-]TIL$\mathrm{VM}[-]$, con letras de c. 1,2 cm de altura.

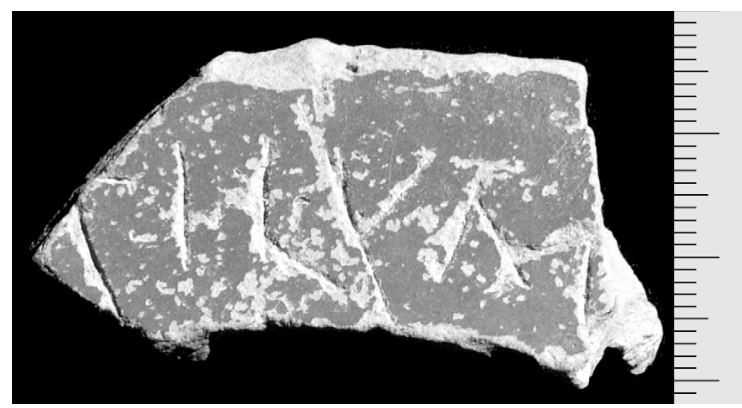

143 (2002, UE 5929, n. 24). Fragmento de pared de un ánfora bética con grafito exterior antecocción cuyas letras miden c. $2.5 \mathrm{~cm}$ de altura. Sólo puede leerse [-]VIVM. 


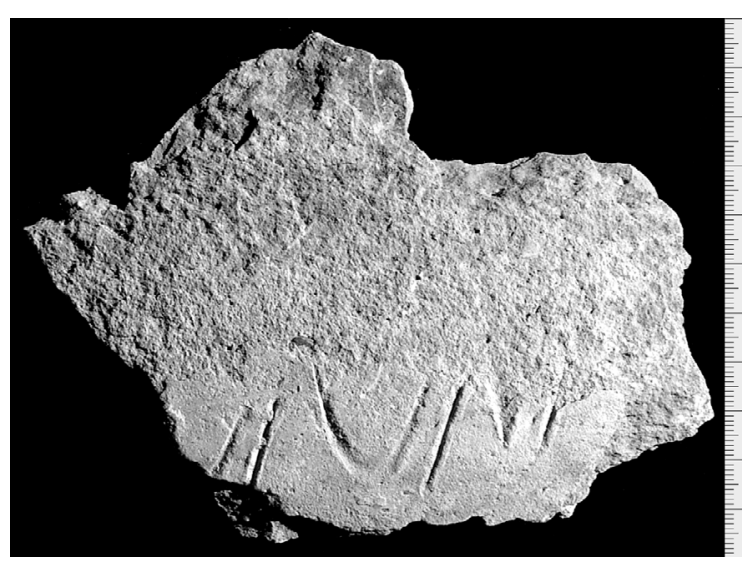

\section{Tabernae del foro y curia (2003)}

144 (2003, UE 7000, n. $\left.{ }^{\circ} 1349\right)$. Borde de un cuenco de terra sigillata hispánica, forma Ritt. 08 , en cuyo exterior figura el grafito [-]+SCE con letras de $0,6 \mathrm{~cm}$ de altura y muy bien grabadas. Delante de la $S$ queda la evidencia de una letra perdida.

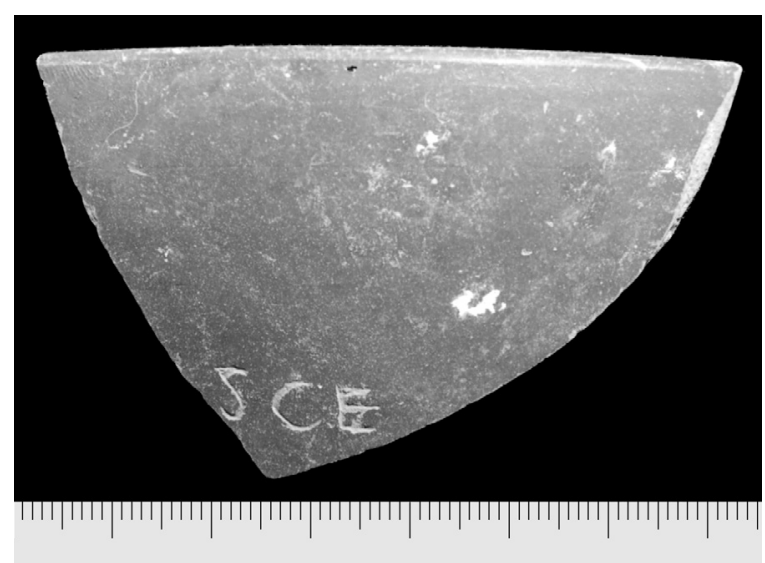

145 (2003, UE 7000, n. ${ }^{\circ}$ 1809). Fragmento de pared de un vaso de cerámica pintada romana del siglo I d.C., con el inicio de un grafito en la forma N[-] al exterior y sobre una banda de color vinoso; la altura de las letras es de 1,2 cm.

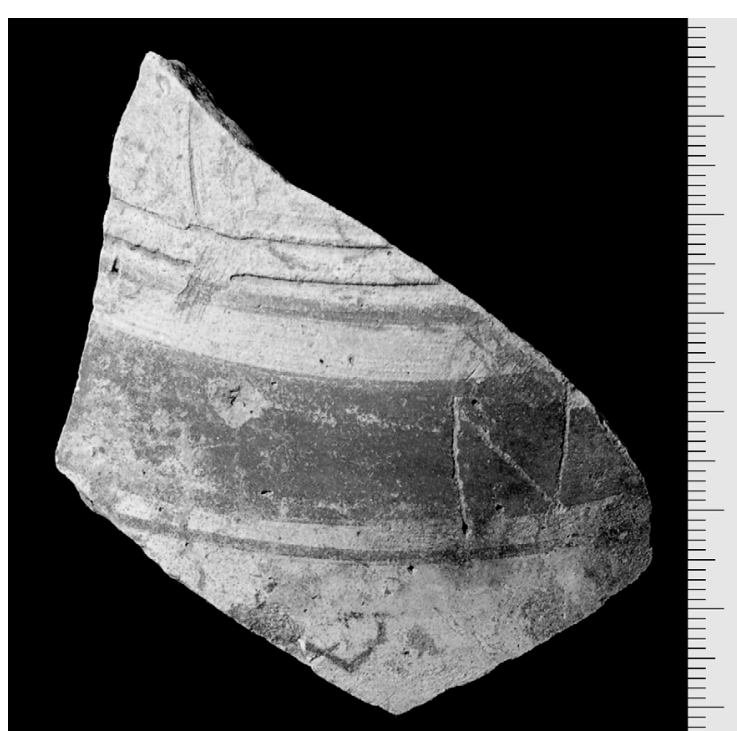

146 (2003, UE 7001, n. $\left.{ }^{\circ} 111\right)$. Base de una botella de cerámica común con un grafito en forma de aspa al exterior de la base, en una superficie de $2,9 \times 2,7 \mathrm{~cm}$.

147 (2003, UE 7005, n. ${ }^{\circ} 238$ ). Base de un recipiente de terra sigillata hispánica. Al exterior, con letras de $1,3 \mathrm{~cm}$ de altura, parece leerse [-] TIA[-]; la T sólo es perceptible por su trazo superior en el extremo izquierdo del fragmento y la A posee travesaño oblicuo. Debería tratarse de parte de un nombre personal.

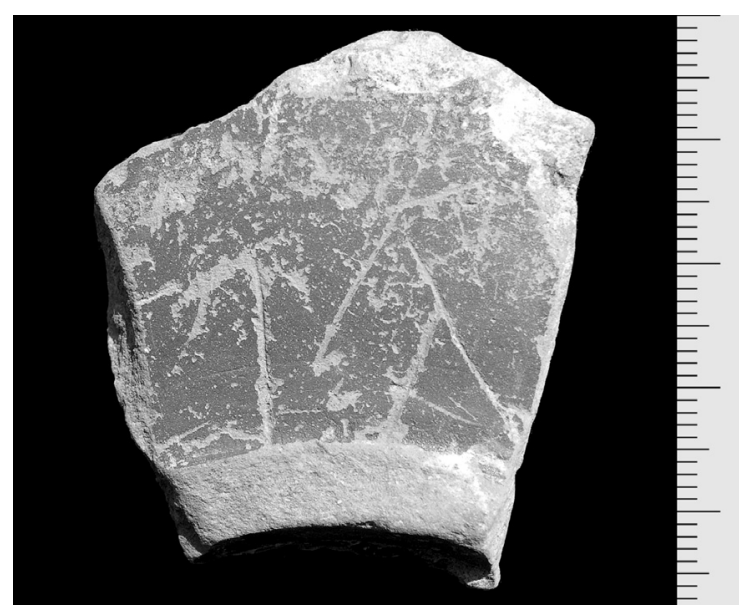

148 (2003, UE 7044, n. ${ }^{\circ} 86$ ). Base de una copita de terra sigillata hispánica que, junto al anillo del pie, presenta un grafito en la forma [-]+ENTINI, con letras de c. $1 \mathrm{~cm}$ de altura; delante de la $E$ se ve un asta vertical difícilmente asignable a una L. En la parte inferior de la base se ha grabado un aspa. El grafito es el genitivo de un nombre personal. 


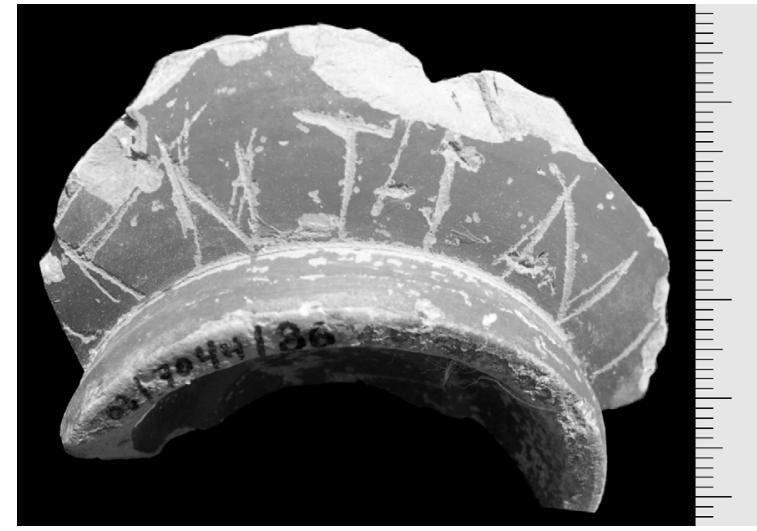

149 (2003, UE 7077, n. ${ }^{\circ} 22$ ). Fragmento de pared de un vaso de terra sigillata hispánica, forma $\mathrm{Dr}$. 27 , que al exterior presenta restos de un grafito muy deteriorado en el que apenas pueden leerse las letras $\mathrm{VI}$, de c. $0,9 \mathrm{~cm}$ de altura.

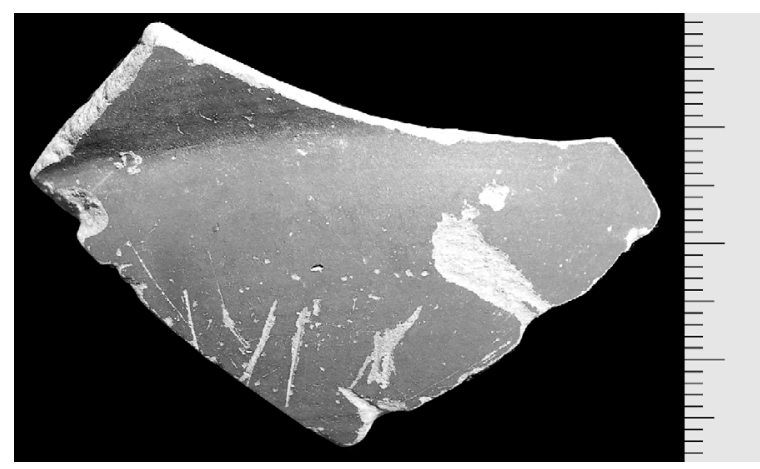

150 (2003, UE 7089, n. ${ }^{\circ}$ 9). Fragmento de pared de un recipiente de terra sigillata hispánica brillante, tipo 9, que presenta al exterior el extremo de una letra de $1,1 \times[0,7] \mathrm{cm}$, perteneciente a un grafito ya perdido.

151 (2003, UE 7090, n. $\left.{ }^{\circ} 56\right)$. Base de una copa de terra sigillata hispánica, en cuyo interior se conservan trazos muy gastados en una superficie de $1,2 \times[1,9] \mathrm{cm}$, pertenecientes a un grafito ya perdido.

152 (2003, UE 7100, n. ${ }^{\circ} 92$ ). Base de una plato de terra sigillata hispánica que al interior del pie presenta los extremos de dos letras de un grafito irreconocible.

153 (2003, UE 7100, n. $\left.{ }^{\circ} 301\right)$. Fragmento de pared de un plato de terra sigillata hispánica, forma Dr. 44. Al exterior presenta los restos de un grafito en la forma [-]VN[-], con letras de c. $1 \mathrm{~cm}$ de altura.

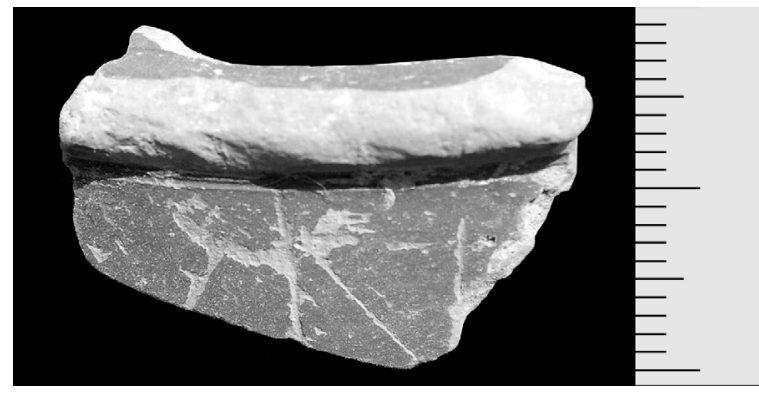

154 (2003, UE 7100, n. $\left.{ }^{\circ} 1121\right)$. Fragmento de pared de un recipiente de terra sigillata hispánica, que al exterior presenta restos de un grafito irreconocible en una superficie de $[1,7] \times[1,9 \mathrm{~cm}]$.

155 (2003, UE 7102, n. ${ }^{\circ} 53$ ). Base de una olla de cerámica de cocina que en la parte inferior presenta un grafito con forma de aspa de 5,2 $\mathrm{x}$ $5,8 \mathrm{~cm}$.

156 (2003, UE 7134, n. ${ }^{\circ}$ 51). Base de una jarra de cerámica común que presenta en su parte inferior una doble aspa sobre una superficie de 1,5 $x 2,8 \mathrm{~cm}$. Podría tratarse de una indicación de capacidad.

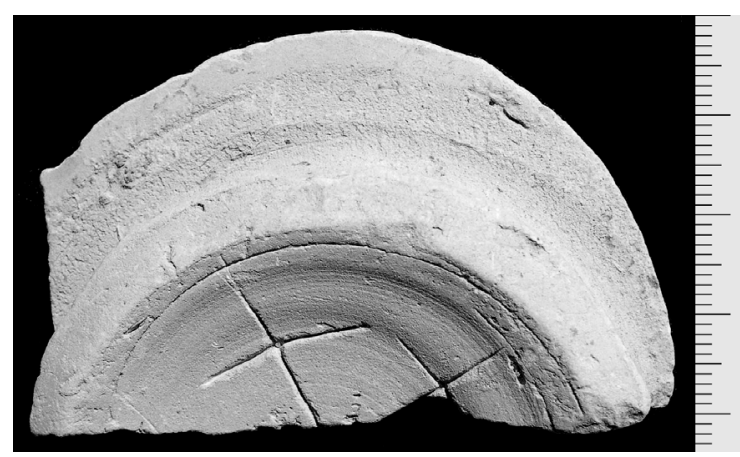

157 (2003, UE 7155, n. $\left.{ }^{\circ} 11\right)$. Fragmento de pared de un recipiente de terra sigillata hispánica, forma Dr. 27, que al exterior presenta tres trazos verticales paralelos de $1 \mathrm{~cm}$ de altura.

158 (2003, UE 7159, n. ${ }^{\circ}$ 1). Fragmento de pared de un recipiente de terra sigillata itálica, que al exterior presenta restos de un grafito irreconocible en una superficie de $[0,9] \times] 0,8] \mathrm{cm}$.

159 (2003, UE 7200, n. $\left.{ }^{\circ} 135\right)$. Fragmento de pared de un recipiente de terra sigillata hispánica que presenta al exterior restos de la letra de un grafito no identificable.

160 (2003, UE 7311, n. $\left.{ }^{\circ} 4\right)$. Fragmento de pared de un recipiente de terra sigillata hispánica con un grafito exterior en la forma BAIT[-], con le- 
tras de $0,9 \mathrm{~cm}$ de altura. Aunque puede tratarse de un nombre personal, no conocemos formas asimilables.

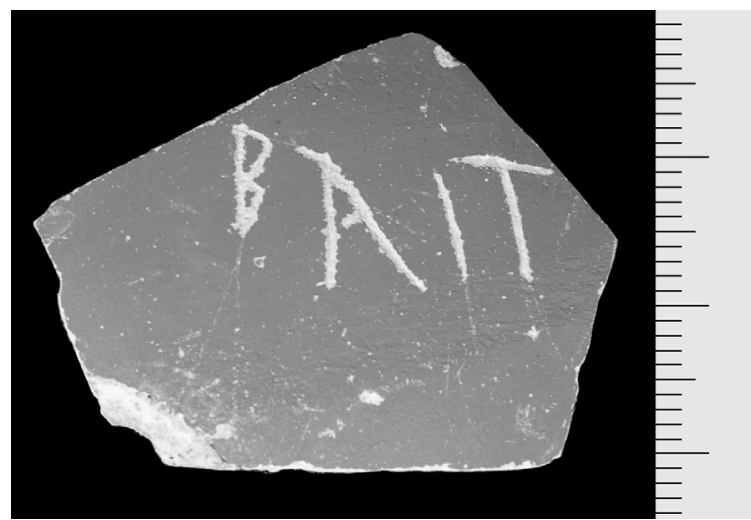

161 (2003, UE 7318, n. $\left.{ }^{\circ} 10\right)$. Base de un cuenco de terra sigillata hispánica en el que se conserva el inicio de un grafito en la forma $\mathrm{H}[-]$; la letra mide $0,6 \mathrm{~cm}$ de altura.

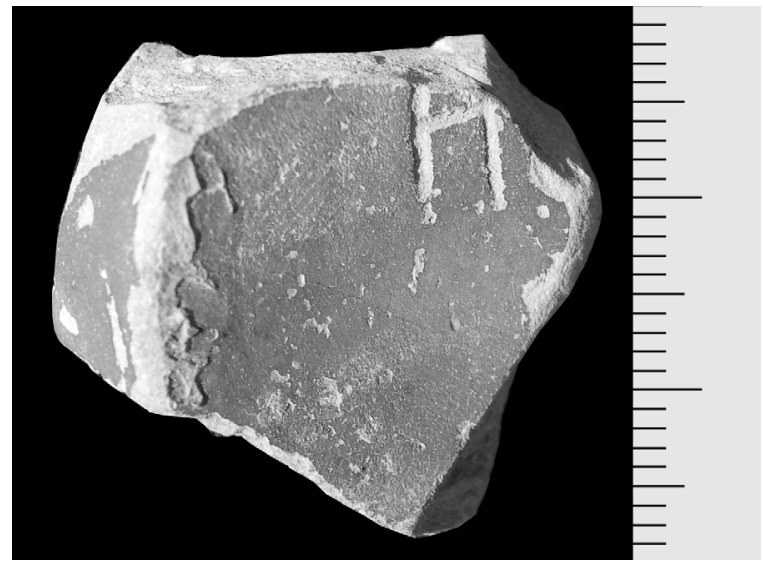

162 (2003, UE 7323, n. ${ }^{\circ}$ ). Base de una copita de terra sigillata hispánica con sello (E)X.O.PAT. Al exterior conserva un grafito en la forma SVRI, con letras de c. 0,6 cm de altura. El texto podría ser el genitivo del cognomen Surus.

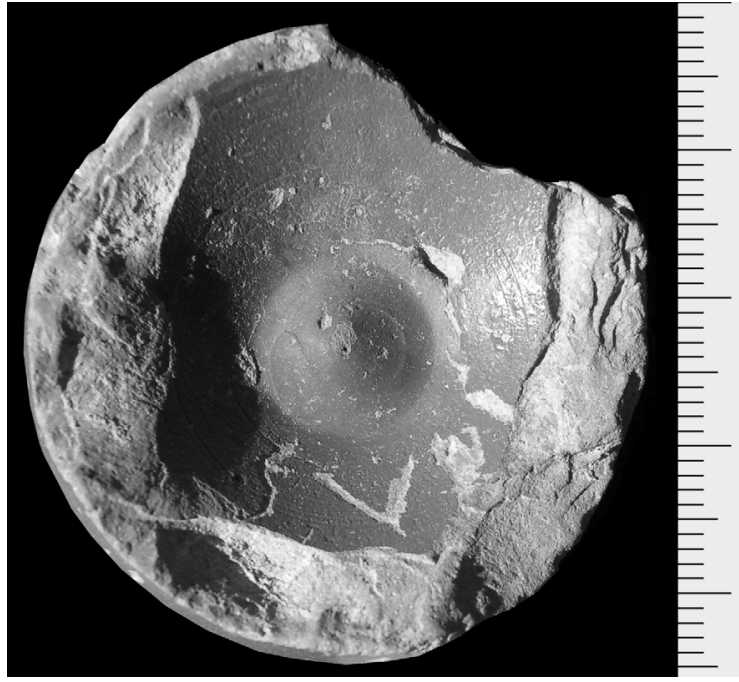

163 (2003, UE 7331, n. ${ }^{\circ} 4$ ). Fragmento de pared de un recipiente de terra sigillata hispánica. Al exterior conserva el inicio de un grafito en la forma $\mathrm{P}[-]$, con una letra de $2,6 \mathrm{~cm}$ de altura.

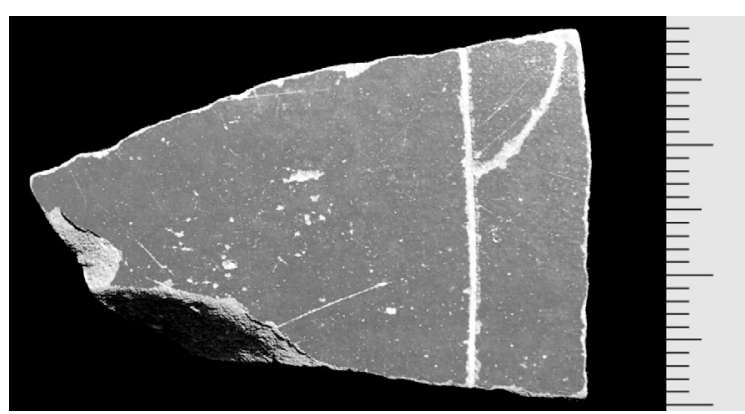

164 (2003, UE 7355, n. $\left.{ }^{\circ} 114\right)$. Base de una copita de terra sigillata hispánica con restos de un grafito no determinable cuyas letras miden algo más de $2 \mathrm{~cm}$ de altura.

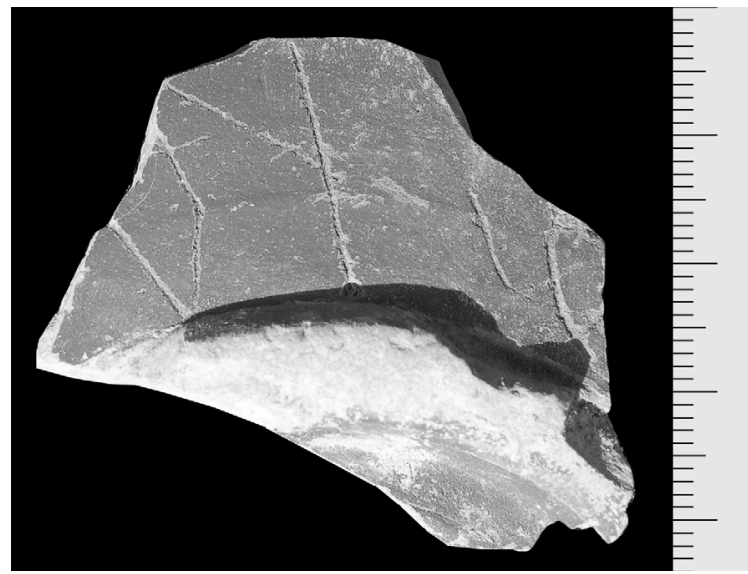

165 (2003, UE 7382, n. $\left.{ }^{\circ} 15\right)$. Base de un cuenco de terra sigillata hispánica. Al exterior, y junto al 
anillo del pie pero en posición invertida, se lee el texto PACAT[-], con letras de $1,1 \mathrm{~cm}$ de altura. Quizá se trate de la voz Pacati, genitivo del cognomen Pacatus (Kajanto, 1982, 67 y 261), para indicar la propiedad de la pieza.

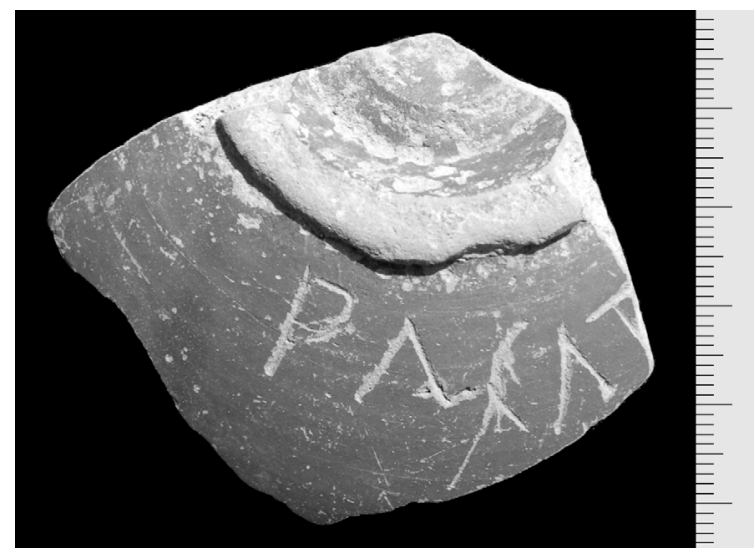

166 (2003, UE 7386, n. $\left.{ }^{\circ} 80\right)$. Base de un cuenco de terra sigillata hispánica, forma Dr. 37. Al exterior y junto al anillo del pie se conserva parte de un grafito en la forma [-]IDI[-], con letras de c. $1,2 \mathrm{~cm}$ de altura. No es posible identificar estas letras más allá de su probable pertenencia a un nombre propio como Candidianus, Placidina o similar.

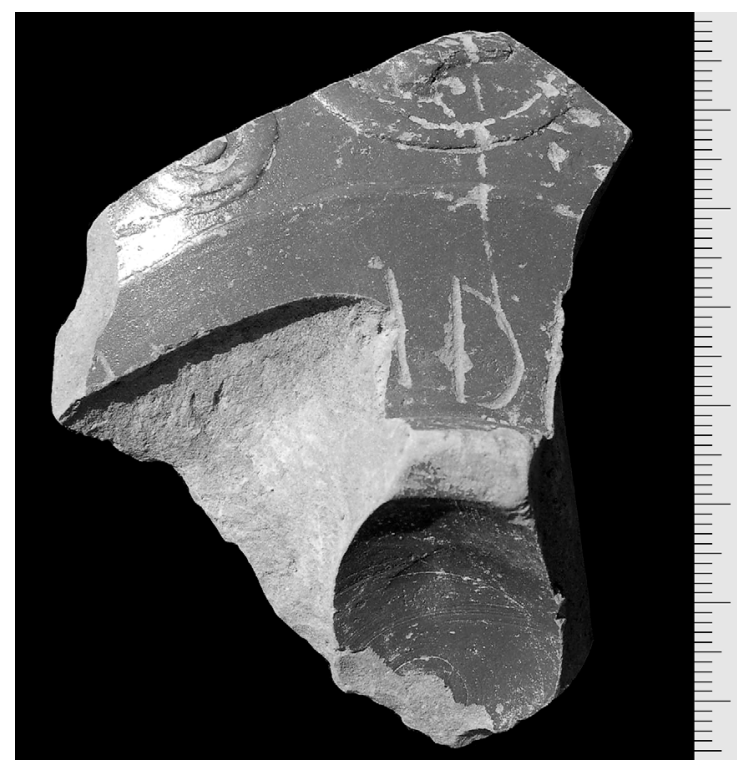

167 (2003, UE 7392, n. 74). Base de un cuenco de terra sigillata hispánica, forma Ritt. 08, que presenta al exterior el extremo final de un grafito en la forma [-]RES, con letras de 1,2 cm de altura y una longitud de $2,4 \mathrm{~cm}$. Podría tratarse de parte de un nombre personal de origen griego como Chares, Ares, Nigres, etc.

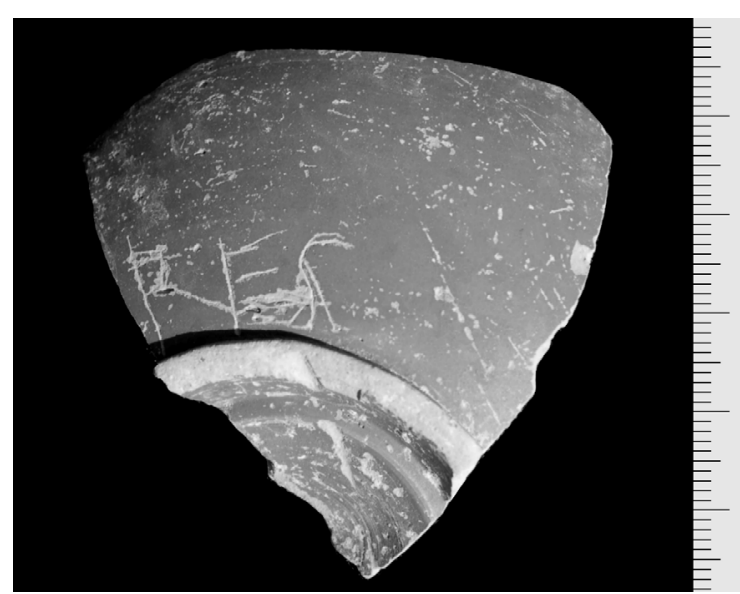

168 (2003, UE 7392, n. ${ }^{\circ} 82$ ). Base de terra sigillata hispánica, forma Dr. 27, que presenta al exterior de la pared dos trazos pertenecientes a un grafito perdido y no identificable, ocupando una superficie de $1,7 \times 1,2 \mathrm{~cm}$.

169 (2003, UE 7392, n. $\left.{ }^{\circ} 94\right)$. Base de un cuenco de terra sigillata hispánica, con parte de un grafito exterior en la forma [-]TIN [-], cuyas letras miden $1,3 \mathrm{~cm}$ de altura. Debe ser parte de un cognomen latino.

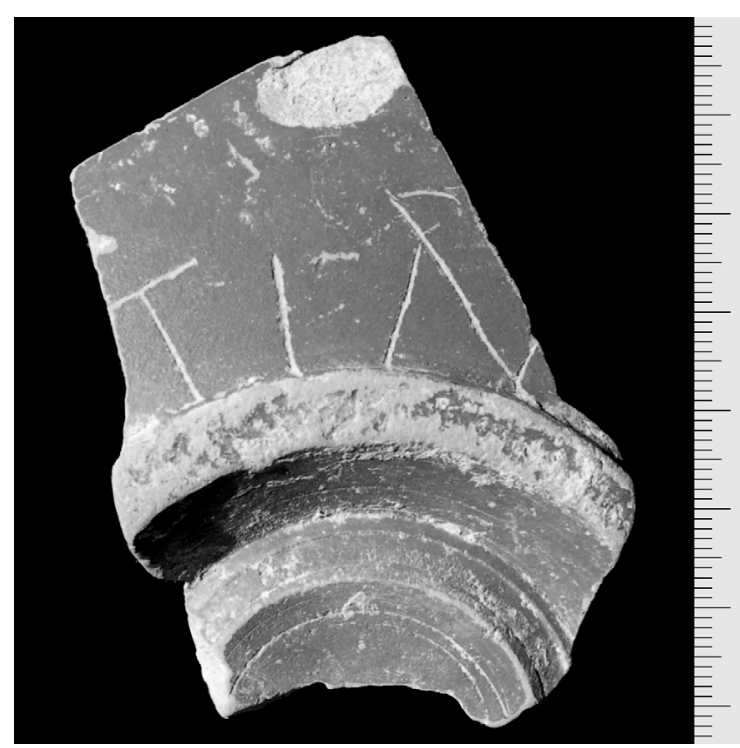

170 (2003, UE 7392, n. ${ }^{\circ}$ 95). Base de un cuenco de terra sigillata hispánica, con restos de un grafito exterior junto al anillo del pie en el que apenas se puede distinguir una A con travesaño horizontal; la altura de las letras es de 1,4 cm. 


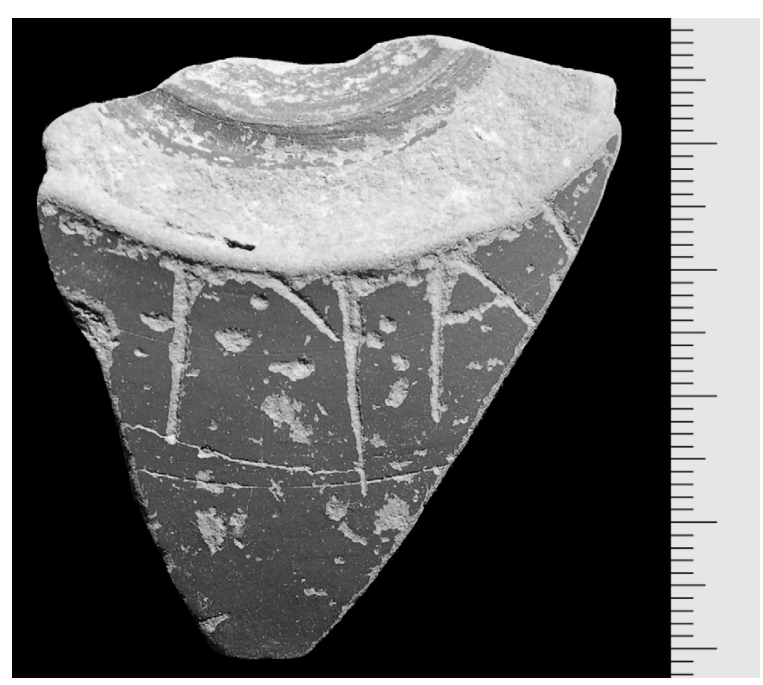

171 (2003, UE 7392, n. ${ }^{133}$ ). Base de un plato de terra sigillata hispánica brillante, del tipo 9 . Al exterior presenta un grafito en caracteres griegos, bien grabado y quizá alusivo al nombre de su propietario. El tercer carácter ha sido corregido para conseguir una $\mathrm{A}$ en el último momento. Las letras miden $1,2 \mathrm{~cm}$ de altura y en el texto puede leerse $\Pi \lambda \mathrm{a}[-]$.

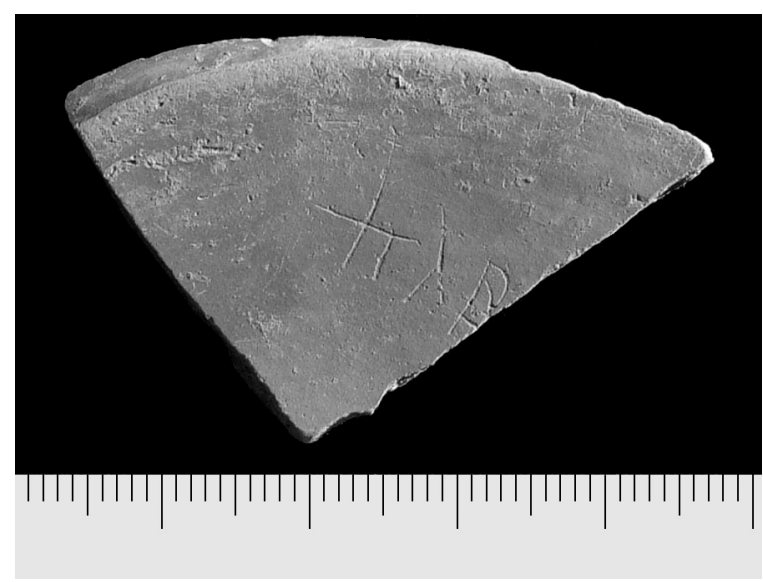

172 (2003, UE 7392, n. $\left.{ }^{\circ} 164\right)$. Fragmento de pared de una botella de cerámica común con un grafito exterior con el texto [-]MARCl; hay nexo MA y la altura de las letras es de c. 1,5 cm de altura.

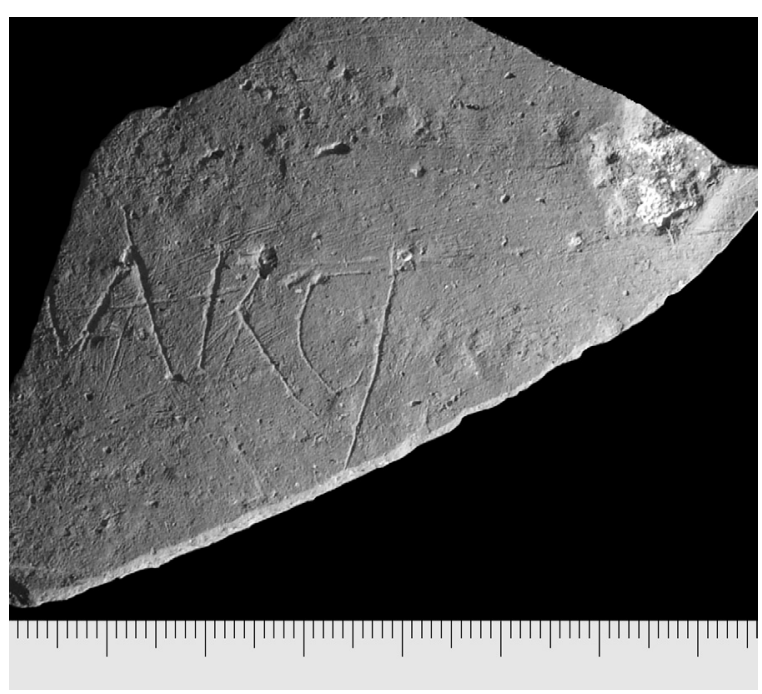

173 (2003, UE 7427, n. ${ }^{\circ} 68$ ). Base de un cuenco de terra sigillata hispánica, forma Dr. 37 . Al exterior, entre el pie y la decoración, quedan restos de un grafito seguramente formado en su día por varias palabras, de las que sólo queda una preposición en la forma [-] IN [-]; las letras miden $1,3 \mathrm{~cm}$ de altura.

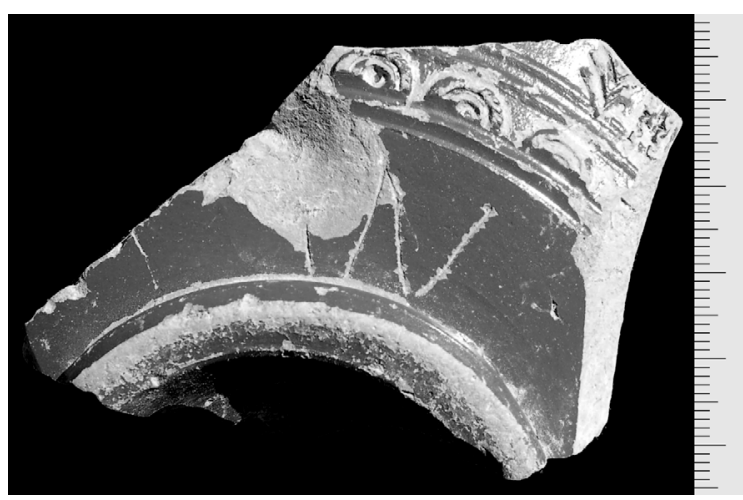

174 (2003, UE 7427, n. $\left.{ }^{\circ} 115\right)$. Borde de un cuenco (panna) de terra sigillata hispánica, forma Ritt. 08, con el inicio de un grafito con el texto MAT $+[-]$, en el que las letras miden c. $0,8 \mathrm{~cm}$ de altura. Debe tratarse de parte de un nombre personal no identificable, pues tras la T figura el arranque de una letra que por la inclinación de su asta parece una $\mathrm{V}$, algo sobre lo que no hay seguridad. 


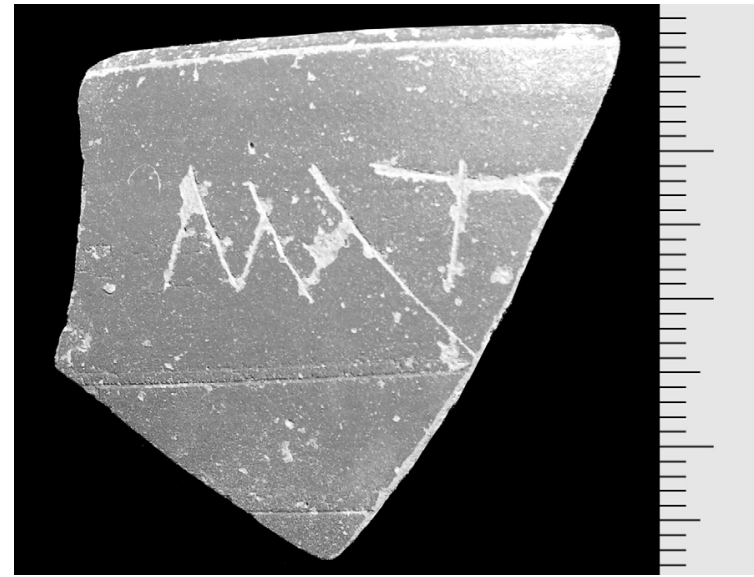

175 (2003, UE 7427, n. $\left.{ }^{\circ} 116\right)$. Borde de un cuenco (panna) de terra sigillata hispánica, forma Ritt. 08 , que presenta al exterior parte de una palabra en caracteres griegos en la forma [-]EMII[-]. La altura de las letras es de $0,8 \mathrm{~cm}$.

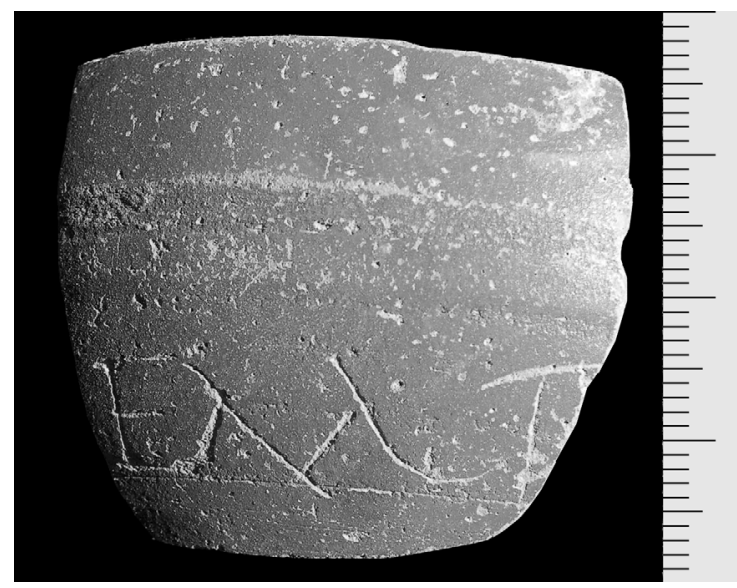

176 (2003, UE 7470, n. ${ }^{\circ} 82$ ). Base de una copita de terra sigillata hispánica del taller de VLLO. En la parte inferior figura una letra $M$ de $1,1 \mathrm{~cm}$ de altura.

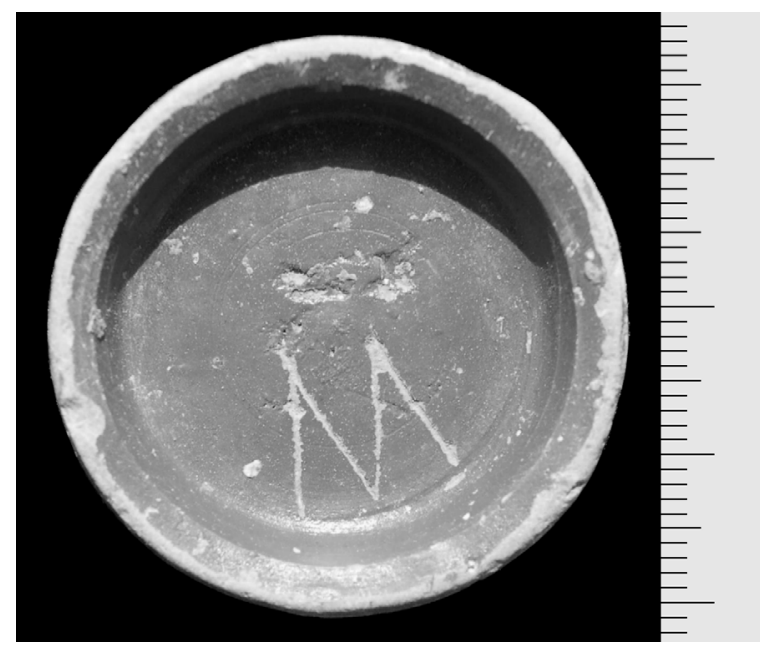

177 (2003, UE 7475, n. $\left.{ }^{\circ} 64\right)$. Base de un plato de terra sigillata hispánica, forma Dr. $15 / 17$, que presenta al exterior y junto al anillo del pie el extremo final de un grafito en el que se distinguen dos astas verticales seguidas de una $\mathrm{P}$; la primera de ellas podría ser el extremo de una $\mathrm{N}$, pese a lo cual no tiene sentido aparente el texto; la altura de las letras es de $1,4 \mathrm{~cm}$.

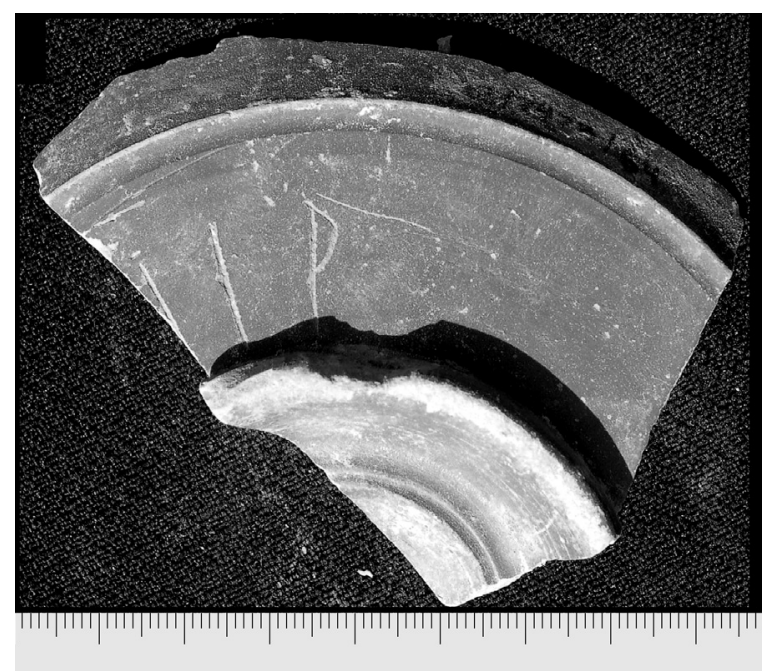

178 (2003, UE 7478, n. $\left.{ }^{\circ} 36\right)$. Fragmento de pared de un vaso de cerámica pintada romana, que presenta al exterior restos de un grafito muy tosco, formado en dos líneas, con caracteres muy desiguales y de difícil lectura. En la línea superior, sobre una superficie de $1,2 \times[2,7] \mathrm{cm}$, sólo se distinguen los caracteres $S$ y $F$ ó $E$ precedidos de un signo no identificable. En la inferior, que ocupa $0,7 \times[2,8] \mathrm{cm}$, se ve una $C$ inicial seguida de trazos irreconocibles.

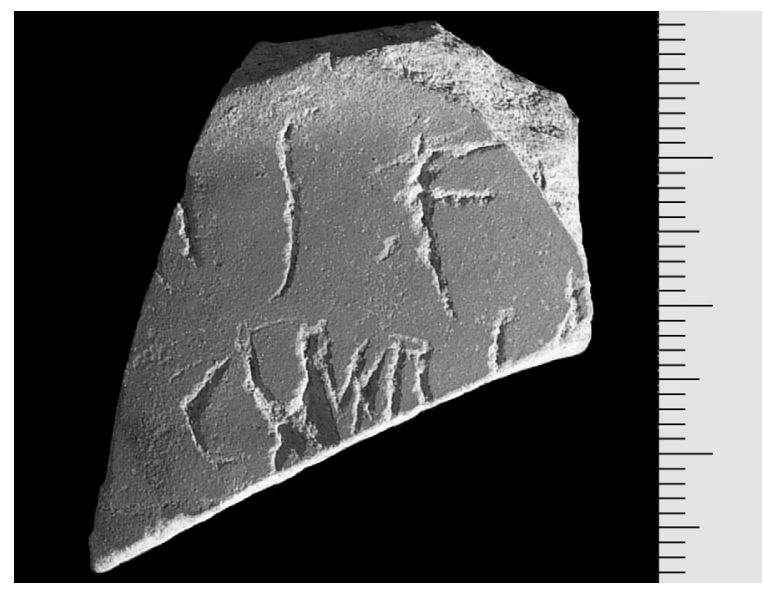

179 (2003, UE 7511, n. $\left.{ }^{\circ} 15\right)$. Fragmento de pared de un vaso de terra sigillata sudgálica, forma $D r$. 27 , con un grafito al exterior en forma de aspa de $1,5 \times 1,4 \mathrm{~cm}$. 
180 (2003, UE 7511, n. ${ }^{\circ} 38$ ). Fragmento de pared de un plato de terra sigillata hispánica que conserva al exterior restos de un grafito sobre una superficie de $0,7 \times[2,8] \mathrm{cm}$. En su parte final parece distinguirse una $T$ seguida de una $A$, a la que precederían dos astas verticales y quizá una $\mathrm{X}$, aunque no hay garantías para la lectura.

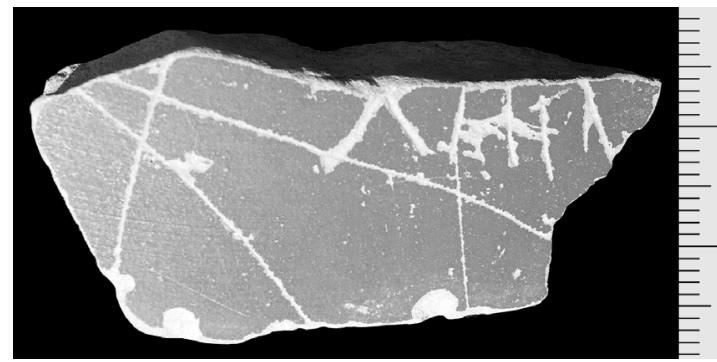

181 (2003, UE 7518, n. $\left.{ }^{\circ} 55\right)$. Fragmento de pared de un cuenco de terra sigillata hispánica que conserva al exterior el inicio de un grafito en la forma $\mathrm{N}[-]$; la altura de la letra es de $1 \mathrm{~cm}$.

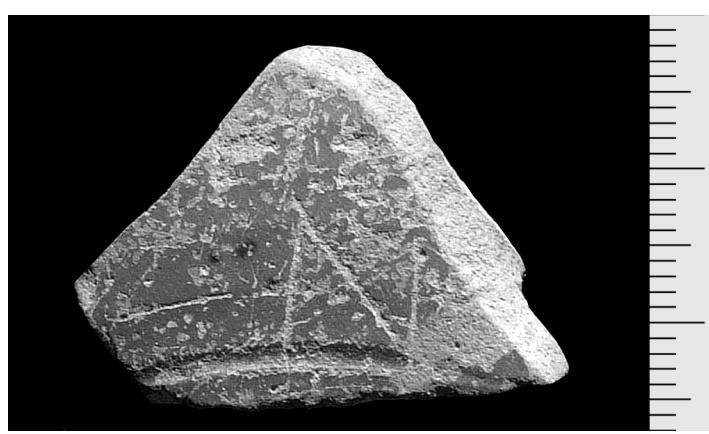

182 (2003, UE 7518, n. ${ }^{\circ} 47$ ). Borde de un cuenco (panna) de terra sigillata hispánica. Al exterior conserva el inicio de un grafito en la forma $\mathrm{CO}[-]$ con letras de $0,9 \mathrm{~cm}$ de altura.

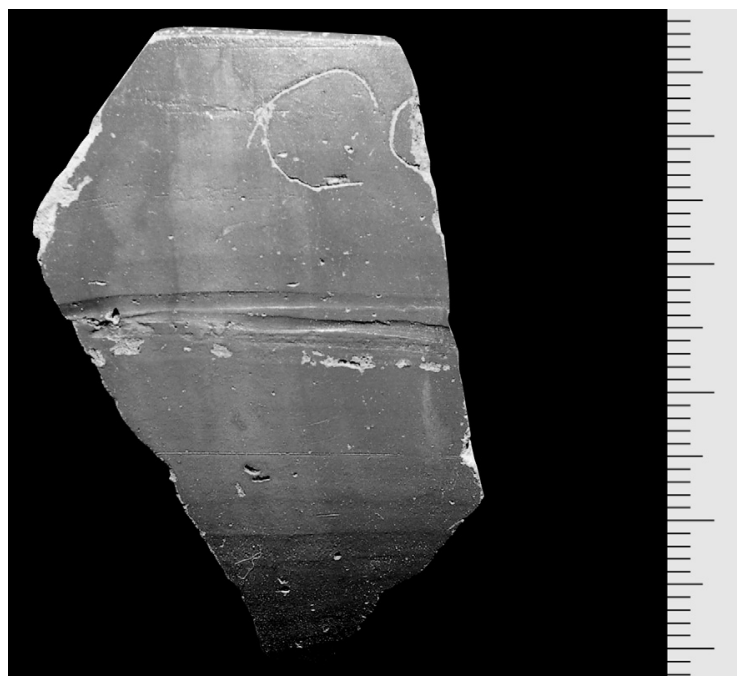

183 (2003, UE 7543, n. $\left.{ }^{\circ} 21\right)$. Fragmento de pared de un vaso de terra sigillata hispánica, forma Dr. 37. Junto a la decoración exterior presenta restos de un grafito en el que parece verse una $P$ muy estilizada seguida de una $A$ con travesaño central casi vertical y de c. $1,5 \mathrm{~cm}$ de altura; aparentemente, delante hay restos de otra letra, aunque podría tratarse de una rotura. La forma $[-]+P A[-]$ podría pertenecer a un nombre personal.

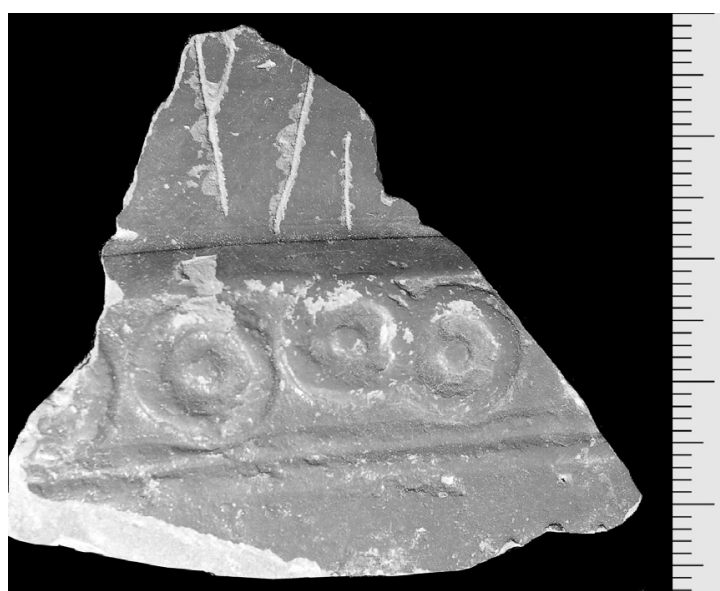

184 (2003, UE 7559, n. ${ }^{\circ} 27$ ). Base de un cuenco de terra sigillata hispánica, forma Dr. 37 , que presenta al interior el comienzo de un nombre personal en la forma PRIMI[-]; la altura de las letras es de $\mathrm{c} .1 \mathrm{~cm}$ y delante de la $\mathrm{P}$ se observa un asta que debe ser un arañazo. Lo conservado invita a pensar en un nombre como Primillus/-a.

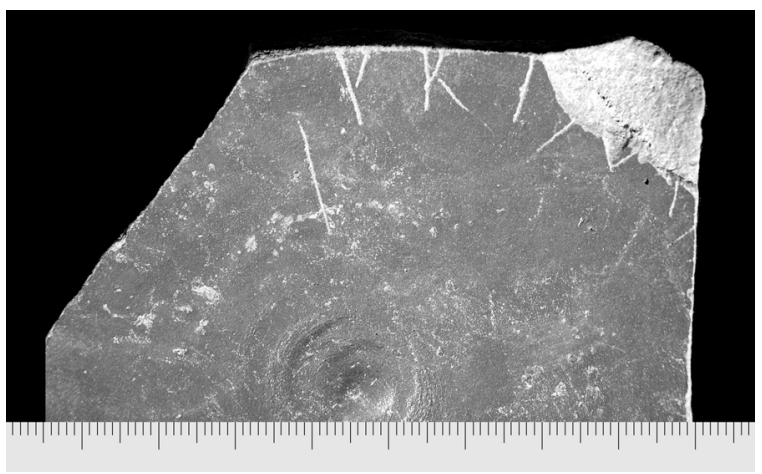

185 (2003, UE 7571, n. $\left.{ }^{\circ} 10\right)$. Base de un plato de terra sigillata hispánica que presenta al exterior los pies de diversas letras de un grafito no identificable en una superficie de $[0,9] \times[2,9] \mathrm{cm}$.

186 (2003, UE 7656, n. $\left.{ }^{\circ} 140\right)$. Fragmento de pared de un vaso de terra sigillata hispánica, forma Dr. 37. Al exterior, y por encima del anillo del pie perdido, figura el texto [-]VST[-], con letras de 
c. $1,2 \mathrm{~cm}$ de altura. Se trata de la huellas de un cognomen como Rusticus, Faustus o similar, incluyendo las formas femeninas y derivados.

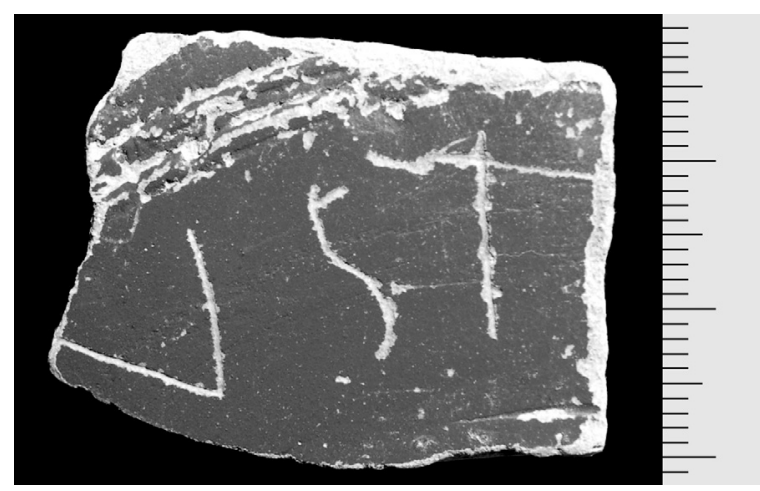

\section{Vivienda tardo-romana (2002)}

187 (2002, UE 8011, n. ${ }^{\circ} 63$ ). Base de un cuenco de terra sigillata hispánica, forma Dr. 37 . En la parte interior presenta un círculo de $2,6 \mathrm{~cm}$ de diámetro cruzado por una doble aspa. En trazos más tenues y dibujados con anterioridad se lee claramente [-] Romanu[s-], en una superficie de $0,6 \times[3,8] \mathrm{cm}$. El cognomen Romanus es sobradamente conocido (Solin - Salomies, 1988, 392), incluso en Hispania (Abascal, 1994, 484).

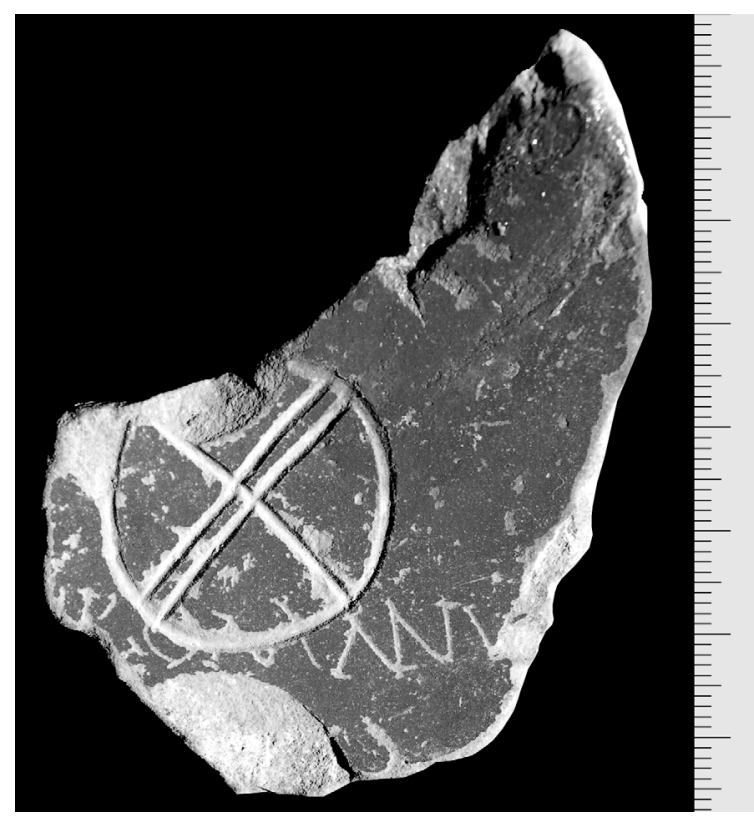

188 (2002, UE 8014, n. ${ }^{\circ} 88$ ). Base de una urna de cerámica común con un grafito al exterior en forma de aspa de $4,5 \times 3,4 \mathrm{~cm}$.

189 (2002, UE 8023, n. ${ }^{\circ}$ 93). Base de un recipiente de terra sigillata hispánica marcado con sello interior y con un grafito exterior en forma de aspa de $2,2 \times 1,8 \mathrm{~cm}$.

190 (2002, UE 8074, n. ${ }^{4}$ ). Base de un cuenco de terra sigillata hispánica, forma Dr. 37. Al exterior conserva restos de un grafito en el que sólo puede reconocerse una $M$ de $1,2 \mathrm{~cm}$ de altura, seguida de un carácter indeterminable.

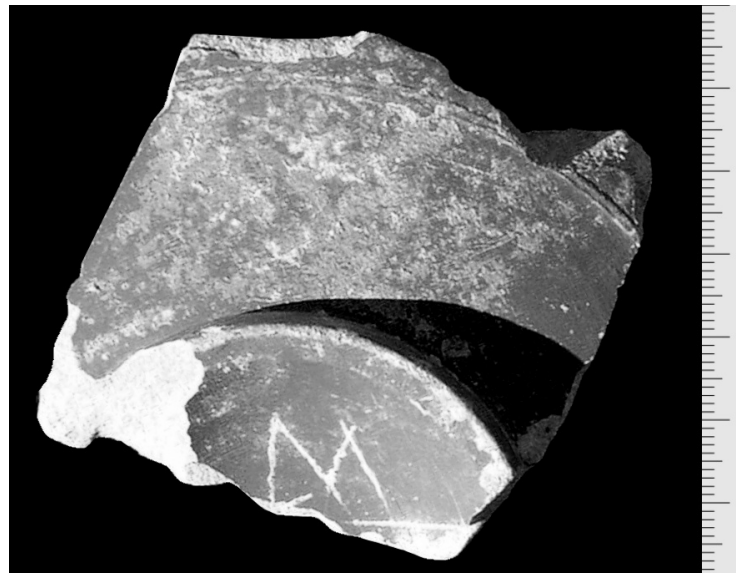

191 (2002, UE 8078, n. $\left.{ }^{\circ} 31\right)$. Base de un recipiente de terra sigillata sudgálica con sello SATV[-]. Al exterior presenta un grafito en forma de aspa de $1 \times 0,8 \mathrm{~cm}$.

192 (2002, UE 8093, n. ${ }^{\circ} 7$ ). Fragmento de pared de un vaso de terra sigillata hispánica, forma Dr. 27, que conserva al exterior el inicio de un grafito en la forma AVGV[-], con letras de c. 0,6 cm de altura. Nombres como Augustanus, Augurinus y sus femeninos podrían encajarse en este texto.

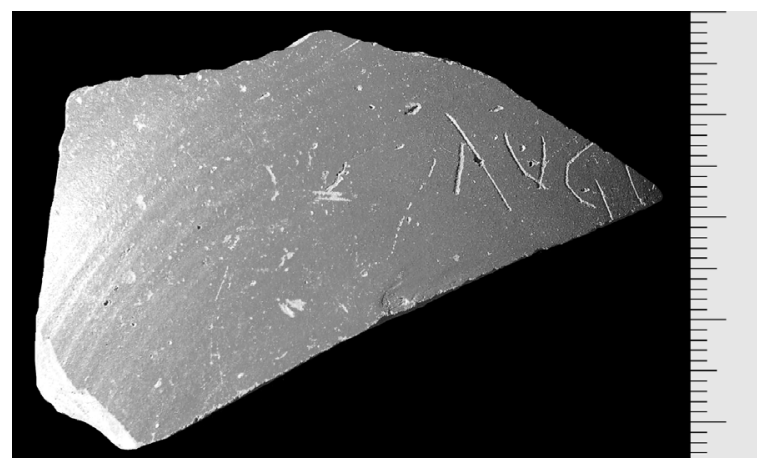

193 (2002, UE 8105, n. ${ }^{\circ}$ 9). Dos fragmentos del cuello de una jarra de cerámica común, que presentan al exterior un grafito ante cocción, apoyado en un baquetón, cuyas letras miden c. $1 \mathrm{~cm}$ de altura. En el texto puede leerse [-]ANDRI[-] $\mathrm{V} \cdot \mathrm{I}[-]$, con letras de muy buena ejecución; entre las dos últimas aparece una interpunción triangular con vértice hacia abajo. Los primeros 
caracteres recuerdan al cognomen Andronicus, pero es evidente que nada tiene que ver con él lo contenido en el texto, cuyo estado fragmentario impide una solución lógica.

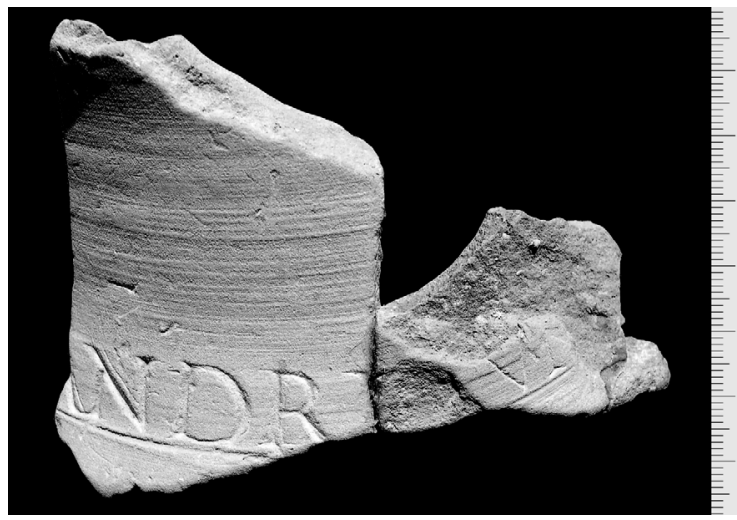

194 (2002, UE 8114, n. ${ }^{\circ}$ 1). Base de un recipiente de terra sigillata itálica con sello HILAR[-] / L. TETTI[-]. Conserva los extremos de los trazos pertenecientes a un grafito no identificable, que ocupan una superficie de $1,2 \times[0,7] \mathrm{cm}$.

195 (2002, UE 8120, n. ${ }^{\circ} 8$ ). Fragmento de pared de un recipiente de terra sigillata hispánica tipo Hermet 13. Al exterior, grafito en forma de hoja de palma sobre una superficie de $[1,4] \times 1 \mathrm{~cm}$.

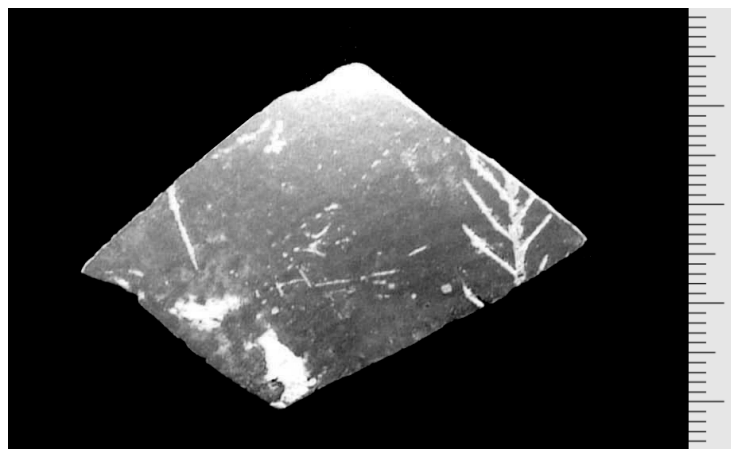

196 (2002, UE 8130, n. ${ }^{\circ} 3$ ). Fragmento de pared de un recipiente de terra sigillata hispánica, con parte de un grafito no identificable en una superficie de $1,6 \times[1,2] \mathrm{cm}$. Podría tratarse del inicio de una palabra con las letras NV, pero no hay seguridad de ello.

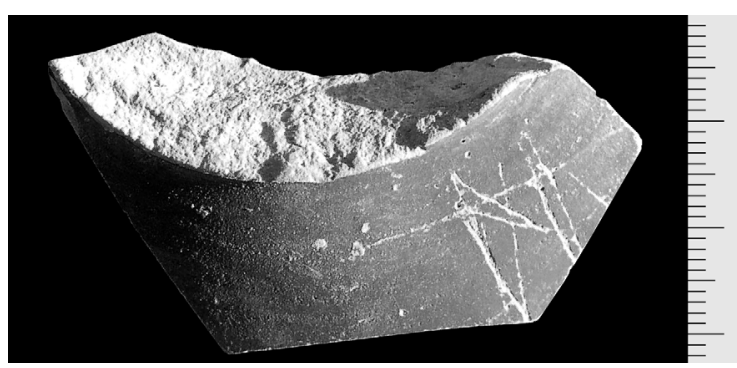

\section{Cloaca y Puerta Norte (2001)}

197 (2001, UE 2778, n. ${ }^{\circ} 13$ ). Borde de un cuenco de terra sigillata hispánica, forma Ritt. 8 (panna), con restos de un grafito ilegible al exterior en una superficie de $0,9 \times[1,5] \mathrm{cm}$.

198 (2001, UE 2788, n. ${ }^{\circ} 28$ ). Borde de un cuenco de terra sigillata hispánica, forma Dr. 37. Aunque muy erosionado, conserva restos de un grafito en caracteres griegos en la forma $[-] \lambda \pi[-]$, con una altura de $2 \mathrm{~cm}$.

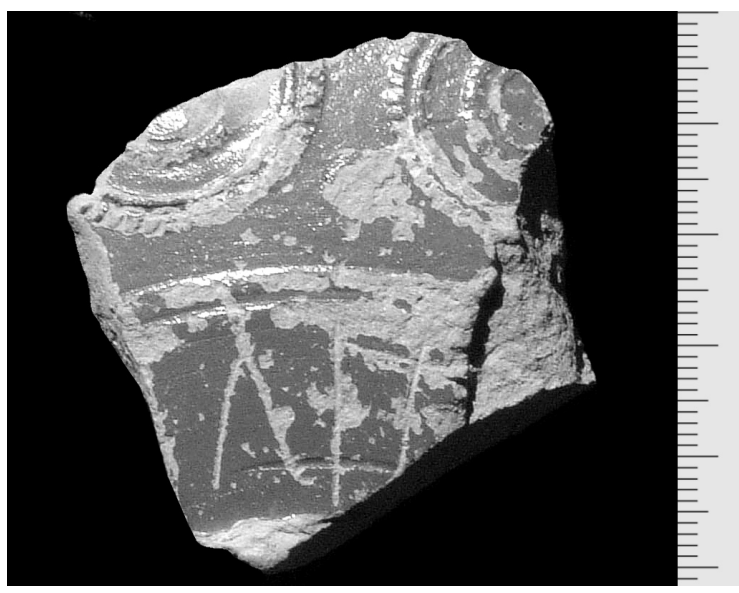

199 (2001, UE 2805, n. ${ }^{\circ} 31$ ). Base de un recipiente de terra sigillata hispánica decorado con un grafito en forma de hoja de palma de $2,2 \mathrm{x}$ $1,8 \mathrm{~cm}$.

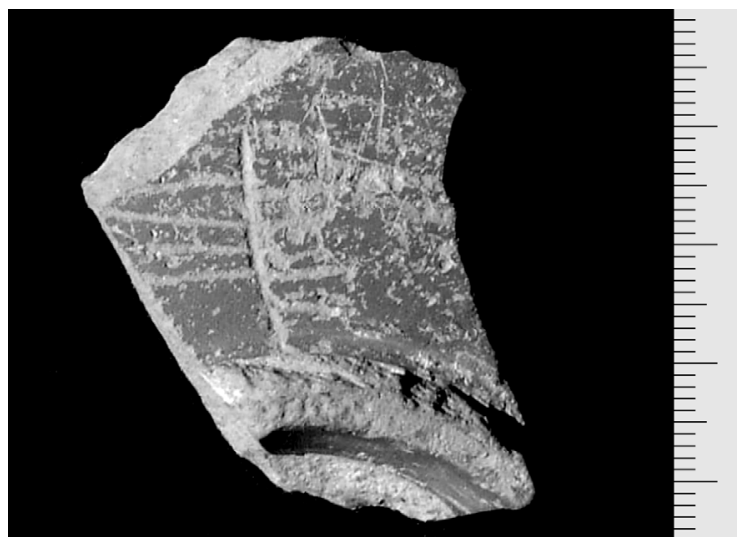

200 (2001, UE 2807, n. ${ }^{\circ}$ 2). Fragmento de pared de un recipiente de terra sigillata hispánica. En la parte inferior presenta una sucesión de signos que más que caracteres llegan a parecer un dibujo indeterminado. Ocupan una superficie de $1,8 \times 1 \mathrm{~cm}$. En el exterior de la pared figura incisa una letra $A$ de $1,2 \times 0,6 \mathrm{~cm}$. 


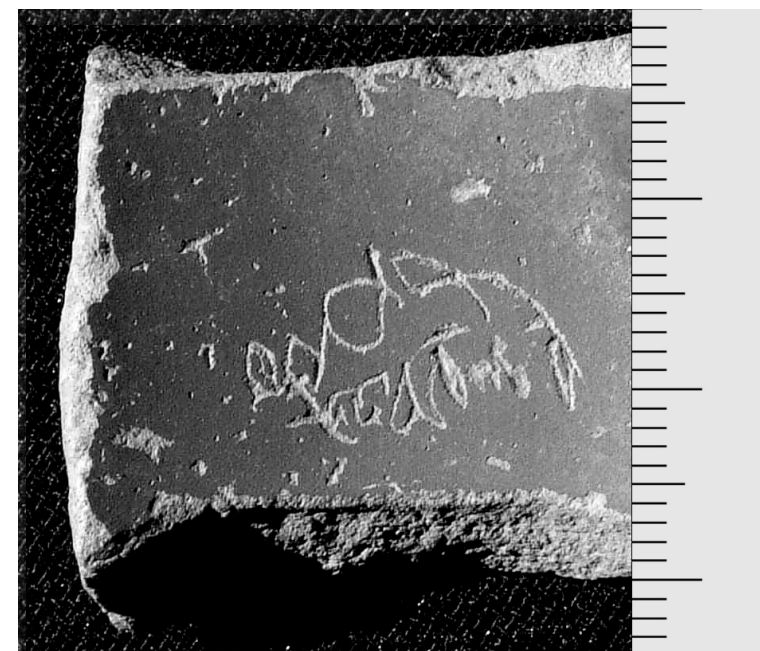

\section{Basílica forense (2004-2005)}

201 (2004, UE 7178, n. $\left.{ }^{\circ} 130\right)$. Base de una copita de terra sigillata hispánica decorada al interior con una doble aspa de 2,2 cm de longitud.

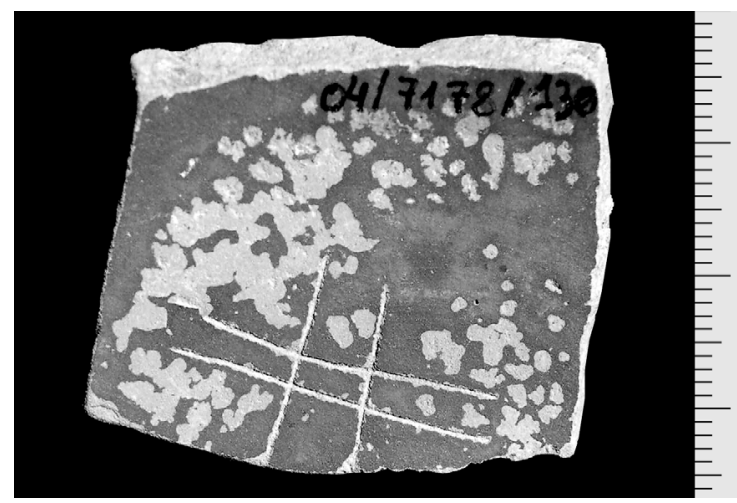

202 (2004, UE 7179, n. $\left.{ }^{\circ} 20\right)$. Borde de ánfora de tipo Dressel 28, que conserva al exterior el extremo de una letra, quizá $\mathrm{A}$ o $\mathrm{M}$, ocupando una superficie de [1] x 0,7 cm.

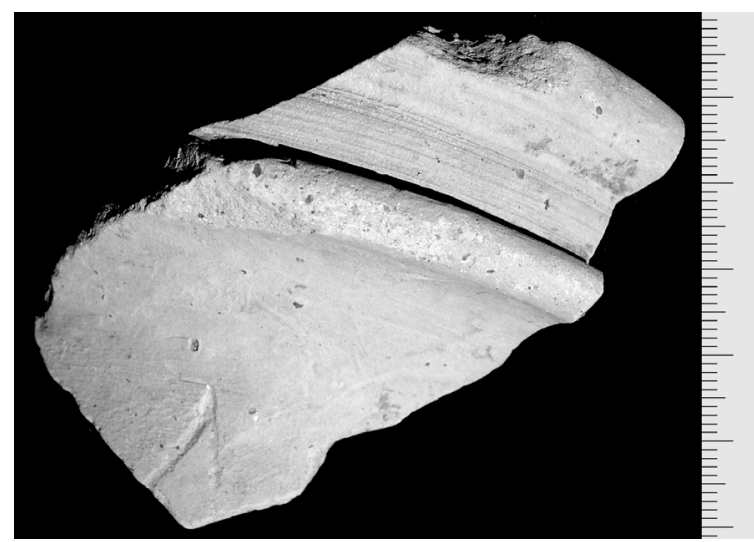

203 (2004, UE 7184, n. ${ }^{\circ} 45$ ). Base de un cuenco de terra sigillata hispánica. Al exterior y junto al pie presenta en posición invertida el extremo final de un grafito en la forma [-]VRIL(-), con letras de $1,3 \mathrm{~cm}$ de altura, ocupando una superficie longitudinal de $3,9 \mathrm{~cm}$. Cognomina como Maurillus/-a, Surilla, etc., podrían estar enmascarados bajo esta abreviuatura.

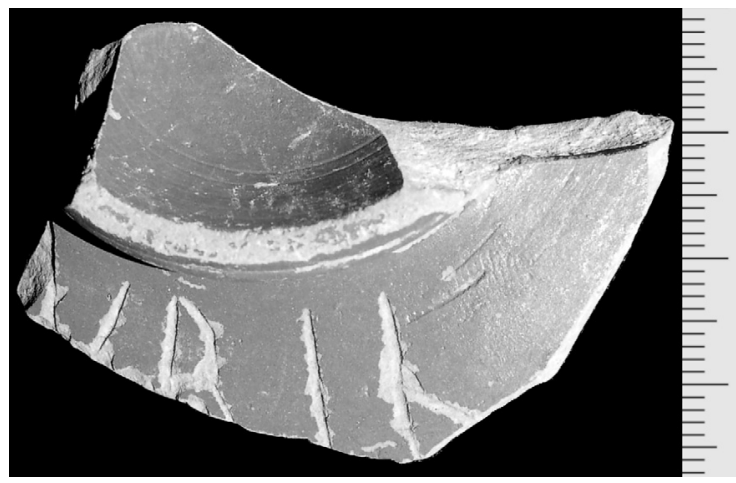

204 (2004, UE 7726, n. $\left.{ }^{\circ} 161\right)$. Fragmento de pared de un cuenco de terra sigillata hispánica, forma Dr. 37. Al exterior conserva parte de un grafito en el que sólo puede reconocerse una $V$ de $0,9 \mathrm{~cm}$ de altura.

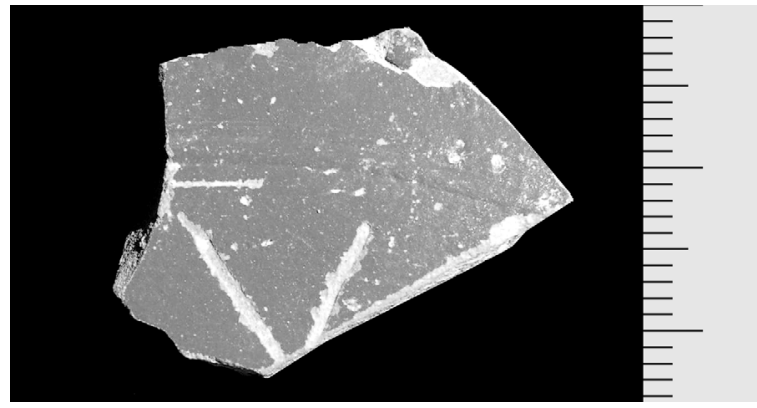

205 (2004, UE 7781, n. ${ }^{\circ} 67$ ). Base de una copita de terra sigillata hispánica. Por el interior del pie discurre un grafito cuyas letras miden c. 0,6 $\mathrm{cm}$ de altura, en el que sólo puede leerse [-] EST[-]; la E está escrita con un doble trazo vertical. Véase lo dicho para la pieza $\mathrm{n}^{\circ} 32$.

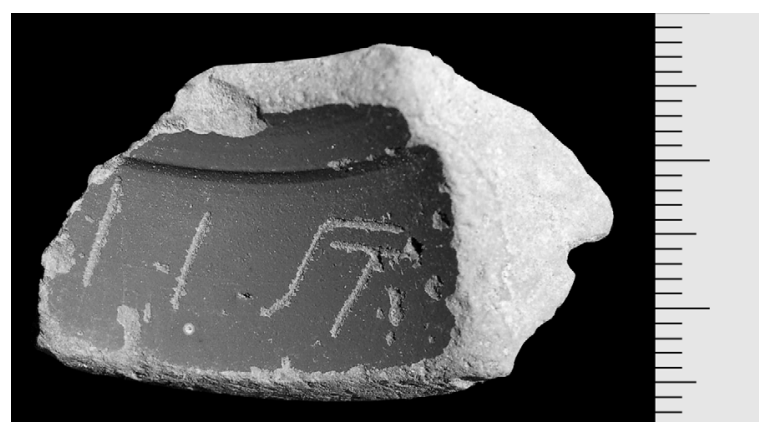


206 (2004, UE 7786, n. ${ }^{\circ}$ 52). Fragmento de pared de un plato de terra sigillata hispánica, forma Dr. 15/17. Entre el pie y la inflexión de la pared conserva tres caracteres de un grafito exterior en la forma [-]DE[-], de $2 \mathrm{~cm}$ de altura. La E está grabada con un doble trazo vertical.

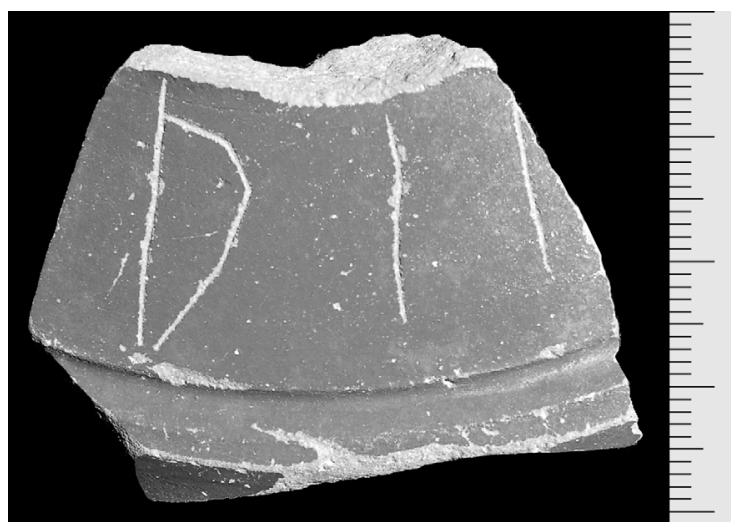

207 (2004, UE 7786, n. $\left.{ }^{\circ} 53\right)$. Base de un plato de terra sigillata hispánica, forma $\mathrm{Dr}$. 15/17. Junto al anillo del pie quedan letras de c. $1,5 \mathrm{~cm}$ de altura de un grafito del que sólo se ven ya dos caracteres en la forma $[-] \mathrm{TV}[-]$.

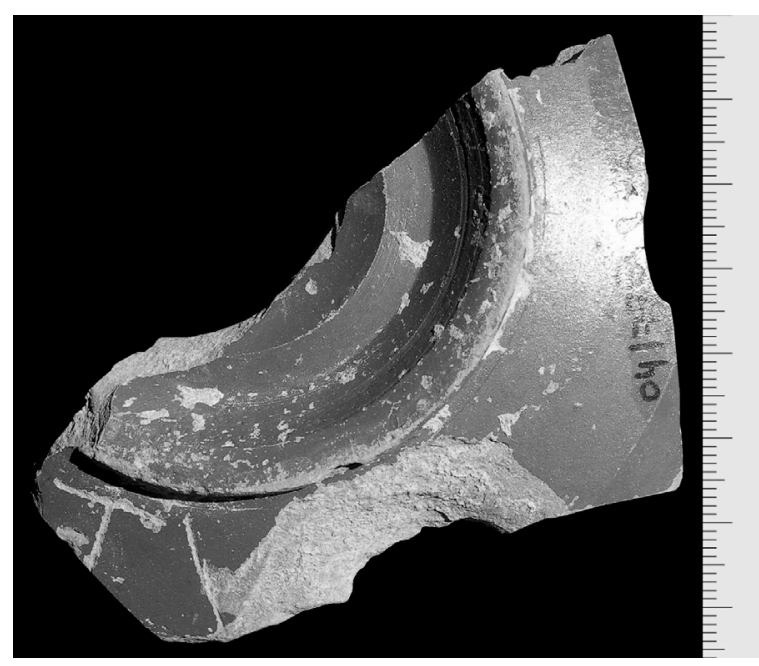

208 (2004, UE 7832, n. ${ }^{\circ} 329$ ). Base de un plato de terra sigillata hispánica en cuyo interior se conserva un grafito, aparentemente completo, con la forma LVPVLII escrita en caracteres de $1,1 \mathrm{~cm}$ de altura, ocupando una superficie de $[4,8] \mathrm{cm}$ de longitud. Lo conservado puede ser el genitivo del rarísimo nomen Lupulius (Solin - Salomies, 1988, 108) y, más probablemente, el genitivo del cognomen Lupula (Kajanto, 1982, 328), en donde se ha simplificado la desinencia y la $E$ se ha escrito con doble trazo vertical, con lo que habría que entender en el texto la voz Lupul(a)e.

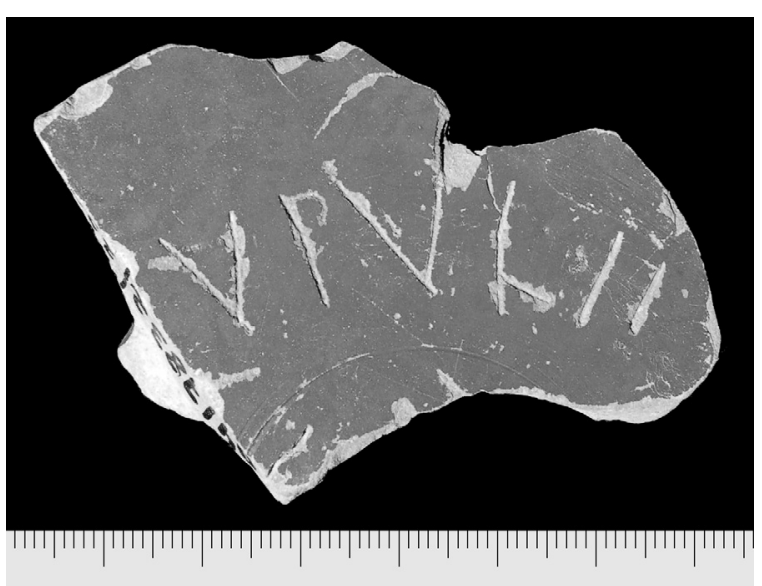

209 (2004, UE 7832, n. ${ }^{\circ}$ 96). Base de una copita de terra sigillata hispánica, que al exterior presenta una letra $R$ de $1,8 \mathrm{~cm}$ de altura.

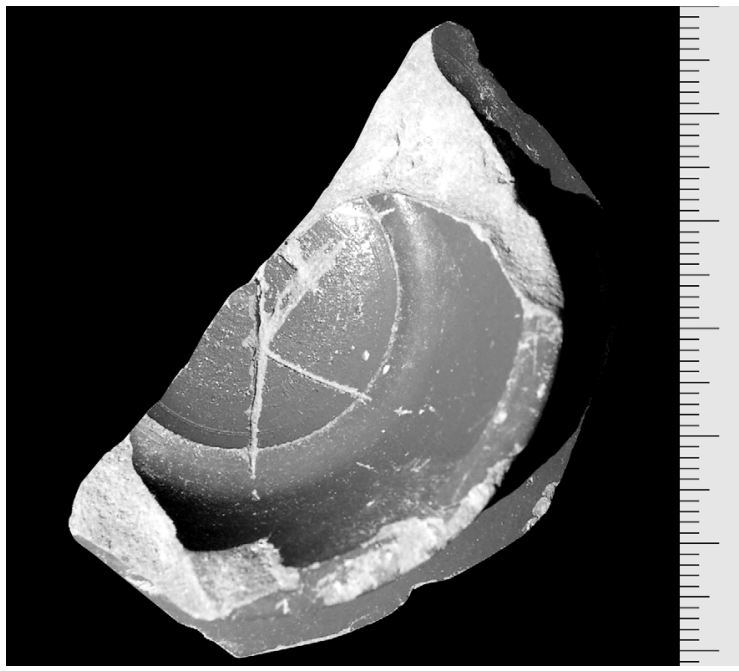

210 (2004, UE 7836, n. ${ }^{\circ}$ 5). Base de una copita de terra sigillata hispánica con restos de un grafito cuyas letras miden c. 0,6 cm de altura. Pese al deterioro, parece leerse algo como [-]+VTI[-], siendo la cruz el resto de un carácter con asta vertical.

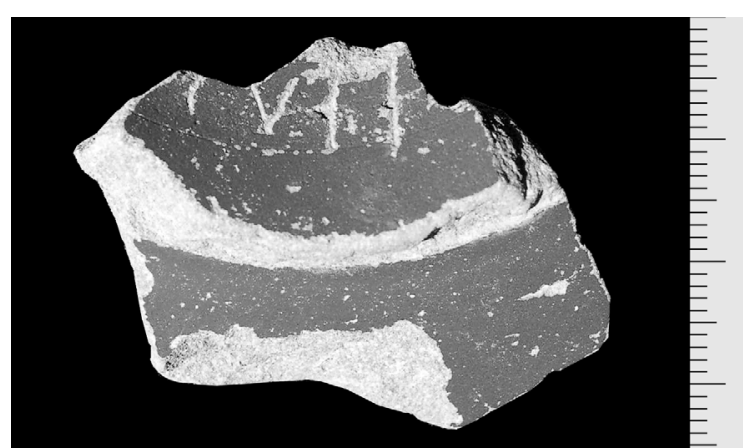


211 (2005, UE 7750, n. ${ }^{\circ}$ 1056). Urna de cerámica común con una marca en forma de $\mathrm{X}$ en el exterior del labio; la marca mide $2,3 \times 1,2 \mathrm{~cm}$ y puede ser un indicador de capacidad.

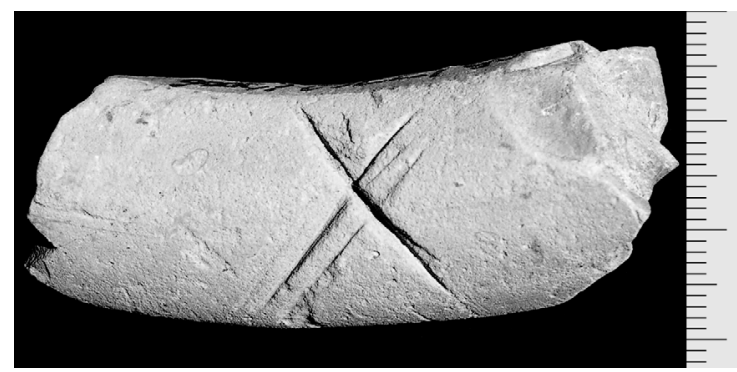

212 (2005, UE 10056, n. $\left.{ }^{\circ} 3\right)$. Fragmento de cuenco de terra sigillata hispánica brillante, en cuyo interior se conserva la letra $T$ de un grafito con una altura de $1,8 \mathrm{~cm}$.

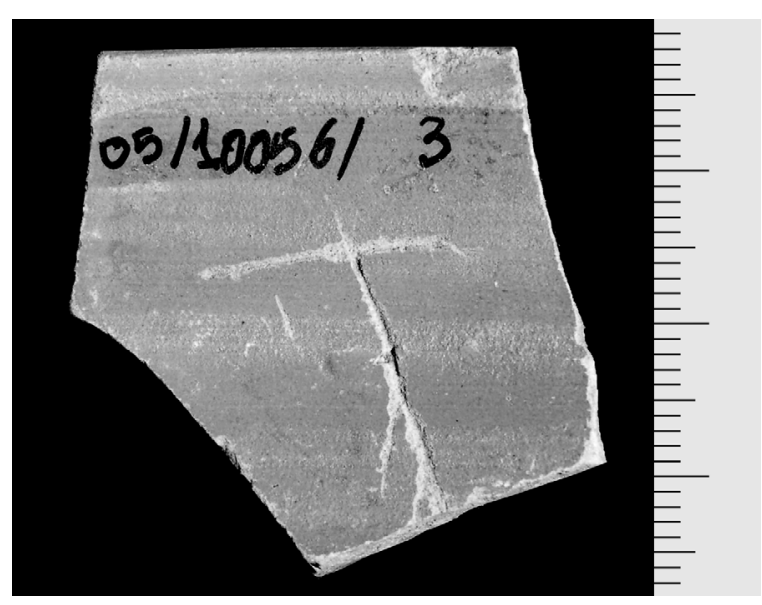

213 (2005, UE 10154, n. $\left.{ }^{\circ} 4\right)$. Fragmento del borde de un gran contenedor de cerámica común que presenta sobre el labio las letras AR, ocupando una superficie de $3 \times 5 \mathrm{~cm}$.

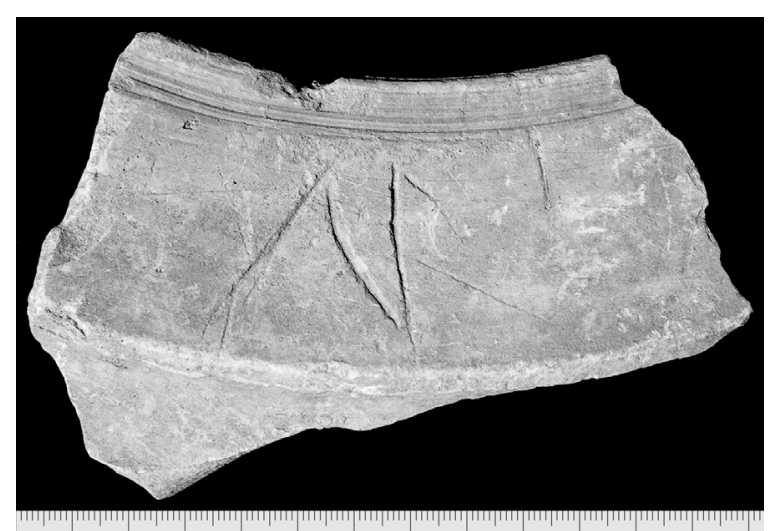

\section{Vivienda adosada a la muralla oriental (2005)}

214 (2005, UE 2902, n. ${ }^{\circ} 7$ ). Base de cuenco de terra sigillata hispánica en cuya parte inferior se han grabado las letras NR con caracteres de c. $0,6 \mathrm{~cm}$ de altura.

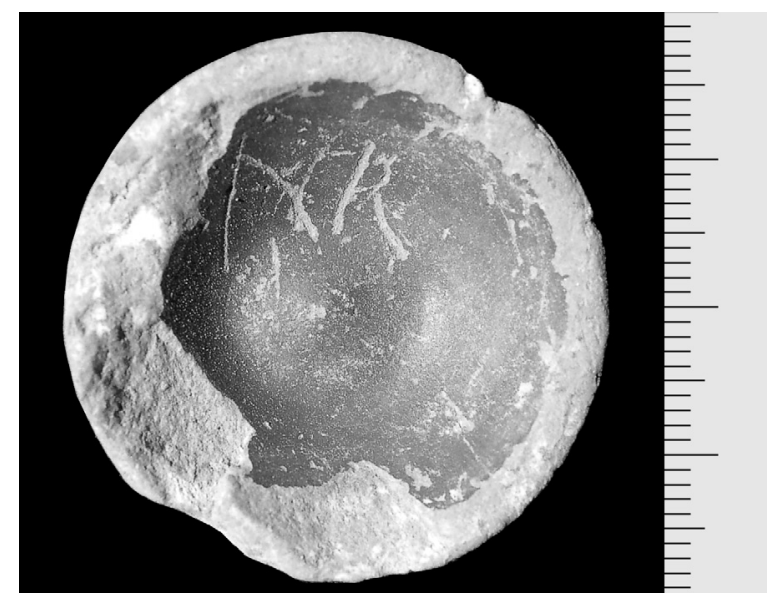

\section{Circo (2004-2006)}

215 (2004, UE 9001, n. ${ }^{\circ} 5$ ). Fragmento de pared de un recipiente de terra sigillata hispánica con restos de un grafito exterior cuyas letras miden $0,9 \mathrm{~cm}$ de altura. Lo visible podría ser una A seguida de una $\mathrm{M}$ o una $\mathrm{M}$ con sus trazos centrales sin unir.

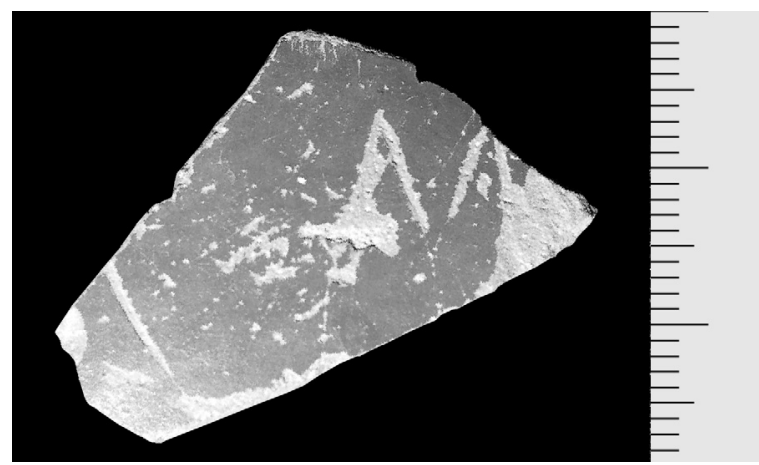

216 (2004, UE 9011, n. ${ }^{\circ} 438$ ). Borde de un cuenco de terra sigillata hispánica, forma Dr. 37 , que presenta bajo el labio el inicio de un grafito en la forma $L A[-]$; la altura de las letras es de 1,6 $\mathrm{cm}$. 


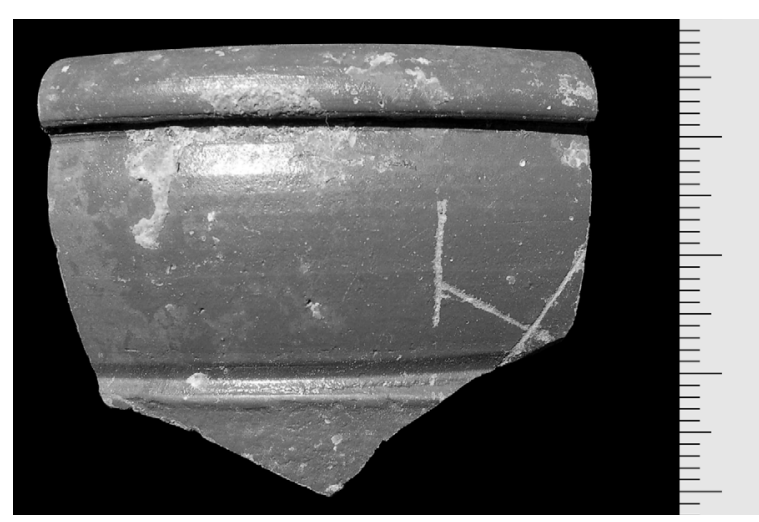

217 (2004, UE 9011, n. ${ }^{\circ} 458$ ). Fragmento de pared de un recipiente de terra sigillata hispánica de forma no determinable, Al exterior conserva restos de un grafito ocupando una superficie de $1,2 \times[2,2] \mathrm{cm}$; no es posible fijar la identidad de los caracteres visibles.

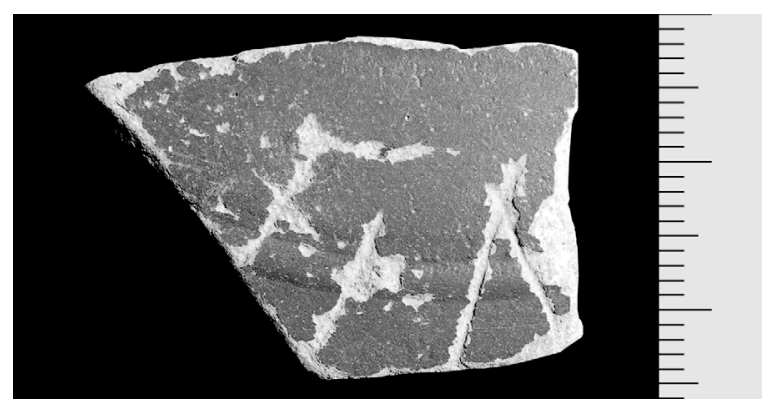

218 (2004, UE 9011, n. ${ }^{\circ} 835$ ). Base de un vaso de terra sigillata hispánica. En la parte interior del anillo presenta un grafito con el texto $[\mathrm{H}]$ eraclei, cuyas letras miden $0,7 \mathrm{~cm}$ de altura. Hay nexo $C L$ en una forma poco habitual.

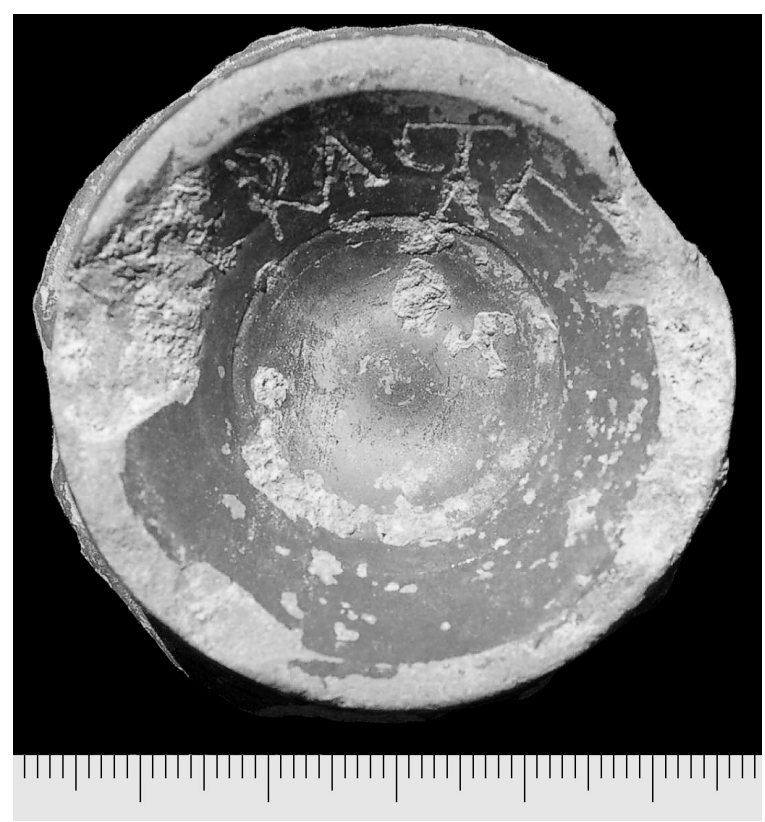

219 (2004, UE 9028, n. ${ }^{\circ} 38$ ). Fragmento de pared de un contenedor de cerámica común con un grafito exterior en forma de aspa de $[3,5] \mathrm{x}$ $2,7 \mathrm{~cm}$.

220 (2004, UE 9033, n. ${ }^{\circ} 72$ ). Base de un cuenco de terra sigillata hispánica en el que parece distinguirse el comienzo de un grafito con el nexo $\mathrm{HE}$; los caracteres miden $2 \mathrm{~cm}$ de altura.

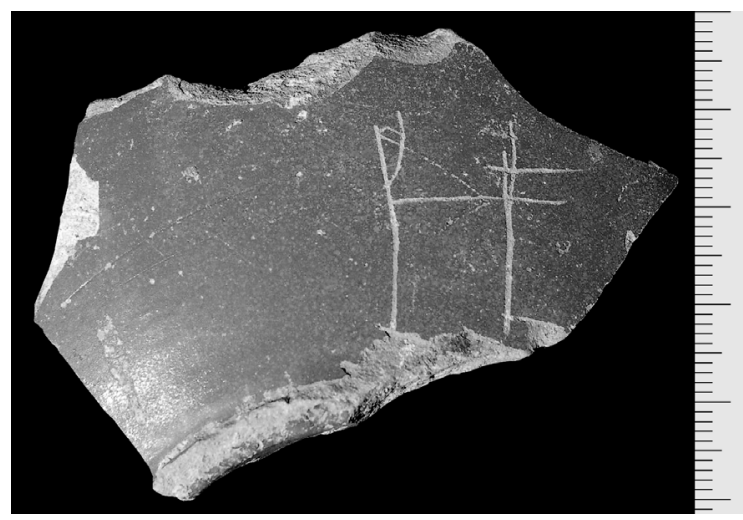

221 (2004, UE 9088, n. ${ }^{\circ} 6$ ). Fragmento de pared de un recipiente de terra sigillata hispánica con el comienzo de un grafito en la forma ICI[-] y menos probablemente ILI[-]. Los caracteres miden c. $0,7 \mathrm{~cm}$ de altura.

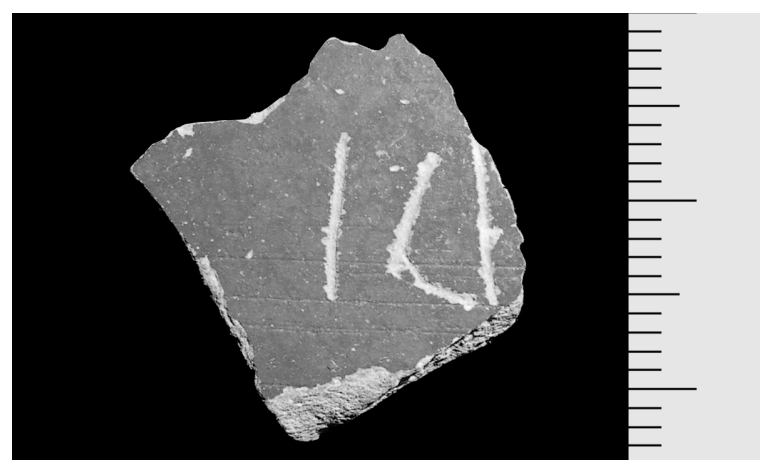

222 (2004, UE 9114, n. ${ }^{\circ}$ 54). Base de una copita de terra sigillata hispánica con sello interior y una $\mathrm{M}$ grabada al exterior de $0,7 \mathrm{~cm}$ de altura. 


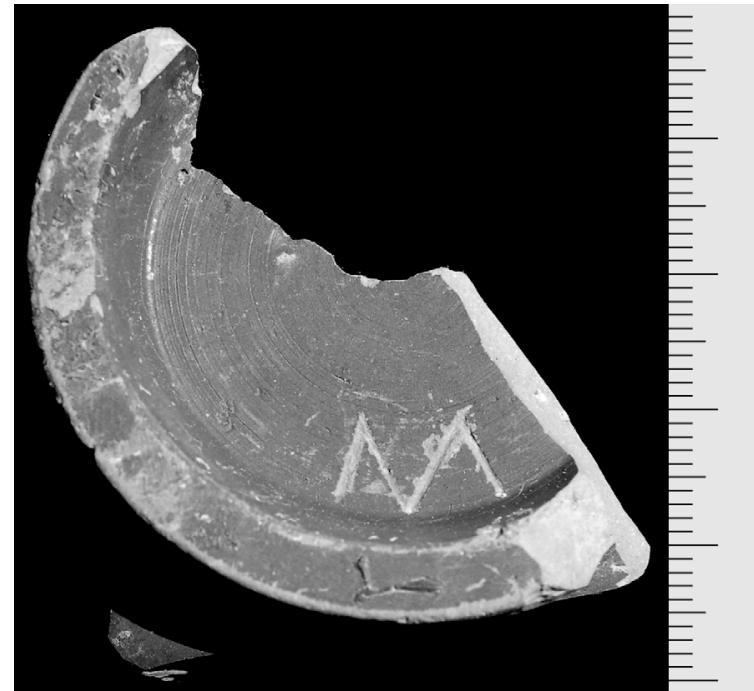

223 (2004, UE 9121, n. ${ }^{\circ}$ 57). Base de un plato de terra sigillata hispánica con una $\mathrm{R}$ de $3,8 \mathrm{~cm}$ de altura grabada en su parte inferior.

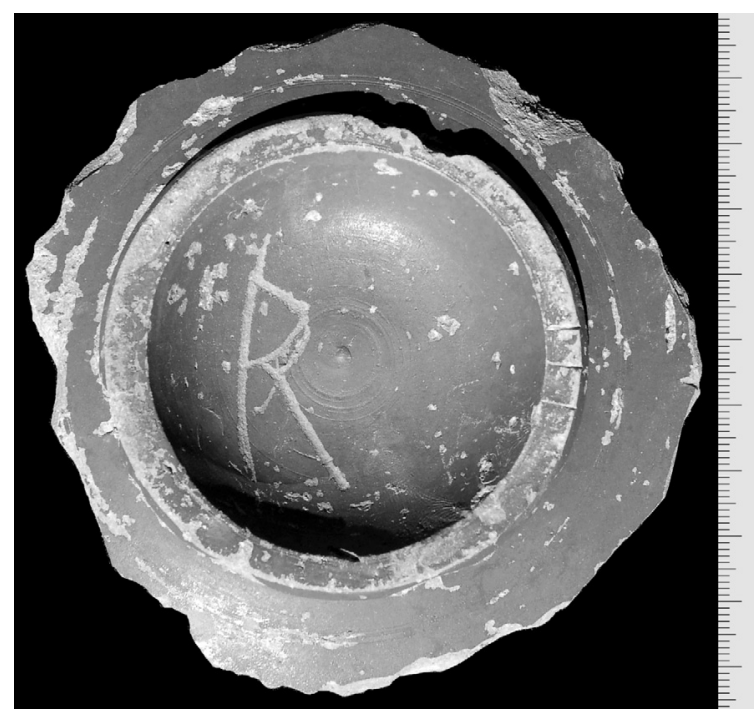

224 (2004, UE 9121, n. 88). Base de un cuenco de terra sigillata sudgálica, forma Ritt. 8 (marmorata), con sello interior. En el exterior del pie, con trazos de $0,4 \mathrm{~cm}$ de altura, parece leerse el grafito AVITI, genitivo del popular cognomen latino Avitus.

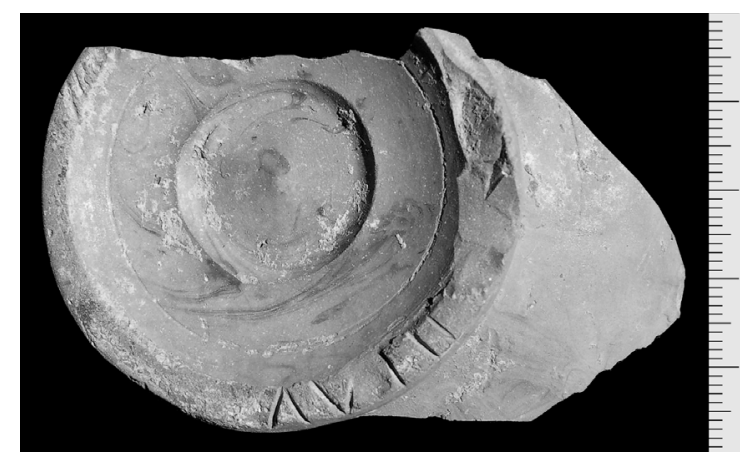

225 (2005, UE 9201, n. $\left.{ }^{\circ} 94\right)$. Base de un cuenco de terra sigillata hispánica con restos de un grafito en el que parece distinguirse una $\mathrm{N}$ y una $\mathrm{V}$ junto a otros trazos no identificables; la altura de las letras es de c. $2,6 \mathrm{~cm}$.

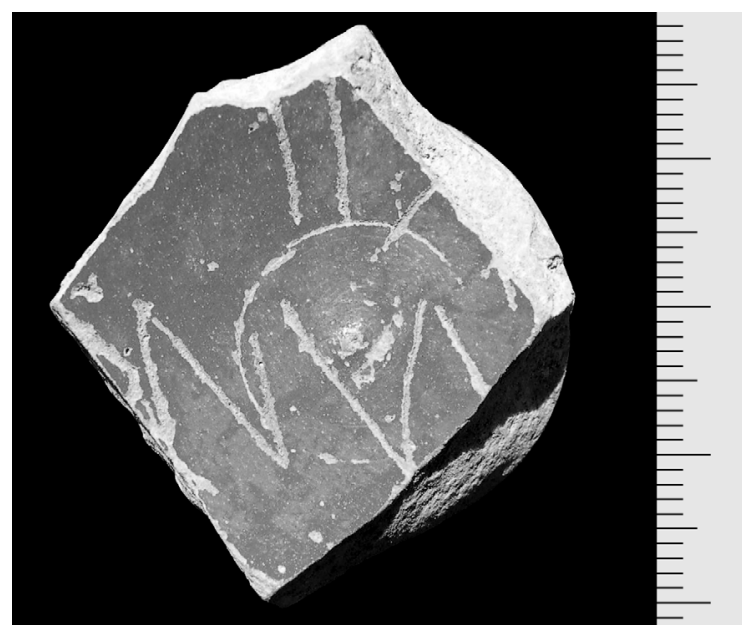

226 (2005, UE 9212, n. $\left.{ }^{\circ} 2\right)$. Fragmento de pared de un cuenco de terra sigillata hispánica, forma Dr. 37 , con restos de un grafito no identificable en una superficie de $[1,1] \times[2,2] \mathrm{cm}$.

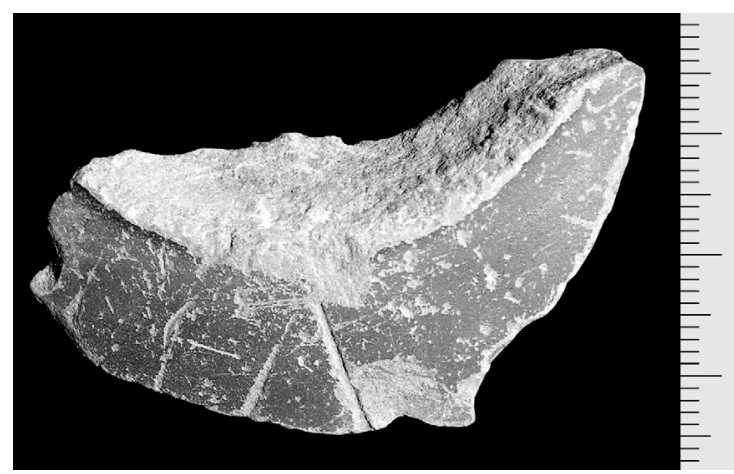

227 (2005, UE 9245, n. $\left.{ }^{\circ} 100\right)$. Fragmento de pared de un contenedor de cerámica común con parte de un grafito formado con letras de c. $4 \mathrm{~cm}$ de altura, en el que parece leerse [-]OM[-]. 


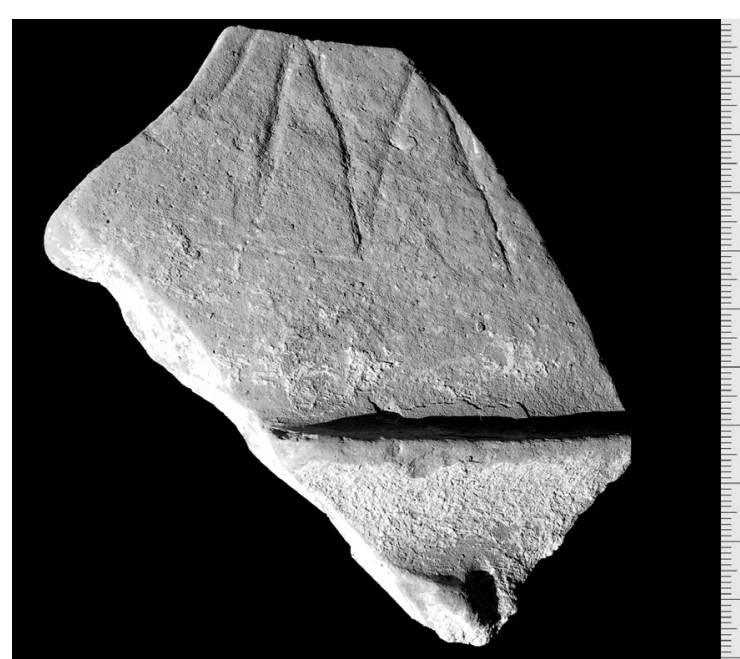

228 (2005, UE 9245, n. $\left.{ }^{\circ} 101\right)$. Fragmento de pared de un contenedor de cerámica común con un grafito ante-cocción del que sólo queda una $\mathrm{R}$ de c. $3 \mathrm{~cm}$ de altura.

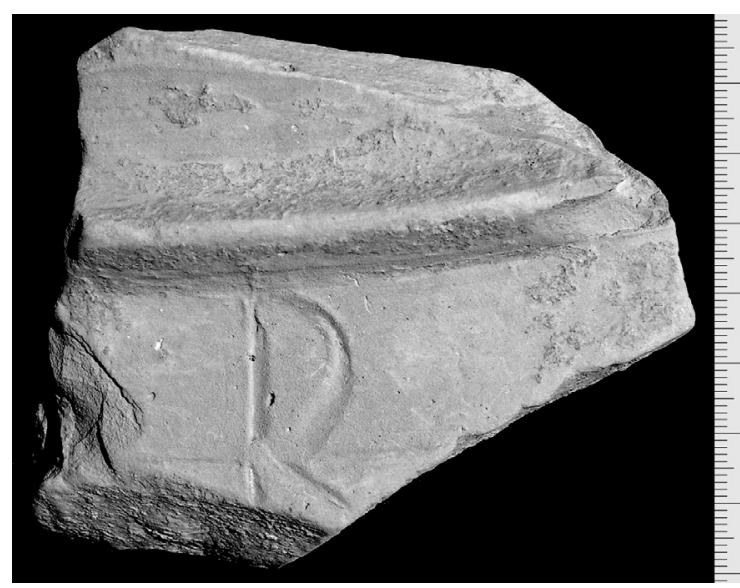

229 (2005, UE 9297, n. ${ }^{\circ} 53$ ). Fragmento de pared de un cuenco Drag. 27 de terra sigillata hispánica. En la base presenta un grafito en forma de aspa de [2,5] x 2,6 cm; en la pared exterior, palma de $4,2 \times 3 \mathrm{~cm}$.

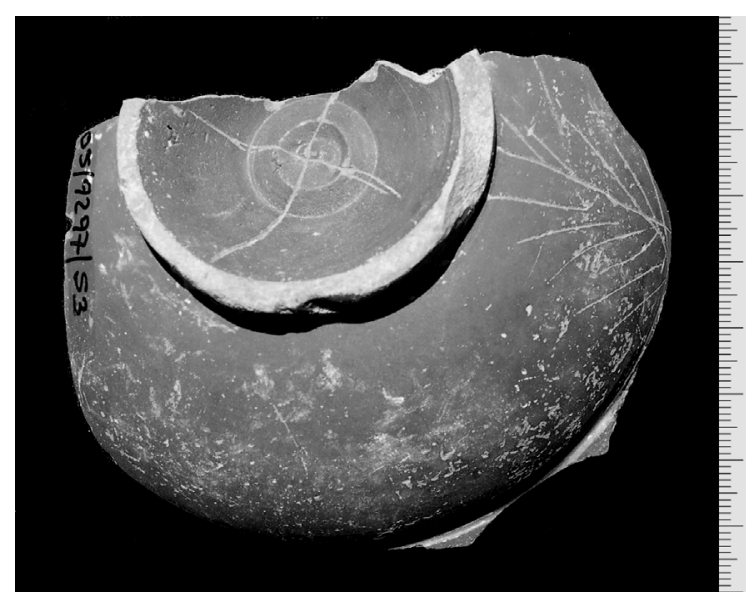

230 (2006, UE 9349, n. ${ }^{\circ}$ 81). Fragmento de pared de un recipiente de terra sigillata hispánica con restos de un grafito no identificable en una superficie de [1] x [2,8 cm].

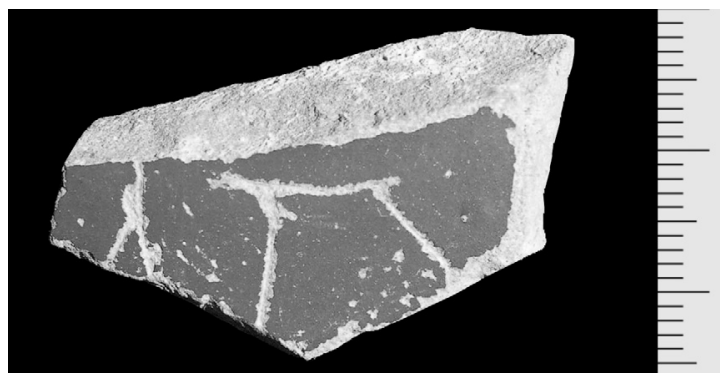

231 (2006, UE 9360, n. ${ }^{120}$ ). Base de un recipiente de terra sigillata hispánica en el que se conserva la parte final de un grafito ocupando una superficie de $0,8 \times$ [3] $\mathrm{cm}$. En lo conservado parece leerse [-]MIATRI.

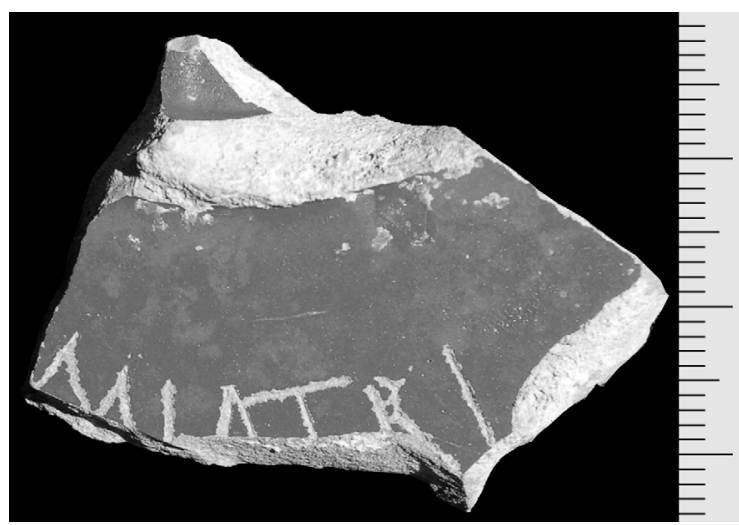

232 (2006, UE 9361, n. ${ }^{\circ}$ 27). Base de un cuenco de terra sigillata hispánica, forma Dr. 37 . Conserva parte de un grafito con el texto [-]MIDI[-], cuyas letras miden $0,8 \mathrm{~cm}$ de altura. Los caracteres podrían servir a una forma como Pergamidis (Mérida, HEp 6, 116; cf. Pergamis: Solin, 1982, 610).

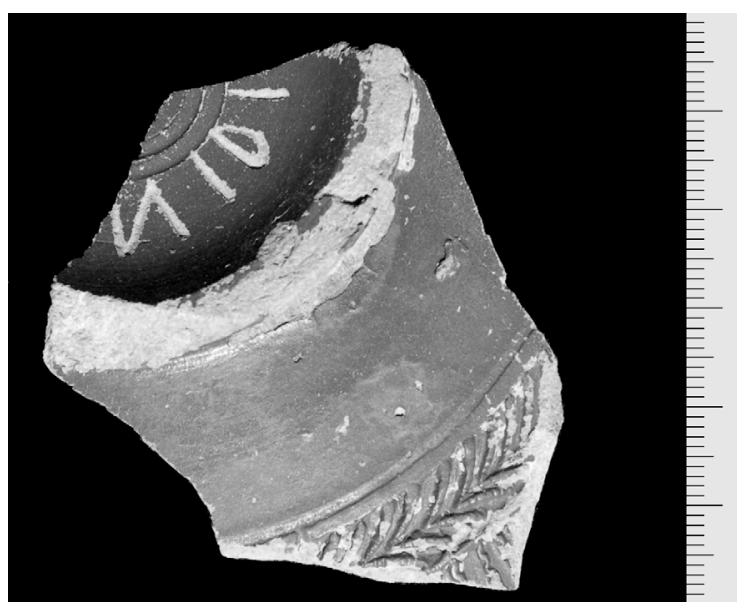


233 (2006, UE 9361, n. ${ }^{\circ} 450$ ). Fragmento de la base de un recipiente de cerámica común; por encima del pie conserva restos de un grafito en el que sólo pueden distinguirse con seguridad los caracteres RV, de c. $1 \mathrm{~cm}$ de altura.

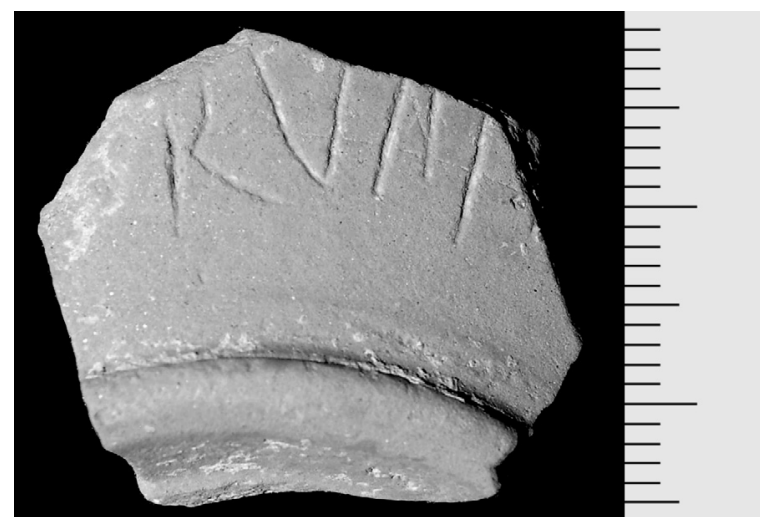

234 (2006, UE 9365, n. ${ }^{\circ} 7$ ). Cinco fragmentos de la base de un cuenco de terra sigillata hispánica, forma Dr. 37. En la parte inferior, con caracteres de c. $1 \mathrm{~cm}$ de altura, parece leerse [Te]renti(a)e pa[nna]. La primera E está escrita con dos astas verticales, mientras que de la $\mathrm{R}$ que la precede sólo se conserva el extremo del trazo oblicuo.

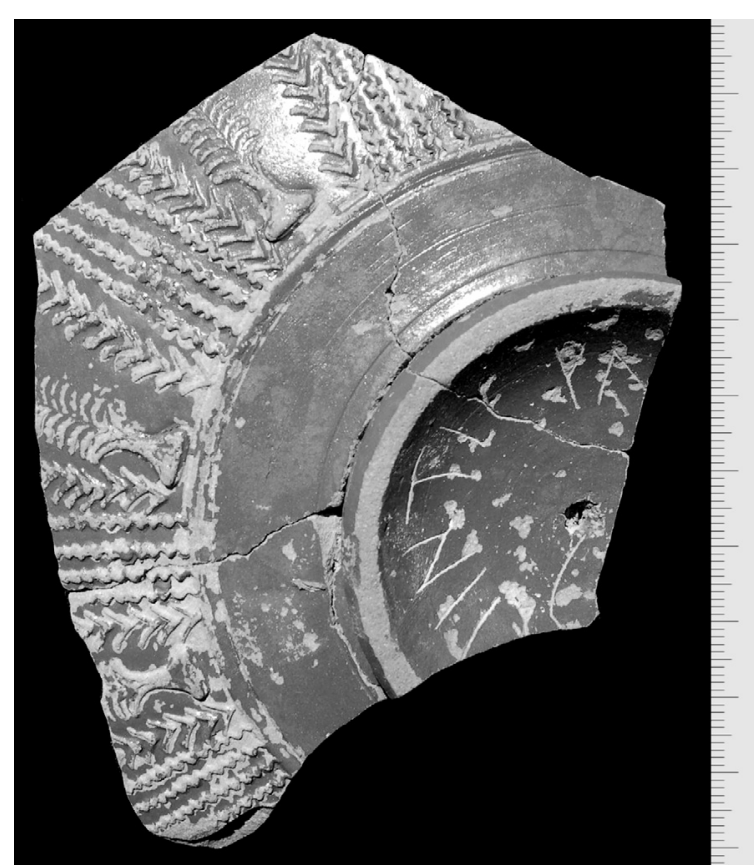

235 (2006, UE 9368, n. $\left.{ }^{\circ} 210\right)$. Fragmento de pared de un contenedor de cerámica común con un grafito central sobre el que aparecen dos trazos paralelos y un aspa en la parte inferior; en el texto, con letras de c. $4,2 \mathrm{~cm}$ de altura, parece leerse [-]MICRE[-].

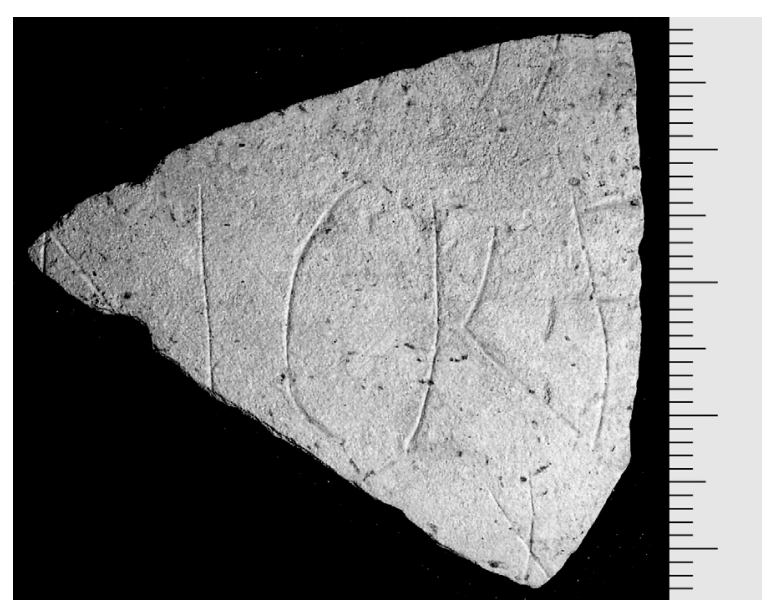

236 (2006, UE 9368, n. ${ }^{\circ} 700$ ). Base de un cuenco de terra sigillata hispánica con grafito exterior junto al anillo del pie en posición invertida, Las letras miden $1,1 \mathrm{~cm}$ de altura y el texto dice [-] PELE[-]; las E están dibujadas con un doble trazo vertical.

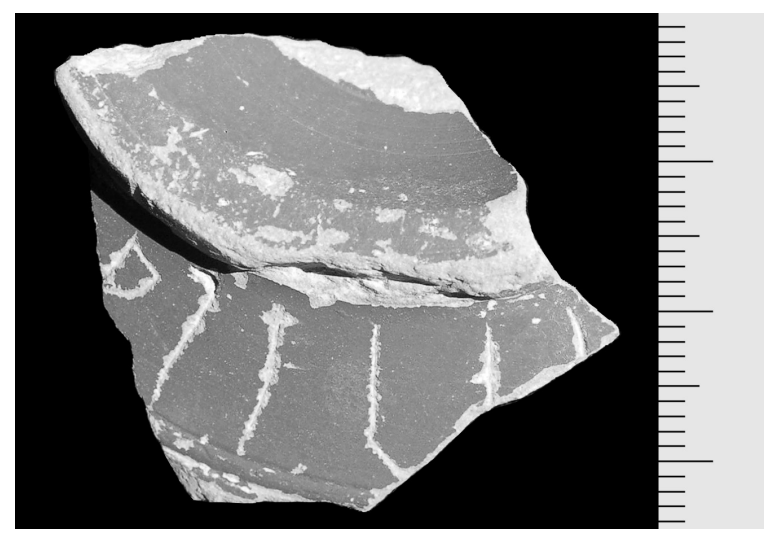

237 (2006, UE 9400, n. $\left.{ }^{\circ} 24\right)$. Borde de una tinaja sobre el cual, con letras de $3,8 \mathrm{~cm}$ de altura, discurre una inscripción en la que sólo puede distinguirse lo que parece una A sin travesaño central, seguida de restos de un signo no identificable. No habría que descartar que se tratara de grafía ibérica (I-a). 


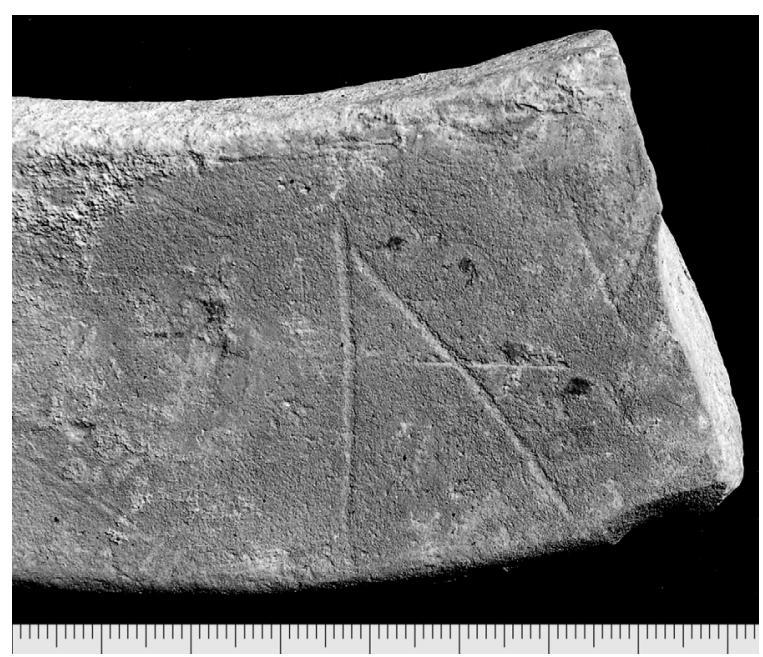

238 (2006, UE 9458, n. ${ }^{\circ}$ 94). Fragmento de pared de un gran contenedor de cerámica común partido en varios fragmentos, que presenta bajo el arranque del asa un grafito en letras de c. 1,3 $\mathrm{cm}$ de altura en el que puede leerse FES.

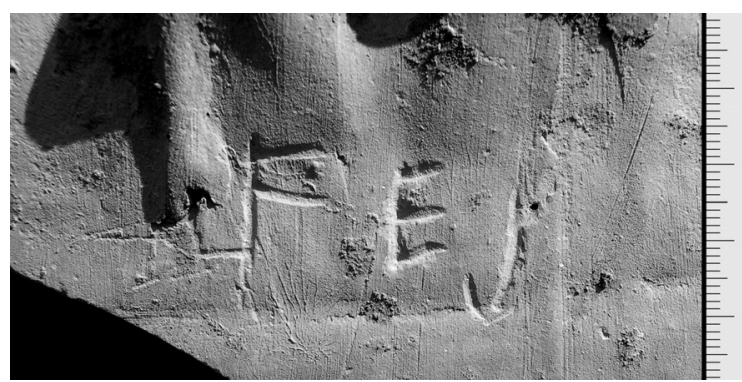

239 (2006, UE 9459, n. ${ }^{\circ}$ 8). Base de un recipiente de cerámica común en cuya base, con letras de c. $1,1 \mathrm{~cm}$ de altura, figura el comienzo de un texto en el que puede verse $A D[-]$ ó $A B[-]$; la A está dibujada con travesaño interior oblicuo, mientras que de la segunda letra sólo queda la parte inferior, lo que induce a dudar entre $D$ y $B$.

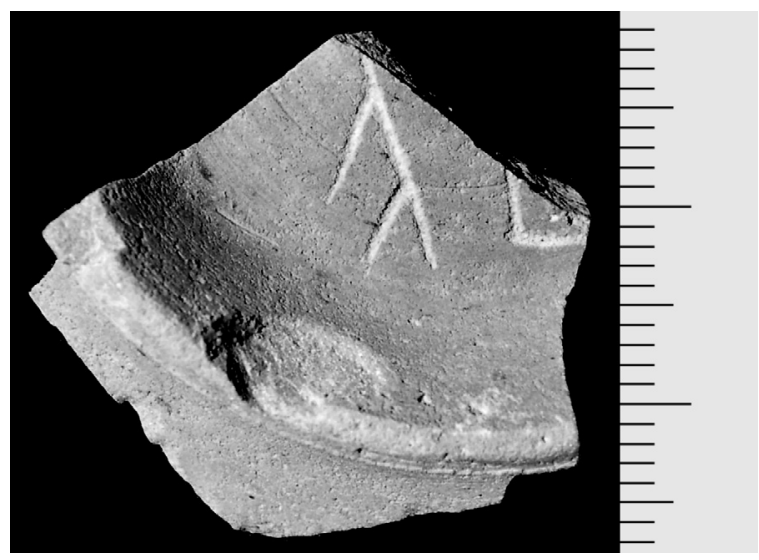

\section{Prospección del territorio de Segobriga (1998 y 2005)}

240 (1998, punto 36, n. ${ }^{\circ} 21$ ). Base de un recipiente de terra sigillata hispánica con restos de un grafito irreconocible en la parte exterior, cuyos trazos miden $[1,8] \times[1,6] \mathrm{cm}$. El texto parece decir SO[-]

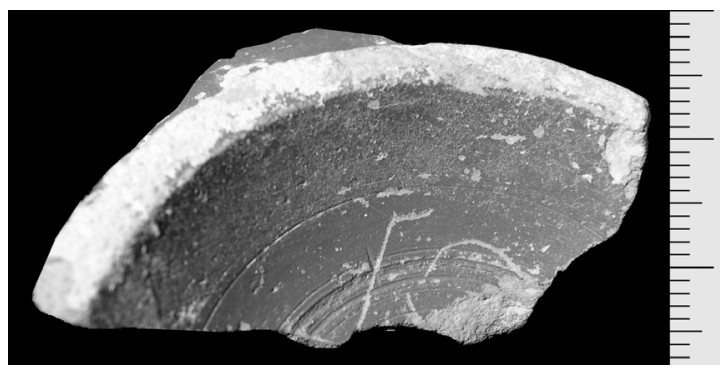

241 (1998, punto 86, n. $\left.{ }^{\circ} 16\right)$. Base de terra sigillata hispánica con un grafito en su parte interior; de tratarse de signos alfabéticos, y no de un simple esgrafiado, sería una $V$ de $1,3 \mathrm{~cm}$ de altura.

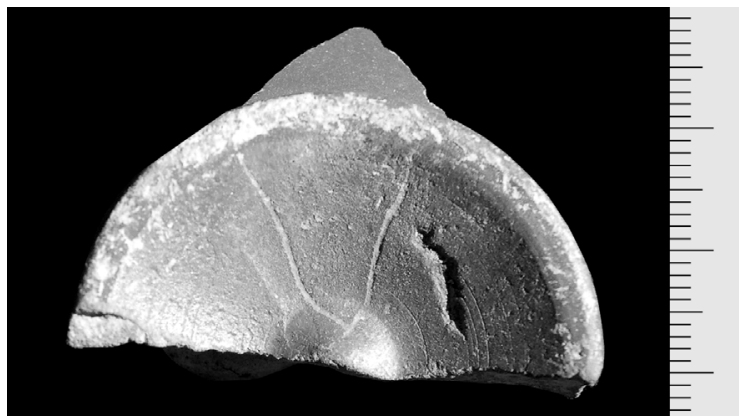

242 (1998, punto 86, n. ${ }^{\circ} 21$ ). Base de un recipiente de terra sigillata hispánica con un grafito exterior en forma de aspa de 2,2 x 1,9 cm.

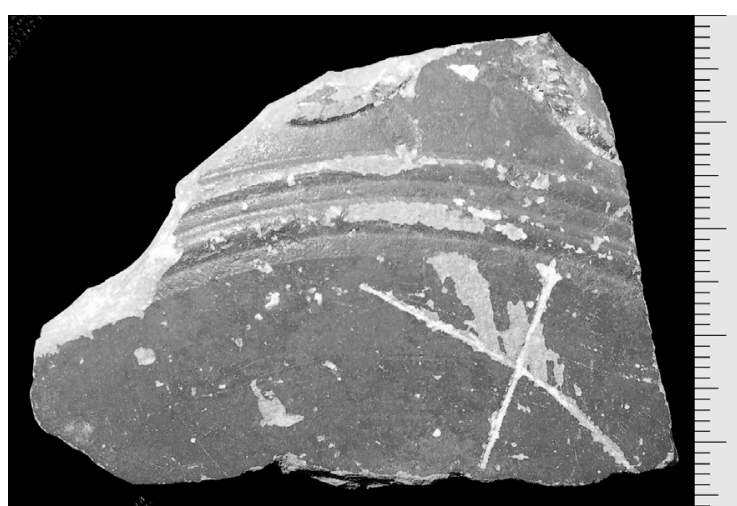

243 (2005, Cerro Carraplín, al este de Segobriga n. $\left.{ }^{\circ} 26\right)$. Fragmento de pared de un recipiente de terra sigillata hispánica. Al interior conserva restos de un grafito en el que parece verse una $V$ se- 
guida de un trazo curvo no identificable y precedida de otra letra que poseía un asta vertical a la derecha; posibles combinaciones como ...TVC..., NUG, LVC, etc. impiden ofrecer una propuesta de lectura. La $\vee$ mide $1,2 \mathrm{~cm}$ de altura.

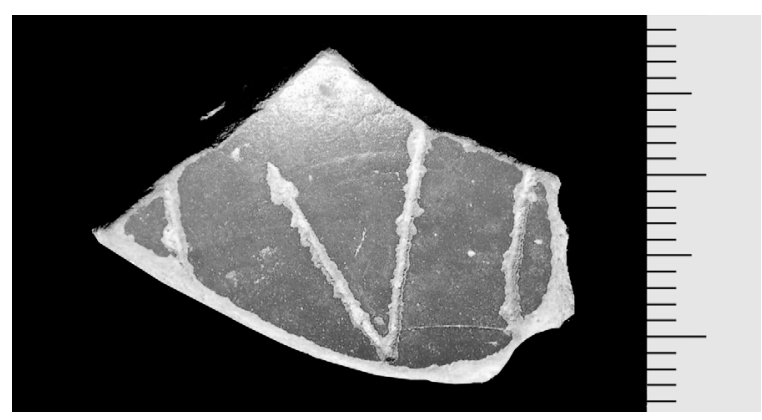

\section{ÍNDICE \\ (en la forma original de los textos)}

\section{Latinos}

$A D[-]$ ó $A B[-]: 239$

AEIOV: 27

Apolei llas: 42

AR: 213

Arim[-]: 98

Augu[-]; 192

Aviti: 224

Bait[-]: 160

$\mathrm{Ca}[-]: 109$

Clari [-?]: 70

Co[-]: 182

$\mathrm{Cu}[-]: 53$

[Cu]rsori[s]: 31

E: 104

$\mathrm{E}+[-]: 121$

Euc[-]: 9

FES: 238

Gem[-]: 40

GIA ó SIA: 79

Grati: 28

$\mathrm{H}[-] ; 161$

$\mathrm{HE}[-]: 220$

[H] eraclei: 218

ICI[-] o ILI[-]: 221

Ilas Apolei: 42

In [-]: 173

La[-]: 216

Lu[-]: 135

Lucifer: 139

Lupul(a)e: 208

M: 176, 222

Marci: 172

Marto[-]: 43

Mat+[-]: 174

$\mathrm{N}: 24$
$\mathrm{N}[-]: 145,181$

NR: 214

$\mathrm{O}($ 一) $\mathrm{P}($ (一), $\mathrm{M}($ arci): 54

$P[-]: 163$

Pacat[-]: 165

[P]anna[-]: 114

Pan(n)as+ [-]XXXII: 102

$\mathrm{Pa}[\mathrm{nn}$ ]]: 234

Pone fu[r]: 133

Ponti (-) F(-) ó Pontif(-): 6

Primi[-]: 184

Protae; 75

R: 103, 209, 223

$\mathrm{Ra}[-]: 87$

[R]ebur[-]

$\operatorname{Rec}[-]: 60$

Riosci p[anna ?]: 80

Romanu[s]: 187

Salvae: 78

Satur[-]: 127

S(ervi): 54

SIA ó GIA: 79

SO[-]: 240

Suri: 162

[Te]renti(a)e pa[nna]: 234

Them[-]: 108

Vegeti Bu[-]: 56

Veg[-]: 57

Victo(r): 101

Vir[-]: 61

[-]+E[-]: 35

[-]A: 51

[-]ANDRI[-]V · I[-]: 193

[-]ANEA[-]: 130

[-]anu[-]: 47

[-]DE[-]: 206

[-]DR[-]: 7

[-]E[-]: 37

[-]ER[-]: 16

[-]ERP: 86

[-]EST[-]: 32, 205

[-]ico: 69

[-]idi[-]: 166

[-]ILIC+[-]: 76

[-]IM[-]: 30

[-]IS: 17

[-]ma: 52

[-]MAR[-]: 29

[-]mia: 63

[-]MIATRI: 231

[-]MICRE[-]: 235

[-]MIDI[-]: 232

[-]MVESV[-]: 64

[-]mus: 36

[-]N: 134

[-]N[-]: 129 
[-]NV[-]: 225

[-]na: 45

[-]ni: 25

[-]OCl+[-]: 50

[-]OM[-]: 227

[-]os: 65

[-]PELE[-]: 236

[-]res: 167

[-]s CCCCCX: 102

[-]sod[-]: 83

[-]ti: 110

[-]tia[-]: 147

[-]TILVM[-]: 142

[-] tin[-]: 169

[-]tu[-]: 207

[—]uli(a)e: 90

[-]uni: 46

[-]urii: 88

[-]uril(-): 203

[-]ust[-]: 186

[-]V[-]: 137

[-]vi: 120

[-]vii: 33

[-]vium: 143

[-]VN[-]: 153

[-]+entini: 148

[-]+IP: 177

[-]+nus: 96

[-]+PA[-]: 183

[-]+sce: 144

[-]+su: 128

[—]+VTI[—]: 210

\section{Griegos:}

П: 22

П入а[-]: 171

[-]EMI[-]: 175

$[-] \lambda \Pi[-]: 198$

\section{Ibéricos:}

I-a (?): 237

ti: 23

Capacidad y numerales:

$\mathrm{X}: 211$

$X X: 156$

[-]X[-]: 55

$[-] \mathrm{XII}+[-]: 141$

[-]XX[-]: 105

[-]XXXII: 102

[-]CCl ó [-]CCL: 111

CCCCCX: 102
Prof. Juan Manuel Abascal

Área de Historia Antigua

Dpto. de Prehistoria, Arqueología,

$\mathrm{H}^{\mathrm{a}}$ Antigua, Filología Griega y

Filología Latina

Universidad de Alicante

030080 Alicante

juan.abascal@ua.es

Dra. Rosario Cebrián Fernández

Parque Arqueológico de Segobriga

16430 Saelices

Cuenca

segobriga@jccm.es

\section{BIBLIOGRAFÍA}

ABASCAL, J.M., 1994: Los nombres personales en las inscripciones latinas de Hispania, Murcia.

ABASCAL, J.M., 2004: "Élites y sociedad romana en la Meseta sur", en Epigrafía y sociedad en Hispania durante el Alto Imperio: estructuras y relaciones sociales (Acta Antiqua Complutensia 4), 141-158, Madrid.

ABASCAL, J.M., CEBRIÁN, R. y RIQUELME, T., 2000: "Retucenus Elocum, Turanus, Antirus y la producción de tegulae en Segobriga", Anales de Prehistoria y Arqueología [Murcia], 16, 187-197.

ABASCAL, J.M. y LÓPEZ DE LOS MOZOS, J.R., 1993: "Inscripciones latinas de Sayatón (Guadalajara) en territorium de Ercavica", Wad-al-Hayara, 20, 357-364.

ALFÖLDY, G., 1975: Die römischen Inschriften von Tarraco, Berlín.

HILGERS, H., 1969: Lateinische Gefässnamen, Düsseldorf.

KAJANTO, I., 1982: The Latin Cognomina, Helsinki 1965, Roma ${ }^{2}$.

MARICHAL, R., 1988: Les graffites de La Graufesenque, Paris.

MAYER, M., 1999: «Encol dun interesante esgrafiado sobre cerámica achado en Lugo», Larouco, 2, 127-128.

SÁNCHEZ-LAFUENTE, J., 1991: «Grafitos sobre instrumenta domestica en sigillata de Segobriga y su entorno», Hispania Antiqua, 15, 207-238.

SÁNCHEZ-LAFUENTE, J. - RASCÓN, S. - POLO, J., 1999: "Grafitos sobre instrumental doméstico en Hispania», $X I$ Congresso Internazionales di epigrafia greca e latina, 585-599, Roma.

SANFELIÚ, D. y CEBRIÁN, R., 2006: «Un taller de terra sigillata en Segobriga (Saelices, Cuenca)», Lucentum, 25 159-175.

SOLIN, H., 1982: Die griechischen Personennamen in Rom. Ein Namenbuch, Berlin.

SOLIN, H. y SALOMIES, O., 1988: Repertorium nominum gentilium et cognominum Latinorum, Hildesheim.

STYLOW, A.U., 1998: "Ficha 29", en Complutum. Roma en el interior de la Península, 202, Alcalá de Henares. 